\title{
Athens Journal of Social Sciences
}

Quarterly Academic Periodical, Volume 9, Issue 1, January 2022 VRL: https://www.athensjournals.gr/ajss Email: journals@atiner.gr e-ISSN: 2241-7737 DOI: 10.30958/ajss

Front Pages

LEDA NATH, NICHOLAS PEDRIANA, CHRISTOPHER GIFFORD, JAMES W. MCAULEY \& MARTA FÜLÖP

Examining Moral Foundations Theory through Immigration Attitudes

BAODONG LIU, PORTER MORGAN E DIMITRI KOKOROMYTIS

Nation-State Contexts and Authoritarian Value Changes of Ethnic Chinese

ELENI D. TSELIGKA

Greek Gastarbeiter in Germany and European Expatriates from Greece: Diaspora Interactions between Immigrants and Neo-Immigrants

MIKE SOSTERIC

Rethinking the Origins and Purpose of Religion:

Jesus, Constantine, and the Containment of Global Revolution 


\section{$\underline{\text { Athens Journal of Social Sciences }}$}

Published by the Athens Institute for Education and Research (ATINER)

\section{$\underline{\text { Editors }}$}

- Dr. Gregory T. Papanikos, Honorary Professor of Economics, University of Stirling, UK. (Economics)

- Dr. Barbara Zagaglia, Associate Professor, Polytechnic University of Marche, Italy. (Demography)

- Dr. Nikolaos I. Liodakis, Associate Professor, Wilfrid Laurier University, Canada. (Sociology)

- Dr. Domenico Maddaloni, Professor, University of Salerno, Italy. (Sociology)

- Dr. Thanos Patelis, Lecturer, Teachers College at Columbia University and Achievement and Assessment Institute, University of Kansas, USA. (Psychology)

- Dr. Yannis Stivachtis, Professor, Jean Monnet Chair, Director of International Studies Program \& Director, Diplomacy Lab Program, Virginia Tech - Virginia Polytechnic Institute \& State University, USA. (Political \& International Studies)

Editorial \& Reviewers' Board

https://www.athensjournals.gr/ajss/eb

Administration of the Journal

1. Vice President of Publications: Dr Zoe Boutsioli

2. General Managing Editor of all ATINER's Publications: Ms. Afrodete Papanikou

3. ICT Managing Editor of all ATINER's Publications: Mr. Kostas Spyropoulos

4. Managing Editor of this Journal: Ms. Eirini Lentzou

ATINER is an Athens-based World Association of Academics and Researchers based in Athens. ATINER is an independent and non-profit Association with a Mission to become a forum where Academics and Researchers from all over the world can meet in Athens, exchange ideas on their research and discuss future developments in their disciplines, as well as engage with professionals from other fields. Athens was chosen because of its long history of academic gatherings, which go back thousands of years to Plato's Academy and Aristotle's Lyceum. Both these historic places are within walking distance from ATINER's downtown offices. Since antiquity, Athens was an open city. In the words of Pericles, Athens"...is open to the world, we never expel a foreigner from learning or seeing". ("Pericles' Funeral Oration", in Thucydides, The History of the Peloponnesian War). It is ATINER's mission to revive the glory of Ancient Athens by inviting the World Academic Community to the city, to learn from each other in an environment of freedom and respect for other people's opinions and beliefs. After all, the free expression of one's opinion formed the basis for the development of democracy, and Athens was its cradle. As it turned out, the Golden Age of Athens was in fact, the Golden Age of the Western Civilization. Education and (Re)searching for the 'truth' are the pillars of any free (democratic) society. This is the reason why Education and Research are the two core words in ATINER's name.

$* * * * * * * * * * * * * * * * * * * * * * * * * * * * * * * * * * * * * * * * * * * * * * * * * * * * * * * * * * * * * * * * * * * * * * * * * * * * * * * * * * * * * * * * * * * * * * * *$

The Athens Journal of Social Science (AJSS) is an Open Access quarterly double-blind peer reviewed journal and considers papers from all areas of social sciences, including papers on sociology, psychology, politics, media, and economics. Many of the papers in this journal have been presented at the various conferences sponsored the Social Sciences Division of the Athens Institute for Education and Research (ATINER). All papers are subject to ATINER's Publication Ethical Policy and Statement. 
The Athens Journal of Social Sciences

ISSN NUMBER: 2241-7737- DOI: 10.30958/ajss

Volume 9, Issue 1, January 2022

Download the entire issue ( $\underline{\mathrm{PDF}})$

Front Pages

Examining Moral Foundations Theory through

Immigration Attitudes

Leda Nath, Nicholas Pedriana, Christopher Gifford, James W. McAuley E Marta Fülöp

Nation-State Contexts and Authoritarian Value Changes of Ethnic Chinese

Baodong Liu, Porter Morgan \& Dimitri Kokoromytis

Greek Gastarbeiter in Germany and European

Expatriates from Greece: Diaspora Interactions between

Immigrants and Neo-Immigrants

Eleni D. Tseligka

Rethinking the Origins and Purpose of Religion:

Jesus, Constantine, and the Containment of Global

$\underline{\text { Revolution }}$

Mike Sosteric 


\section{Athens Journal of Social Sciences Editorial and Reviewers' Board}

\section{Editors}

- $\quad$ Dr. Gregory T. Papanikos, Honorary Professor of Economics, University of Stirling, UK. (Economics)

- Dr. Barbara Zagaglia, Associate Professor, Polytechnic University of Marche, Italy. (Demography)

- Dr. Nikolaos I. Liodakis, Associate Professor, Wilfrid Laurier University, Canada. (Sociology)

- Dr. Domenico Maddaloni, Professor, University of Salerno, Italy. (Sociology)

- Dr. Thanos Patelis, Lecturer, Teachers College at Columbia University and Achievement and Assessment Institute, University of Kansas, USA. (Psychology)

- Dr. Yannis Stivachtis, Professor, Jean Monnet Chair, Director of International Studies Program \& Director, Diplomacy Lab Program, Virginia Tech - Virginia Polytechnic Institute \& State University, USA. (Political \& International Studies)

\section{Editorial Board}

1. Dr. Bettina Koch, Head, Politics \& International Affairs Research Unit, ATINER \& Associate Professor of Political Science, Virginia Polytechnic Institute and State University, USA.

2. Dr. Thanos Patelis, Head, Psychology Research Unit, ATINER \& Research Scholar, Graduate School of Education, Fordham University, USA

3. Dr. Christos Sakellariou, Vice President of Finance, ATINER \& Associate Professor of Economics, Nanyang Technological University, Singapore.

4. Dr. David Carey, Academic Member, ATINER \& Dean, College of Progressive Education \& Director of Psychology, City Colleges, Ireland.

5. Dr. Van Coufoudakis, Emeritus Professor of Political Science, Indiana University-Purdue University, USA.

6. Dr. Albert Harris, Professor Emeritus, Department of Politics, Humboldt State University, USA.

7. Dr. Asafa Jalata, Academic Member, ATINER \& Professor, Tennessee University, USA.

8. Dr. Kimberly S. Adams, Professor of Political Science, East Stroudsburg University, USA.

9. Dr. António Duarte, Professor, Faculty of Psychology, University of Lisbon, Portugal.

10. Dr. Gail Matthews, Professor, Dominican University of California, USA.

11. Dr. Giuseppe Luca De Luca Picione, Academic Member, ATINER \& Professor, University of Naples "Federico II", Italy.

12. Dr. Michael F. Shaughnessy, Professor, School of Education, Eastern New Mexico University, USA.

13. Dr. Max Stephenson, Academic Member, ATINER \& Founding Director, Virginia Tech Institute for Policy and Governance (VTIPG), USA.

14. Dr. Christopher Dreisbach, Associate Professor, Johns Hopkins University, USA.

15. Dr. Michaelene Cox, Associate Professor, Department of Politics and Government Illinois State University, USA.

16. Dr. Domenico Maddaloni, Head, Sociology Research Unit, ATINER \& Associate Professor, University of Salerno, Italy.

17. Dr. Emmanouil Mentzakis, Academic Member, ATINER \& Associate Professor, University of Southampton, UK.

18. Dr. Auke R. Leen, Assistant Professor, Leiden University, Netherlands.

19. Dr. Timothy Zeiger, Academic Member, ATINER \& Assistant Professor, Pennsylvania State University, USA.

- General Managing Editor of all ATINER's Publications: Ms. Afrodete Papanikou

- ICT Managing Editor of all ATINER's Publications: Mr. Kostas Spyropoulos

- Managing Editor of this Journal: Ms. Eirini Lentzou (bio)

\section{Reviewers' Board}

Click Here 


\section{President's Message}

All ATINER's publications including its e-journals are open access without any costs (submission, processing, publishing, open access paid by authors, open access paid by readers etc.) and is independent of presentations at any of the many small events (conferences, symposiums, forums, colloquiums, courses, roundtable discussions) organized by ATINER throughout the year and entail significant costs of participating. The intellectual property rights of the submitting papers remain with the author. Before you submit, please make sure your paper meets the basic academic standards, which includes proper English. Some articles will be selected from the numerous papers that have been presented at the various annual international academic conferences organized by the different divisions and units of the Athens Institute for Education and Research. The plethora of papers presented every year will enable the editorial board of each journal to select the best, and in so doing produce a top-quality academic journal. In addition to papers presented, ATINER will encourage the independent submission of papers to be evaluated for publication.

The current issue is the first of the ninth volume of the Athens Journal of Social Sciences (AJSS), published by the Social Sciences Division of ATINER.

Gregory T. Papanikos

President

ATINER 


\section{Athens Institute for Education and Research}

A World Association of Academics and Researchers

\section{$16^{\text {th }}$ Annual International Conference on Psychology \\ 23-26 May 2022, Athens, Greece}

The Psychology Unit of ATINER organizes its 16th Annual International Conference on Psychology, 23-26 May 2022, Athens, Greece sponsored by the Athens Journal of Social Sciences. The aim of the conference is to bring together scholars and students of psychology and other related disciplines. You may participate as stream leader, presenter of one paper, chair a session or observer. Please submit a proposal using the form available (https://www.atiner.gr/2022/FORM-PSY.doc).

\section{Important Dates}

- Abstract Submission: 31 January 2022

- Acceptance of Abstract: 4 Weeks after Submission

- Submission of Paper: 26 April 2022

\section{Academic Member Responsible for the Conference}

- Dr. Thanos Patelis, Head, Psychology Unit of ATINER \& Research Scholar, Fordham University, USA.

\section{Social and Educational Program}

The Social Program Emphasizes the Educational Aspect of the Academic Meetings of Atiner.

- Greek Night Entertainment (This is the official dinner of the conference)

- Athens Sightseeing: Old and New-An Educational Urban Walk

- Social Dinner

- Mycenae Visit

- Exploration of the Aegean Islands

- Delphi Visit

- Ancient Corinth and Cape Sounion

More information can be found here: www.atiner.gr/social-program

\section{Conference Fees}

Conference fees vary from $400 €$ to $2000 €$ Details can be found at: https://www.atiner.gr/fees 


\section{Athens Institute for Education and Research}

\section{A World Association of Academics and Researchers}

\section{$16^{\text {th }}$ Annual International Conference on Sociology 2-5 May 2022, Athens, Greece}

The Sociology Unit of ATINER is organizing its 16 $^{\text {th }}$ Annual International Conference on Sociology, 2-5 May 2022, Athens, Greece sponsored by the Athens Journal of Social Sciences. The aim of the conference is to bring together academics and researchers from all areas of Sociology, Social Work and other related fields. Theoretical and empirical research papers will be considered. You may participate as stream leader, presenter of one paper, chair a session or observer. Please submit a proposal using the form available (https://www.atiner.gr/2022/FORM-SOC.doc).

- Abstract Submission: : 10 January 2022

- Acceptance of Abstract: 4 Weeks after Submission

- Submission of Paper: 4 April 2022

\section{Academic Member Responsible for the Conference}

- Dr. Domenico Maddaloni, Head, Sociology Research Unit, ATINER \& Associate Professor, University of Salerno, Italy.

- Dr. Nikolaos I. Liodakis, Director, Social Sciences Division, ATINER \& Associate Professor, Wilfrid Laurier University, Canada.

- Dr. George S. Tsagaris, Associate Professor, Cleveland State University, USA.

- Dr. Sharon Claire Bolton, Head, Management Research Unit, ATINER \& Professor, The Management School, University of Stirling, Scotland.

\section{Social and Educational Program}

The Social Program Emphasizes the Educational Aspect of the Academic Meetings of Atiner.

- Greek Night Entertainment (This is the official dinner of the conference)

- Athens Sightseeing: Old and New-An Educational Urban Walk

- Social Dinner

- Mycenae Visit

- Exploration of the Aegean Islands

- Delphi Visit

- Ancient Corinth and Cape Sounion

More information can be found here: https://www.atiner.gr/social-program

\section{Conference Fees}

Conference fees vary from $400 €$ to $2000 €$

Details can be found at: https://www.atiner.gr/fees 


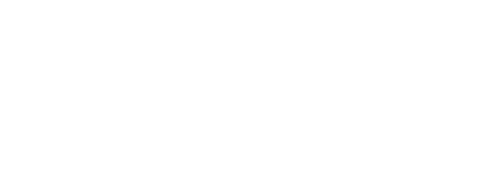




\title{
Examining Moral Foundations Theory through Immigration Attitudes
}

\author{
By Leda Nath ${ }^{*}$, Nicholas Pedriana ${ }^{ \pm}$, Christopher Gifford", \\ James W. McAuley \& Marta Fülöp ${ }^{\S}$
}

\begin{abstract}
Moral foundations theory (MFT) explains how political and cultural attitudes are shaped significantly by people's moral intuitions; gut-level judgments about proper human behavior and social relationships. We examine the theory through the topic of immigration attitudes. Social scientists of various stripes have built a comprehensive research program studying public attitudes towards immigrants and immigration policy. Immigration is currently among the most contentious political issues in the United States and Europe-evidenced in part by the election of Donald Trump, the UK's Brexit vote, and the recent rise of nationalist parties on the continent. Drawing on MFT and using one politically diverse sample and one liberal-leaning sample, we conducted two experiments respectively, to test whether effects of political orientation on US immigration attitudes may be moderated by alternative moral framing of pro-immigration appeals. Data support hypotheses, and is consistent with theoretical claims about moral diversity and political attitudes generally. Also, results shed new light on how shifts in immigration attitudes, that is whether one entrenches further into an original position or is persuaded into a new attitude, depend on one's place on the political spectrum.
\end{abstract}

Keywords: moral foundations theory, moral foundations, immigration, attitudes, moral intuition, experiment

\section{Introduction}

Recent political developments in the US, Great Britain, and across Europe remind of the persistence of race and ethnic conflict in an increasingly globalized world. Accordingly, public attitudes towards immigrants and immigration policy have a longstanding history in the social sciences. Researchers have explored individual and structural-level data in both single-country and cross-national contexts over various time periods (e.g., Dustmann and Preston 2007, Ceobanu and Escandell 2010, Esses et al. 2017), and have identified key variables influencing immigration attitudes including income or class position, education, gender, race/ ethnic identity, religion, economic conditions, degree of labor market competition, etc. (for example, see Álvarez Gálvez et al. 2020, Otjes 2021, McDermott et al. 2019, Macdonald 2021). Some strands of research are grounded in individual-level

\footnotetext{
*Professor, University of Wisconsin -Whitewater, USA.

${ }^{ \pm}$Senior Lecturer, University of Wisconsin - Madison, USA.

${ }^{*}$ Researcher, University of Huddersfield, UK.

Professor, University of Huddersfield, UK.

${ }^{\S}$ Scientific Advisor, Institute of Cognitive Neuroscience and Psychology, Hungarian Academy of Sciences, Eötvös, Loránd University, Hungary.
} 
theories based on self-interest and rational choice (see, Gerber et al. 2017, Malesevic 2002); others are tied to theories on group dynamics and prejudice including Allport's (1954) classic "contact" hypothesis (see also Pérez 2010, Yueh-Ting and Ottati 2002); social identity theory (see, Tajfel 1982, Tajfel and Turner 1986, Mangum 2019, Margolis 2018); and group threat (see, Ramos et al. 2020, Esses et al. 2006; Espinosa et al. 2018 and also Blumer 1958 for a general overview).

We build on this body of scholarship by exploring another theory to explain immigration attitudes: Moral Foundations Theory (MFT) (Haidt 2013). Anchored in moral and political social psychology, MFT argues that political and cultural attitudes are shaped significantly by people's moral intuitions; gut-level judgments about proper human behavior and social relationships that may underlie and/or transcend an individual's socio-economic status, educational attainment, race/ ethnicity, and other demographic variables that correlate with political and cultural attitudes (Haidt 2013, Graham et al. 2011, Graham et al. 2009). Building on prior MFT research, we employ experiments to analyze (1) whether an individual's attitudes towards immigration can be influenced or modified when framed in alternative moral language and (2) why.

\section{Moral Foundations Theory and Political Attitudes}

MFT is built upon on several core principles/arguments about morality and political attitudes. First, it identifies five fundamental moral foundations - and their opposites - shared to greater or lesser extents by people and societies across cultural and spatial contexts: care/harm; fairness/cheating; in-group loyalty/ betrayal; authority/subversion; and purity/degradation. Second, MFT research in the United States (US) has consistently found that an individual's moral intuitions are strong predictors of one's political identity and voting preferences (Graham et al. 2009, Franks and Scherr 2015, Nath et al. 2018). And third, liberals/ progressives consistently score high on the care and fairness foundations (together referred to as the "individualizing" moral foundations) and relatively low on the loyalty, authority, and purity foundations (together referred to as the "binding" moral foundations), while conservatives tend to score relatively high on all five (Haidt and Graham 2007). This finding has led some MFT scholars to conclude that in the US, conservatives are on average more morally diverse than liberals/ progressives (Haidt 2013, Smith et al. 2014).

MFT has been used to explore political sentiments on a wide range of divisive issues including stem-cell research (Clifford and Jerit 2013); governmentsponsored torture (Smith et al. 2014); environmental policy (Kidwell et al. 2013); conservation behavior (Wolsko et al. 2016); the social safety net (Day et al. 2014); climate change (Dawson and Tyson 2012) and crime and punishment (Silver and Silver 2017). This article follows this line of scholarship by using MFT to explore attitudes towards immigration numbers.

That conservatives and liberals/progressives fundamentally disagree on this issue is well-known; the latter is generally pro-immigrant and support laws to 
expand easier access to legal status or citizenship and favor social policies that give immigrants - legal or otherwise - opportunities and access to social resources such as education and health care. Conversely, conservatives generally favor laws and policies that restrict entry, impose harsher penalties for the undocumented, and limit or deny access to social programs. As is the case with other high-octane political issues, MFT offers a straightforward hypothesis for such competing views on immigration: liberals/progressives and conservatives are motivated by different moral foundations that translate to different attitudes toward immigration. For example, to the extent that liberals/progressives are highly driven by the care foundation, their attitudes are likely influenced by a deep sense of compassion and empathy for weaker social groups seeking freedom and opportunity for a better life. In addition, liberals/progressives tend to equate the fairness moral foundation with equality and nondiscrimination, particularly towards disadvantaged racial or ethnic groups to which many immigrants belong (Haidt 2013). Conservatives by contrast are more influenced by, for example, in-group loyalty that in this context may be defined as citizens and/or workers whose jobs are perceived to be threatened by outsiders; the fact that most immigration disputes today involve people of different racial/ethnic backgrounds may further tap into the in-group loyalty foundation.

That said, we do not view MFT as a zero-sum theoretical competitor to established research on attitudes towards outside groups; rather, we see it as adjunct to current knowledge because MFT and current theories of self-interest or group dynamics often converge in ways that complement and inform one another. For instance, the "group threat" hypothesis argues that "prejudice emerges as groups develop a sense of social position relative to one another" (Quillian 1995, p. 588). As originally outlined by Blumer (1958), dominant groups are likely to feel a sense of collective threat when they perceive their material resources, social status, and/or cultural identity are threatened or challenged by outside groups (e.g., immigrants). This sense of threat may be heightened when the size (perceived or otherwise) of outsider groups is large and/or under broader conditions of economic uncertainty or insecurity. When viewed through the lens of MFT, the group threat hypothesis is clearly connected to the moral foundation of in-group loyalty. To the extent that conservatives are on average more strongly influenced by this moral prerogative, they may be more likely to sense collective threat-and thus a heightened sense of in-group loyalty-particularly under unfavorable economic or political conditions. Put another way, MFT offers an explanation for why some groups (e.g., conservatives and liberals/progressives) differ so significantly in their sense of collective threat generally, and with respect to immigration specifically: because it is a partial consequence of underlying moral sensibilities that places group loyalty on a higher (or lower) moral plane. We explore other potential theoretical convergences further in our concluding section. 


\section{MFT and Moral Framing: Are Political Attitudes Malleable?}

In addition to establishing robust links between people's moral intuitions and their political values/preferences, one subset of MFT research in the US has examined whether political attitudes can be modified when liberal (or conservative) stances on issues are explicitly framed in liberal (or conservative)-friendly moral foundations language (see Wolsco et al. 2016, or Feinberg and Willer 2013). The entrenching hypothesis argues that both groups are likely to show even greater commitment to their political attitudes when exposed to resonant moral language. For example, conservatives with anti-abortion attitudes may express even greater anti-abortion attitudes if the issue is framed in the moral foundations language of, say, purity or traditional gender hierarchies; conversely, liberals with pro-choice attitudes may be even more pro-choice if the issue is framed in the moral foundations language of care and fairness towards women.

The persuasion hypothesis argues that when liberal (or conservative) stances on an issue are framed in moral foundations language favored by the other side, it may "persuade" those otherwise opposed to that stance to modify their attitudes in ways that lean, at least somewhat, towards that stance. For example, liberals are significantly more likely than conservatives to favor social policies designed to expand the opportunities and life-chances of disadvantaged racial/ethnic minorities. The persuasion hypothesis suggests that if this issue were framed in the language of, say, loyalty - in the sense that those minorities are loyal Americans who fought and died for the nation in current and past conflicts - conservatives may be more likely to show greater support for such pro-minority policies. And vice versa for conservative stances framed in liberal-resonant moral language.

Day et al. (2014) tested both hypotheses by examining respective conservative and liberal stances on several contested political issues. They found support for the entrenching hypothesis for both groups when liberal (or conservative) stances were framed in morally-resonant language. For the persuasion hypothesis however, they found differences between conservatives and liberals; conservatives were more likely to be persuaded towards liberal stances when they were framed in conservative-resonant moral language: "findings for the in-group [loyalty], authority, and purity foundations support the persuasion hypothesis as conservative respondents adopted more liberal attitudes following exposure to these foundations" (Day et al. 2014, p. 1567). Liberals by contrast "were relatively unaffected" (p. 1563) when conservative stances were framed in the liberal-resonant moral language of care and fairness.

Several US studies focused specifically on attitudes towards pro-environmental behaviors are consistent with Day et al.'s (2014) findings. Kidwell et al. (2013) found that liberals were more committed to pro-recycling and sustainability practices when moral framing was congruent with the liberal-resonant moral foundations of care and fairness (the entrenching hypothesis). Conversely, they found that conservatives expressed greater commitment to such pro-environmental behavior when exposed to moral foundations language emphasizing "duty and an obligation to adhere to authority" (the persuasion hypothesis). Feinberg and Willer (2013) similarly found that conservatives were more likely to adopt pro- 
environmental attitudes when framed in the conservative-leaning moral language of purity. Finally, they concluded in part that "while liberals did not generally differ across conditions, conservatives shifted substantially in the pro-environmental direction after exposure to [the binding moral foundations] ... of obeying authority, defending the purity of nature, and demonstrating one's patriotism to the United States" (p. 7).

Recall the aim of our study is to (1) examine whether an individual's attitudes towards immigration can be influenced or modified when framed in alternative moral language and (2) explain why. Following this body of research outlined above, we explore the entrenching and the persuasion hypotheses with respect to attitudes on US immigration numbers. Based on prior literature and the different moral foundation profiles of liberal-leaning and conservative-leaning individuals, the entrenching hypothesis suggests:

H1. Left-leaning participants in the individualizing pro-immigration appeal condition will support immigration significantly more than those in the binding pro-immigration appeal condition.

The persuasion hypothesis suggests:

H2. Right-leaning participants in the binding pro-immigration appeal condition will support immigration significantly more than those in the individualizing proimmigration appeal condition.

Finally, we furthermore take special note of the Wolsko et al.'s (2016) study noted above because we modeled our methodology on their experimental design, both of which we discuss in the following section.

\section{Methods}

We examine political orientation, moral foundations, and attitudes on immigration via an experimental design adapted from Wolsko et al.'s (2016) prior study, which examined conservation behaviors. The experimental procedure was such that after each participant gave informed consent, they were assessed on a twelve-item political orientation measure, and which included an item specifically on immigration. Following this, they experienced one of three conditions in the form of reading a morally framed pro-immigration appeal. Finally, they answered additional questions to assess the treatment, demographic information, and a final measure on immigration attitudes. Below we outline the sampling method, measures, and experimental conditions in more detail for each experiment.

\section{Experiment 1}

\section{$\underline{\text { Sample }}$}

We drew a stratified random sample of undergraduate courses from each of the five university units (i.e., College of Letters \& Arts, College of Curriculum \& 
Instruction, College of Business \& Economics, College of Arts \& Communication, and the General Education Program) at a Carnegie Classified "Baccalaureate" state university in the US Midwest. After gaining permission from the course instructors, we arranged to visit classes to administer the survey in person. All surveys were first randomized before distributing to students. After ample time was given for all students to complete their survey, they were collected and combined later with all surveys for analyses. This process yielded a random sample size of $\mathrm{N}=160$ students. It's important to note that while many scholars draw on university students to complete research experiments, and where those methods are apt for testing theoretical processes, those samples may be limited to a particular class of students (e.g., students from an introductory psychology course). For the purpose of our study, we opted to expand our sample across campus and to reach, as just noted, across all colleges and several disciplines. This provided us with a more diverse sample of participants, including across the political spectrum from which to randomly assign to the experimental conditions. This more diverse sample also aimed to help reduce effects from other forms of sampling bias one might find from participants from a single course.

Measures Included in the Survey

Below are the measures and manipulations in this first experiment.

\section{Political Orientation}

Participants were first assessed on their political orientation using a modified measure established by Nail et al. (2009). Participants were asked to reveal to what extent they were in favor or against "each of the following policies, practices, and political groups" on a seven-point Likert scale (i.e., where $1=$ strongly against to $7=$ strongly in favor): Legalization of same sex marriage; Punishing illegal immigration; Democrats; Republicans; Donald Trump; Conservatives; Increase military spending; Increasing immigration numbers; Less strict gun control; Liberals; Socialized medicine; and Feminists. Relevant items were reverse coded so all items rated in the same direction such that higher numbers indicated a more conservative political orientation. Next, a single political orientation variable was created by adding up all measures and dividing by the number of items (i.e., 12), resulting in the new political orientation measure (Cronbach Alpha reliability $=0.90$ ). Furthermore, we converted the new measure into a dichotomous one using the mean score of $3.42\left(\mathrm{~S}_{\mathrm{x}}=1.09\right)$ cut-off between "left" (i.e., 0) and "right" (i.e., 1) leaning participants. The two variables correlated highly with one another $\left(\mathrm{R}_{\mathrm{xy}}=0.82, \mathrm{p}<0.001\right)$.

\section{US Immigration Numbers}

After experiencing the experimental treatment, participants were asked the question, "Currently US immigration policies allow a certain number of people from different groups to enter the US each year; Overall, do you think the US should: a) decrease the number of people allowed to immigrate here legally; b) 
maintain the current number of people allowed to immigrate here legally; c) increase the number of people allowed to immigrate here legally."

\section{Demographics}

After the US immigration numbers question, participants answered a series of questions to measure demographic characteristics. For age, they were asked "How old are you in years?" Race was assessed with the question, "Which category below best reflects your race?" and with answer choices of African American, Asian/Pacific Islander, European American/White, Hispanic/Latino, Native American, Mixed, and Other (with an option to type in an answer). Consistent with how the US socially constructs non-minority versus minority racial groups, this variable was recoded so that European American/White participants were placed in one category (coded 0 ), and all others were in another category (coded 1). Finally, sex was assessed by the question, "What is your sex?" and with answer choices of male, female, or intersex. No participants chose the third category, so this measure was recoded as $0=$ male and $1=$ female.

\section{Experimental Conditions}

Following the political orientation measure, each survey included one of three experimental conditions in the form of a short message on its own page in the survey. It included a morally framed pro-immigration appeal along with two morally consistent images (see Appendix):

(1) the individualizing condition; moral framing emphasizing care and fairness:

Short message: Many caring citizens of the United States are concerned about the well-being of immigrants. We are interested in what you think and feel about this issue. First, please read through the brief public service announcement on the next page before answering a few additional questions.

Longer appeal: America has always been a country of immigrants. Since our founding, the United States has welcomed people from around the world who seek freedom and equality. Show you care for humanity by welcoming our vulnerable immigrants. By doing so, you are helping to ensure they have fair and equal access to the freedoms and protections our nation provides. Demonstrate your love of humanity by reducing the suffering of immigrants and help make sure that no one is denied their opportunity to live and work here. SHOW YOUR COMPASSION

(2) the binding condition: moral framing emphasizing in-group loyalty, authority, and purity:

Short message: Many patriotic citizens of the United States are concerned about the well-being of immigrants. We are interested in what you think 
and feel about this issue. First, please read through the brief public service announcement on the next page before answering a few additional questions.

Longer appeal: America has always been a country of immigrants. Since our founding, the United States has welcomed people from around the world who seek freedom and opportunity. Show your love for America's history and traditions by welcoming loyal and hard-working immigrants. By doing so, you will be honoring and strengthening our nation's sacred values. Demonstrate your love of country by following the many examples of our leaders who protect and welcome America's immigrants and their families.

SHOW YOUR PATRIOTISM!

(3) a neutral control condition.

Many people are concerned about the well-being of immigrants. We are interested in what you think and feel about this issue. Please answer some questions on the following pages.

Novelty

After participants read the message noted in their assigned condition, they were also asked to indicate the extent to which "you think the appeal gives reason for supporting immigration that is new," on a seven-point Likert scale (i.e., $1=$ strongly disagree to $7=$ strongly agree, with $4=$ =neutral).

\section{Experiment 1 Results}

One hundred sixty undergraduate students from a mid-sized Midwestern university in the United States participated in an experiment with 55 in the Individualizing, 52 in the Binding, and 53 in the Control condition. The pretreatment value on a single immigration numbers measure, the political orientation measure plus its dichotomous left-right version, the main dependent variable of US immigration numbers and finally basic descriptive statistics may be seen in Table 1. Based on the twelve political orientation items measured on a scale of 1 to 7 , with higher numbers indicating more conservative orientation, participants averaged a score of $3.42\left(S_{x}=1.09\right)$. Using this mean score, we created a dichotomous left-right measure where left-leaning participants were counted if their score was less than 3.42, and right-leaning participants were counted if their score was greater than or equal to 3.42. This indicated $57 \%$ participants to be "left" and $43 \%$ participants to be "right." In addition, other measures indicated $48 \%$ of the sample was female, $14 \%$ non-white, and the average age of participant was 21.20 years $\left(S_{x}=4.32\right.$ years). Statistics also revealed that participants already generally held neutral or supportive views on immigrant numbers as indicated by a mean score of $3.99\left(\mathrm{~S}_{\mathrm{x}}=1.23\right)$ and where $4=$ "neutral" on this pre-condition individual measure. 
Table 1. Experiment 1 Descriptive Statistics $(N=160)$

\begin{tabular}{|l|c|c|}
\hline & Mean/Percent & $\mathrm{S}_{\mathrm{x}}$ \\
\hline $\begin{array}{l}\text { Pre-treatment measure: } \\
\text { Lower immigration numbers } \\
\text { (1=strongly against; } \\
7=\text { strongly in favor) }\end{array}$ & 3.99 & 1.23 \\
\hline $\begin{array}{l}\text { Political Orientation } \\
(1 \text { to } 7,7=\text { most conservative) }\end{array}$ & & \\
\hline $\begin{array}{l}\text { Dichotomous Left-Right Political Orientation } \\
\text { (1=right) }\end{array}$ & 3.42 & 0.50 \\
\hline $\begin{array}{l}\text { Post-treatment measures: } \\
\text { US Immigration numbers: }\end{array}$ & 0.43 & 0.40 \\
Decrease numbers & $10.2 \%$ & \\
Maintain numbers & $49.7 \%$ & \\
Increase numbers & $40.1 \%$ & 0.50 \\
\hline Sex of participant & 0.48 & \\
$\quad$ (1=female) & & \\
Female & 77.0 & 4.32 \\
\hline Male & 83.0 & 0.35 \\
\hline Age in years & 21.20 & \\
\hline Race of participant & 0.14 & \\
(1=nonwhite) & & \\
\hline
\end{tabular}

After participants read the appeal, they were assessed on various factors including the extent to which they thought the appeal gives reason for supporting immigration that is "new." Recall, MFT scholars have found that in the US, conservatives are on average more morally diverse than liberals/ progressives in that they consider all five moral foundations more often (Haidt 2013, Smith et al. 2014). If this is the case, participants sorted into the "right" category would not likely view the individualizing message as containing more new information compared to the binding message. Conversely, participants sorted into the "left" category would likely perceive information in the binding message as containing significantly more new information compared to the individualizing condition. Based on the post-treatment question, "Please indicate the extent to which you think the appeal gives reason for supporting immigration that is new" with answer choices of $1=$ strongly disagree to $7=$ strongly agree, this assumption was supported. T-tests supported those assumptions, revealing "right" participants did not perceive the binding message $(M=3.70, S x=1.17)$ significantly different from the individualizing message $(\mathrm{M}=3.35, \mathrm{Sx}=1.15)$ in terms of offering novel information $(p<n s)$. "Left" participants on the other hand agreed significantly more that the binding message $(\mathrm{M}=4.13, \mathrm{Sx}=1.41)$ contained more new information compared to the individualizing message $(\mathrm{M}=3.33, \mathrm{Sx}=1.61 ; \mathrm{p}<0.05)$.

We hypothesized the effects of political orientation on immigration attitudes would be moderated by the framing of the pro-immigration appeal/message. The predicted direction of this effect stemmed from the entrenching and the persuasion hypotheses. The entrenching hypothesis suggests participants reading a message consistent with their own stance on a social issue and that matches their moral foundation framework will strengthen their stance compared to if they read the 
message in an alternative moral framework. The persuasion hypothesis however suggests different outcomes based on the political orientation of the participant. "Right" participants reading a message counter with their own stance on a social issue and in language matching their moral foundation framework will shift towards the counter stance.

In our sample, the pre-treatment item measuring participant's level of agreement on whether to "punish illegal immigration" and whether to "increase immigration numbers" differed based on the participants political ideology. T-tests indicated "left" oriented participants significantly agreed less with "punishing illegal immigration" with a score $(\mathrm{M}=2.79, \mathrm{Sx}=1.43)$ suggesting "moderately" to "mildly against" compared with "right" oriented participants whose mean fell close to a score of 5="mildly in favor". $(\mathrm{M}=4.92, \mathrm{Sx}=1.47 ; \mathrm{p}<0.001)$. Similarly, "left" oriented participants significantly agreed more to increase immigration numbers with as mean score falling between "neutral" and "mildly in favor" $(\mathrm{M}=4.52, \mathrm{Sx}=1.23)$ compared with "right" oriented participants whose score fell between "neutral" and "mildly against" $(\mathrm{M}=3.45, \mathrm{Sx}=0.94 ; \mathrm{p}<0.001)$.

Results supported our hypotheses. T-tests revealed "left" participants in the individualizing condition $(\mathrm{M}=2.76, \mathrm{SD}=0.44)$ agreed to increase immigration numbers significantly more than those in the binding condition $(M=2.43$, $\mathrm{SD}=0.57), \mathrm{p}<0.01$. Likewise, right-leaning participants in the binding condition $(\mathrm{M}=2.29, \mathrm{SD}=0.64)$ agreed to increase immigration numbers significantly more than those in the individualizing condition $(\mathrm{M}=1.77, \mathrm{SD}=0.61), \mathrm{p}<0.01$. Also, right-leaning participants in the binding condition $(\mathrm{M}=2.29, \mathrm{SD}=0.64)$ scored significantly higher than those in the control condition $(\mathrm{M}=1.90, \mathrm{SD}=0.44)$, $\mathrm{p}<0.05$. These results are consistent with MFT predictions.

Further support for our hypotheses came in analyses to examine whether the messages acted to moderate the effects of political ideology on immigration attitudes. Two-way analysis of variance revealed political orientation alone, and the interaction of political orientation with the experimental condition were both significant. The main effect for political orientation yielded an $F$ ratio of $F(1,142)$ $=42.134, \mathrm{p}<0.001$, indicating a significant difference between left $(\mathrm{M}=2.57$, $\mathrm{SD}=0.54)$ and right $(\mathrm{M}=1.98, \mathrm{SD}=0.60)$. The interaction effect was also significant, $\mathrm{F}(2,142)=7.10, \mathrm{p}<0.001$, indicating the condition moderated the effect of political orientation on immigration attitude. The experimental condition alone was not statistically significant (see Graph 1 for a depiction of these results). 
Graph 1. Experiment 1 on Immigration Numbers

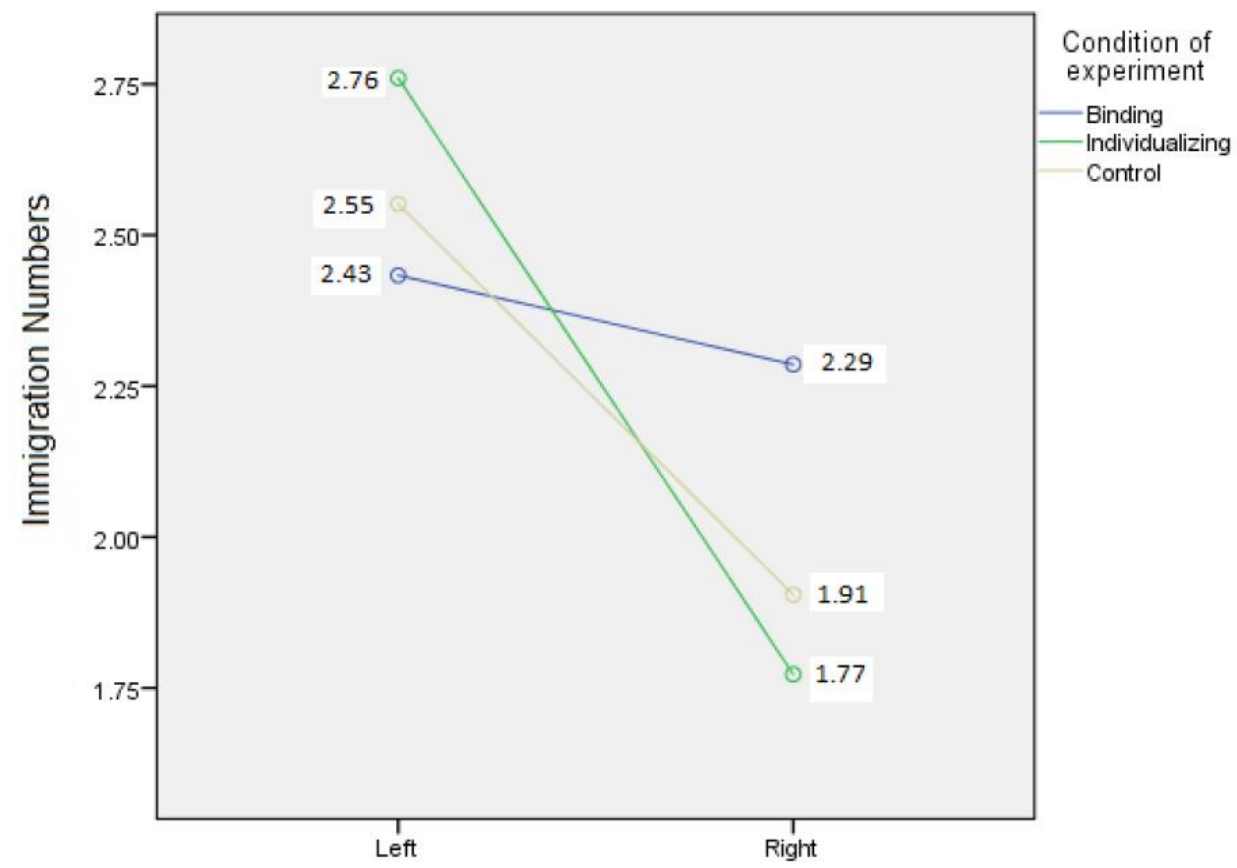

In effort to provide additional support, we conducted a second experiment in a different Midwestern university. Unlike in Experiment 1, which recruited a random sample of participants thereby providing a diverse student sample including in relation to political ideology, the sample in Experiment 2 was different. The majority of participants leaned left, which meant predictions according to MFT would shift as well. With a predominantly left-leaning sample, only the entrenching hypothesis would apply.

Also different from Experiment 1, Experiment 2 included an additional immigration-related variable. Besides measuring immigration numbers, a measure assessing support for policy related to amnesty was added (more details on this measure in the next section). Therefore, we had two hypotheses also in Experiment 2:

H3. Left-leaning participants in the individualizing pro-immigration appeal condition will support immigration significantly more than those in the binding pro-immigration appeal condition.

H4. Left-leaning participants in the individualizing pro-immigration appeal condition will support amnesty significantly more than those in the binding pro-immigration appeal condition.

In the following section, we outline Experiment 2 details.

\section{Experiment 2}

We executed a replication experiment at another Midwestern university, but this time a Carnegie Classified "Research I" (i.e., doctoral-granting university with 
"very high" research activity) location and with a sample that leaned predominantly left, confirmed with T-tests on relevant variables (i.e., Experiment 1's sample was significantly more conservative $[\mathrm{M}=3.42, \mathrm{SD}=1.09]$ and agreed significantly less with the pre-treatment statement to increase immigration numbers $[\mathrm{M}=4.01$, $\mathrm{SD}=1.23]$ compared with Experiment 2's sample [M=2.77, $\mathrm{SD}=0.98, \mathrm{p}<0.001]$ and $[\mathrm{M}=4.57, \mathrm{SD}=1.20, \mathrm{p}<0.001]$, respectively). We also included an additional immigration-related variable linked with amnesty policy.

Sample

In Experiment 2, a single large introductory course gave permission to administer the survey used in Experiment 1. All surveys were first randomized before distributing in person to students. After ample time was given for all to complete their survey, they were collected and coded for analyses. This process yielded a sample size of $\mathrm{N}=282$ students.

\section{Measures Included in the Survey}

The measures included in Experiment 2 were mostly identical to those used in Experiment 1 . Some minor changes were made to some variables, and a new immigration-related measure on amnesty, as noted below.

\section{Political Orientation}

One difference was in political orientation which factored into two constructs (Cronbach Alpha reliability $=0.84$ and 0.85 , respectively) this time instead of one. It made theoretical sense however to consider all items together again and create a measure similar to that used in Experiment 1. Reliability analysis confirmed our decision (Cronbach Alpha reliability $=0.91$ ), and so we used all twelve items to form the single political orientation measure. Also similar to Experiment 1, we examined its histogram and created a dichotomous version splitting the variable at 3.00 on the 7 -point scale. The 12 -item political orientation measure and this dichotomous version correlated highly with one another $\left(R_{x y}=0.83, p<0.001\right)$.

\section{US Immigration Numbers}

This variable was slightly modified for Experiment 2. Two more answer categories were added for increased variance leading to the following five (new categories in italic): greatly decrease the number of people allowed to immigrate here legally; decrease the number of people allowed to immigrate here legally; maintain the current number of people allowed to immigrate here legally; increase the number of people allowed to immigrate here legally; and greatly increase the number of people allowed to immigrate here legally.

Amnesty

We added an additional measure related to immigration policy (in addition to the US Immigration Numbers measure). Adopted from Ayers et al. (2009), this new measure asked, "You may or may not know that in 1986 the US Congress 
passed the Immigration Reform and Control Act, which granted amnesty to nearly two million persons who had lived continuously in this country for four or more years without proper documentation. This amnesty law allowed these immigrants to remain here as permanent residents and to apply for US citizenship. At this time, do you think repeating this amnesty program would be:" with answer categories "a very bad thing," "a bad thing," "a good thing," and "a very good thing" coded 1-4, respectively.

\section{Demographics}

Also similar to Experiment 1, we examined the same demographic indicators (e.g., sex and race made dichotomous, and age).

\section{Experimental Conditions}

The experimental treatments were identical to those in Experiment 1. That is, following the political orientation measure, each survey included one of three experimental conditions in the form of a short message on its own page in the survey; a morally framed pro-immigration appeal along with two morally consistent images reflecting either the individualizing or binding moral framework, or a control message.

Novelty

Similar to Experiment 1, after participants read the appeal, they were asked to indicate the extent to which they thought "the appeal gives reason for supporting immigration that is new to $m e$ " on a scale of $1=$ strongly disagree to $7=$ strongly agree. The words, "to me" were added in Experiment 2's version.

\section{Experiment 2 Results}

Two hundred eighty-two undergraduate students from a large-sized Midwestern university in the United States participated in an experiment with 91 in the Individualizing, 95 in the Binding, and 97 in the Control condition. The pretreatment value on a single immigration numbers measure, the political orientation measure plus its dichotomous left-right version, the main dependent variable of US immigration numbers, amnesty, and finally basic descriptive statistics may be seen in Table 2.

Based on the twelve political orientation items measured on a scale of 1 to 7 , with higher numbers indicating more conservative orientation, participants averaged a score of $2.77\left(\mathrm{~S}_{\mathrm{x}}=0.98\right)$, indicating a more liberal sample on average compared to participants in Experiment 1 (recall mean=3.42, $\mathrm{S}_{\mathrm{x}}=1.09$ ). The dichotomous left-right measure indicated $64.3 \%$ participants to be "left" and $35.7 \%$ participants to be "right," though "right" might arguably be better described as middle-left. In addition, other measures indicated $66 \%$ of the sample was female, $24 \%$ non-white, and the average age of participant was 18.99 years $\left(S_{x}=1.02\right.$ years). Statistics also revealed that participants already generally held neutral or supportive views on immigrant numbers as indicated by a mean score of $3.43\left(S_{x}=1.20\right)$ and where $4=$ "neutral" on the pre-condition measure. 
Table 2. Experiment 2 Descriptive Statistics $(N=282)$

\begin{tabular}{|c|c|c|}
\hline & Mean/Percent & $S_{x}$ \\
\hline $\begin{array}{l}\text { Pre-treatment measures: } \\
\text { Lower immigration numbers } \\
\text { (1=strongly against; } \\
7=\text { strongly in favor })\end{array}$ & 3.43 & 1.20 \\
\hline $\begin{array}{l}\text { Political Orientation } \\
\text { (1 to } 7,7=\text { most conservative })\end{array}$ & 2.77 & 0.98 \\
\hline $\begin{array}{l}\text { Dichotomous Left-Right Political Orientation } \\
\text { (1=right) }\end{array}$ & 0.36 & 0.48 \\
\hline $\begin{array}{l}\text { Post-treatment measures: } \\
\text { US Immigration numbers: } \\
\text { Greatly decrease numbers } \\
\text { Decrease numbers } \\
\text { Maintain numbers } \\
\text { Increase numbers } \\
\text { Greatly increase numbers }\end{array}$ & $\begin{array}{r}3.74 \\
0.4 \% \\
2.1 \% \\
33.0 \% \\
52.5 \% \\
12.1 \%\end{array}$ & 0.71 \\
\hline $\begin{array}{l}\text { Amnesty: } \\
\text { Very good thing } \\
\text { Good thing } \\
\text { Bad thing } \\
\text { Very bad thing } \\
\end{array}$ & $\begin{array}{r}3.11 \\
30.3 \% \\
54.1 \% \\
13.2 \% \\
2.5 \% \\
\end{array}$ & 0.72 \\
\hline $\begin{array}{l}\text { Sex of participant } \\
(1=\text { female })\end{array}$ & 0.66 & 0.48 \\
\hline Age in years & 18.99 & 1.02 \\
\hline $\begin{array}{l}\text { Race of participant } \\
\text { (1=nonwhite) }\end{array}$ & 0.24 & 0.43 \\
\hline
\end{tabular}

Results Examining Immigration Numbers

In Experiment 2 and due to the left-leaning sample, only the entrenching hypothesis applies. That is, in regard to the immigration numbers variable, we hypothesize participants in the individualizing condition would agree significantly more with increasing numbers than those in the binding condition (i.e., H3). In regard to the amnesty variable, we expect the same pattern; participants in the individualizing condition would view amnesty as significantly more a "good thing" compared to those in the binding condition (i.e., H4).

The study yielded support for the immigration numbers hypothesis. The main effect for experimental condition yielded an $\mathrm{F}$ ratio of $\mathrm{F}(2,266)=3.138, \mathrm{p}<0.05$, indicating the effect for condition was significant between the grand mean score for participants in the individualizing $(\mathrm{M}=3.78)$, binding $(\mathrm{M}=3.53)$ and control $(\mathrm{M}=3.63)$ conditions, and in the predicted direction. Similarly, political orientation also yielded an $\mathrm{F}$ ratio of $\mathrm{F}(1,266)=55.003, \mathrm{p}<0.001$, indicating a significant difference between participants in the left $(\mathrm{M}=3.95)$ versus the right $(\mathrm{M}=3.35)$ categories. The interaction of these two however, yielded an $\mathrm{F}$ ratio of $\mathrm{F}(2,266)=$ $0.110, n s$, suggesting one's political ideology did not matter when considering the condition effects. We would expect this however, given participants were predominantly left-leaning in both conditions. 
Furthermore, t-tests were performed within the politically "left" and "right" groups to further understand effects. Results revealed that among the "left" participants, those in the individualizing condition $(\mathrm{M}=4.09, \mathrm{SD}=0.63)$ indicated significantly more often to increase immigration numbers compared to those in the binding condition $(\mathrm{M}=3.81, \mathrm{SD}=0.79), \mathrm{p}<0.05$. That is, reading the message morally framed consistent with their own political orientation significantly increased liberal participants on immigration numbers. This offered more support for our immigration numbers hypothesis for the further left group. It was not supported however for participants in the "right" group, where those in the binding condition ( $\mathrm{M}=3.26, \mathrm{SD}=0.63)$ were not significantly different than those in the individualizing condition $(\mathrm{M}=3.47, \mathrm{SD}=0.61), n s$, though numbers were in the predicted direction (see Graph 2).

Graph 2. Experiment 2 on Immigration Numbers

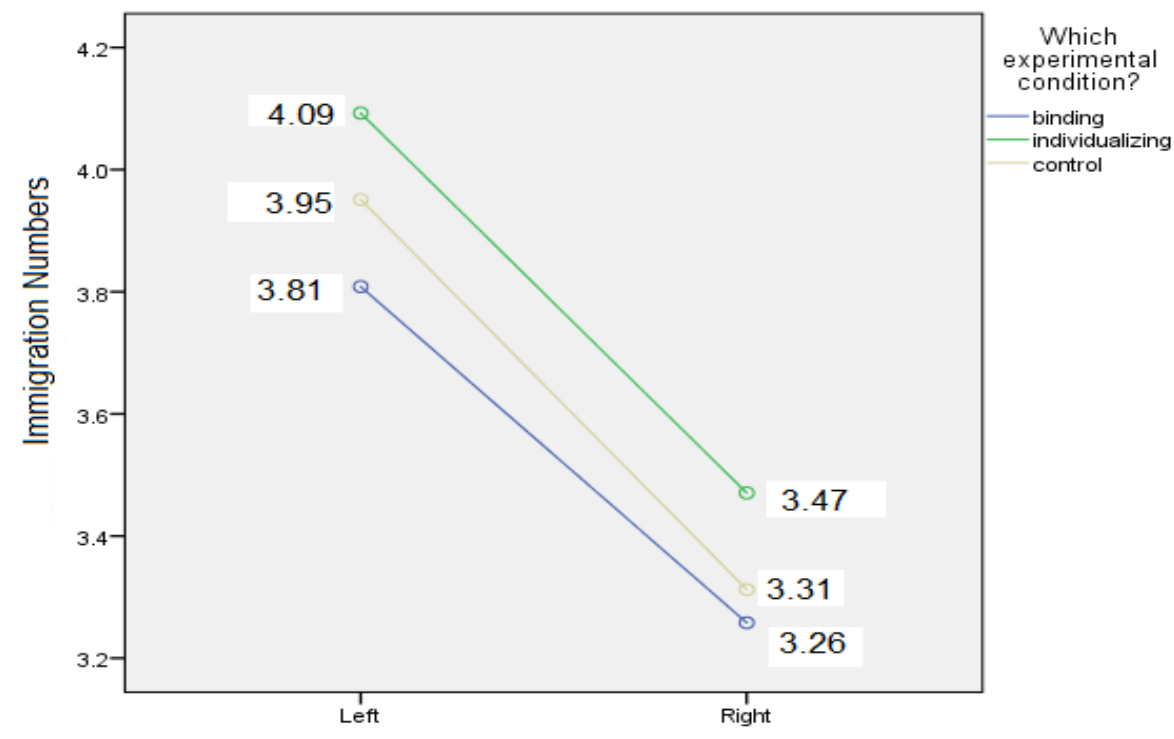

Results Examining Amnesty

In relation to the amnesty hypothesis, we found support. Recall, we hypothesized the effects of political orientation on amnesty would be moderated by the framing of the pro-immigration press release. Specifically, more liberal participants in the individualizing condition will favor amnesty significantly more than those in the binding condition.

The main effect for experimental condition yielded an $\mathrm{F}$ ratio of $\mathrm{F}(2,265)=$ $1.654, \mathrm{p}<0.01$, indicating the effect for condition was significant between the grand mean score for participants in the individualizing $(\mathrm{M}=3.10)$, binding $(\mathrm{M}=2.83)$ and control $(\mathrm{M}=3.04)$ conditions. Similarly, political orientation also yielded an F ratio of $\mathrm{F}(1,265)=139.818, \mathrm{p}<0.001$, indicating a significant difference between participants in the left $(\mathrm{M}=3.42)$ versus the right $(\mathrm{M}=2.56)$ categories. The interaction of these two however, yielded an $\mathrm{F}$ ratio of $\mathrm{F}(2,266)=0.044$, ns, suggesting one's political ideology did not matter when considering the condition effects. 
Furthermore, t-tests were performed within the politically "left" and "right" groups to further understand effects. Results revealed that among the "left" participants, those in the individualizing condition $(\mathrm{M}=3.53, \mathrm{SD}=0.50)$ indicated significantly more often to support amnesty compared to those in the binding condition $(\mathrm{M}=3.27, \mathrm{SD}=0.56), \mathrm{p}<0.01$. That is, reading the message morally framed consistent with their own political orientation significantly increased liberal participants on supporting amnesty. This was not true for participants in the "right" group however, where those in the binding condition $(\mathrm{M}=2.39, \mathrm{SD}=0.67)$ were not significantly different than those in the individualizing condition $(\mathrm{M}=2.67$, $\mathrm{SD}=0.69$ ), $n s$. Likewise, there were no other significant differences between all other combinations (see Graph 3).

Graph 3. Experiment 2 on Amnesty

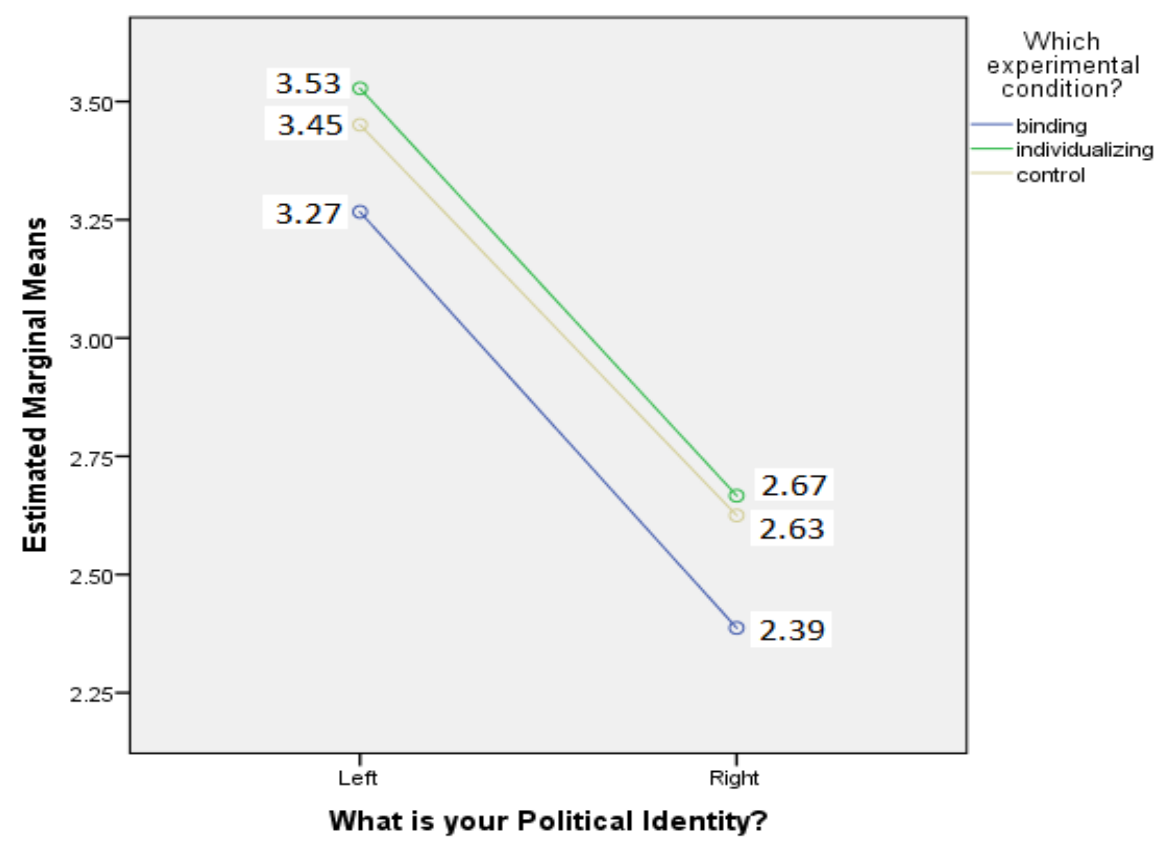

These results support hypotheses. Similar to results related to immigration numbers, for those participates more left, these results support the entrenching hypothesis which states reading a morally framed message consistent with your political orientation values will significantly increase your support for amnesty.

Finally, we examined whether participants viewed their message as containing reasons for supporting immigration that appeared "new" to them. Results indicated that among participants in the "left" group, they rated the binding message $(\mathrm{M}=2.78, \mathrm{SD}=1.35)$ as containing significantly more information that was "new" to them compared to the individualizing message $(\mathrm{M}=2.24, \mathrm{SD}=1.43), \mathrm{p}<0.05$. Participants in the "right" group however did not (Binding $\mathrm{M}=1.40, \mathrm{SD}=0.26$; Individualizing $\mathrm{M}=1.41, \mathrm{SD}=0.24, n s)$. This is surprising since in this study, our "right" group contains many left-leaning participants. Rather, it is consistent with moral foundation theory's assumptions that conservatives consider all five moral foundations more readily than do liberals, who rely primarily on two (i.e., fairness 
and caring). This aspect of difference between conservatives and liberals may be useful in explaining results.

\section{Discussion}

Two similar experiments with two unique samples from two different Midwestern universities were performed to examine if MFT helps explain attitudes on US immigration numbers. For both experiments and using the MFT framework, pro-immigration appeals were written in either the individualizing, binding, or a neutral moral language. We examined the entrenching and the persuasion hypotheses with respect to attitudes on US immigration numbers in both experiments, and also in relation to amnesty policy in the second experiment.

Predictions were driven by the MFT framework plus the sample characteristics. Given Experiment 1 included a more politically diverse sample and Experiment 2, a more left-leaning sample (see each sample's histogram in Figure 1 below), this meant predictions would vary depending on the entrenching and persuasion hypotheses. For Experiment 1, we predicted (i.e., H1-entrenching) liberal-leaning participants in the individualizing pro-immigration appeal condition will support immigration significantly more than those in the binding pro-immigration appeal condition. We also predicted (i.e., H2-persuation) conservative-leaning participants in the binding pro-immigration appeal condition will support immigration significantly more than those in the individualizing pro-immigration appeal condition. Results of experiment 1 were consistent with our predictions.

Figure 1. Histogram of Experiment 1 and Experiment 2 Samples on Political Ideology Measure

Experiment 1 Histogram

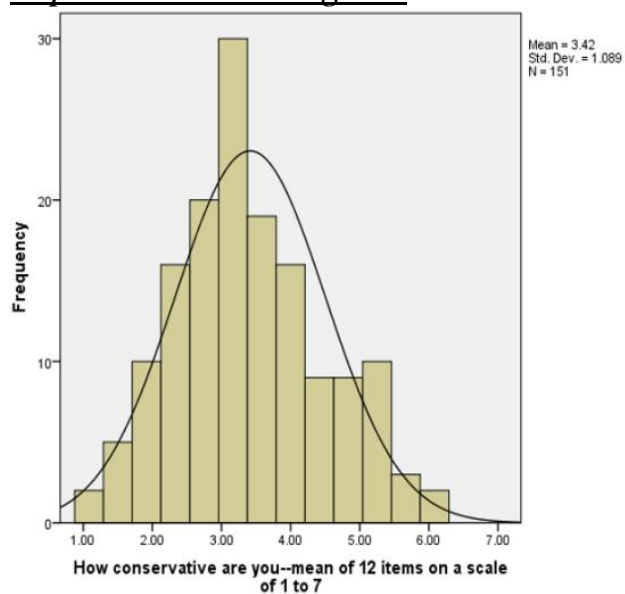

Experiment 2 Histogram

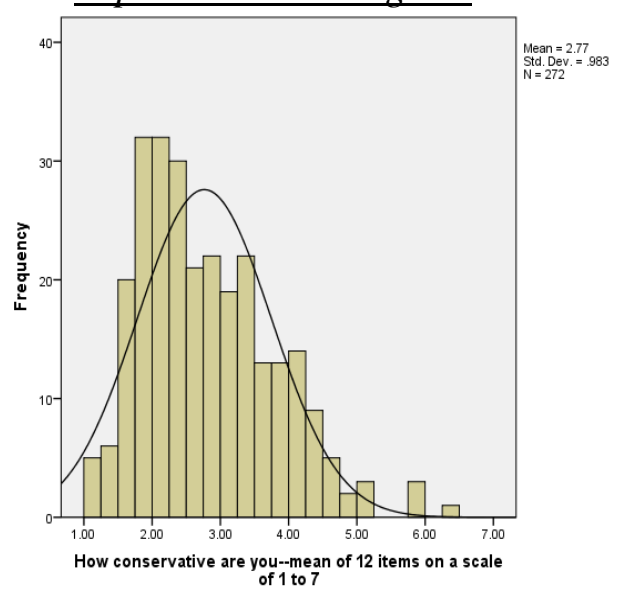

Predictions for Experiment 2 differed based on its more left-leaning sample. Predictions were consistent with the entrenching hypothesis, since most participants were left-leaning and already rather supportive of immigration. We predicted leftleaning participants in the individualizing pro-immigration appeal condition will support immigration significantly more than those in the binding pro-immigration 
appeal condition (i.e., H3). We also predicted left-leaning participants in the individualizing pro-immigration appeal condition will support amnesty significantly more than those in the binding pro-immigration appeal condition (i.e., H4). Results of Experiment 2 were consistent with these hypotheses.

\section{Conclusion}

Overall, results of both experiments reveal support for MFT in explaining immigration attitudes around immigration numbers and amnesty policy. Participants in the "left" increased support for immigration when reading the "individualizing" message, reflecting the entrenching hypothesis. Participants in the "right" increased support for immigration when reading the "binding" message, reflecting the persuasion hypothesis.

Our research also confirmed MFT assumptions that "right" leaning participants refer to a more diverse moral framework than "left" leaning participants. This was indicated in analysis of a post-treatment measure asking participants to rate the level of agreement to whether the message read contained information that was "new." "Right" leaning participants did not rate the "binding" message as significantly different from the "individualizing" message. "Left" participants however did rate the "binding" message as having more new information compared to the "individualizing" message.

This work provides further support for how direction and strength of attitude change may be contingent on the moral framing of the language used in messages. Writing to individuals in this study in the language they morally connect with has more influence than if using neutral or unfamiliar language. The individualizing condition includes language associated more often with those leaning liberal (Graham et al. 2009, Franks and Scherr 2015, Nath et al. 2018). For example, focus on fairness and caring connects with those more highly valued moral intuitions among liberals. The binding condition uses language more often associated with those leaning conservative. While fairness and caring may be included in a conservative-leaning moral framework, moral intuitions linked with loyalty, authority and purity are more often unique to those leaning conservative. Therefore, that messages may link with one politically oriented group versus another has a unique impact compared to any message written without reference to particular moral intuitions. That is, this research demonstrates how the entrenching and persuasion hypotheses depend on the political orientation of the participant as well, thus supporting the intersection of political ideology with moral framing in understanding attitude formations.

\section{References}

Allport GW (1954) The nature of prejudice. Reading: MA: Addison-Wesley.

Álvarez Gálvez J, Salinas Pérez JA, Martínez Cousinou G, Muniategi Azkona E, Antolínez Domínguez I (2020) Attitudes towards immigration at the regional level in Europe in times of crisis. Revista de Fomento Social 75(298): 297-325. 
Ayers JW, Hofstetter CR, Schnakenberg K, Kolody B (2009) Is immigration a racial issue? Anglo attitudes on immigration policies in a boarder county. Social Science Quarterly 90(3): 593-610.

Blumer H (1958) Race prejudice as a sense of group position. Pacific Sociological Review 1(1): 3-7.

Ceobanu AM, Escandell X (2010) Comparative analyses of public attitudes toward immigrants and immigration using multinational survey data: a review of theories and research. Annual Review of Sociology 36(1): 309-328.

Clifford S, Jerit J (2013) How words do the work of politics: Moral foundations theory and the debate over stem cell research. The Journal of Politics 75(3): 659-671.

Dawson SL, Tyson GA (2012) Will morality or political ideology determine attitudes to climate change. The Australian Community Psychologist 24(2): 8-25.

Day MV, Fiske ST, Downing EL, Trail TE (2014) Shifting liberal and conservative attitudes using moral foundations theory. Personality and Social Psychology Bulletin 40(12): 1559-1573.

Dustmann C, Preston I (2007) Racial and economic factors in attitudes to immigration, The BE Journal of Economic Analysis \& Policy 7(1): 11-30.

Espinosa A, Guerra R, Sanatkar S, Paolini S, Damigella D, Licciardello O, et al. (2018) Identity inclusiveness and centrality: investigating identity correlates of attitudes toward immigrants and immigration policies. Journal of Social Issues 74(4): 674-699.

Esses VM, Wagner U, Wolf C, Preiser M, Wilbur CJ (2006) Perceptions of national identity and attitudes toward immigrants and immigration in Canada and Germany. International Journal of Intercultural Relations 30(6): 653-669.

Esses VM, Hamilton LK, Gaucher D (2017) The global refugee crisis: empirical evidence and policy implications for improving public attitudes and facilitating refugee resettlement. Social Issues and Policy Review 11(1): 78-123.

Feinberg M, Willer R (2013) The moral roots of environmental attitudes. Psychological Science 24(1): 56-62.

Franks AS, Scherr KC (2015) Using moral foundations to predict voting behavior: regression models from the 2012 US presidential election. Analyses of Social Issues and Public Policy (ASAP) 15(1): 213-232.

Gerber AS, Huber GA, Biggers DR, Hendry DJ (2017) Self-interest, beliefs, and policy opinions: Understanding how economic beliefs affect immigration policy preferences. Political Research Quarterly 70(1): 155-171.

Graham J, Haidt J, Nosek BA (2009) Liberals and conservatives rely on different sets of moral foundations. Journal of Personality and Social Psychology 96(5): 1029-1046.

Graham J, Nosek BA, Haidt J, Iyer R, Koleva S, Ditto PH (2011) Mapping the moral domain. Journal of Personality and Social Psychology 101(2): 366-385.

Haidt J (2013) The righteous mind: why good people are divided by politics and religion. Allan Lane Publishers.

Haidt J, Graham J (2007) When morality opposes justice: conservatives have moral intuitions that liberals may not recognize. Social Justice Research 20(1): 98-116.

Kidwell B, Farmer A, Hardesty DM (2013) Getting liberals and conservatives to go green: Political ideology and congruent appeals. Journal of Consumer Research, 40(2): 350-367.

Macdonald D (2021) Immigration attitudes and white Americans' responsiveness to rising income inequality. American Politics Research 49(2): 132-142.

Malesevic S (2002) Rational choice theory and the sociology of ethnic relations. Ethnic and Racial Studies 25(2): 193-212. 
Mangum M (2019) Revisiting economic threat and cultural concerns: public opinion toward immigration and non-citizens by race. Social Science Research 83(Sep): 102309.

Margolis MF (2018) How far does social group influence reach? Identities, elites, and immigration attitudes. Journal of Politics 80(3): 772-785.

McDermott M, Knowles ED, Richeson JA (2019) Class perceptions and attitudes toward immigration and race among working-class whites. Analyses of Social Issues \& Public Policy 19(1): 349-380.

Nail PR, McGregor I, Drinkwater AE, Steele GM, Thompson AW (2009) Threat causes liberals to think like conservatives, Journal of Experimental Social Psychology 45(4): 901-907.

Nath L, Pedriana N, Gifford C, McAuley J (2018) Moral foundations theory and the 2016 US presidential election, Sociological Imagination 54(1): 75-85.

Otjes S (2021) Between "eradicate all false religion" and "love the stranger as yourself": how immigration attitudes divide voters of religious parties. Politics \& Religion 14(1): 106-131.

Pérez E (2010) Explicit evidence on the import of implicit attitudes: the IAT and immigration policy judgments. Political Behavior 32(4): 517-545.

Quillian L (1995) Prejudice as a response to perceived group threat: Population composition and anti-immigrant and racial prejudice in Europe. American Sociological Review 60(4): 586-611.

Ramos A, Pereira CR, Vala J (2020) The impact of biological and cultural racisms on attitudes towards immigrants and immigration public policies. Journal of Ethnic \& Migration Studies 46(3): 574-592.

Silver JR, Silver E (2017) Why are conservatives more punitive than liberals? A moral foundations approach. Law and Human Behavior 41(3): 258-272.

Smith IH, Aquino K, Koleva S, Graham J (2014) The moral ties that bind...even to outgroups: the interative effect of moral identity and the binding moral foundations. Psychological Science 25(8): 1554-1562.

Tajfel H (1982) Social psychology of intergroup relations. Annual Review of Psychology 33(Feb): 1-39.

Tajfel H, Turner J (1986) The social identity theory of intergroup behaviour. In S Worchel, WG Austin (eds.), Psychology of Intergroup Relations. Chicago: Nelson Hall.

Wolsko C, Ariceaga H, Seiden J (2016) Red, white, and blue enough to be green: effects of moral framing on climate change attitudes and conservation behaviors. Journal of Experimental Social Psychology 65(Jul): 7-19.

Yueh-Ting L, Ottati V (2002) Attitudes toward US immigration policy: the roles of ingroup-out-group bias, economic concern, and obedience to law. Journal of Social Psychology 142(5): 617-634. 


\section{Appendix}

Individualizing Condition Images
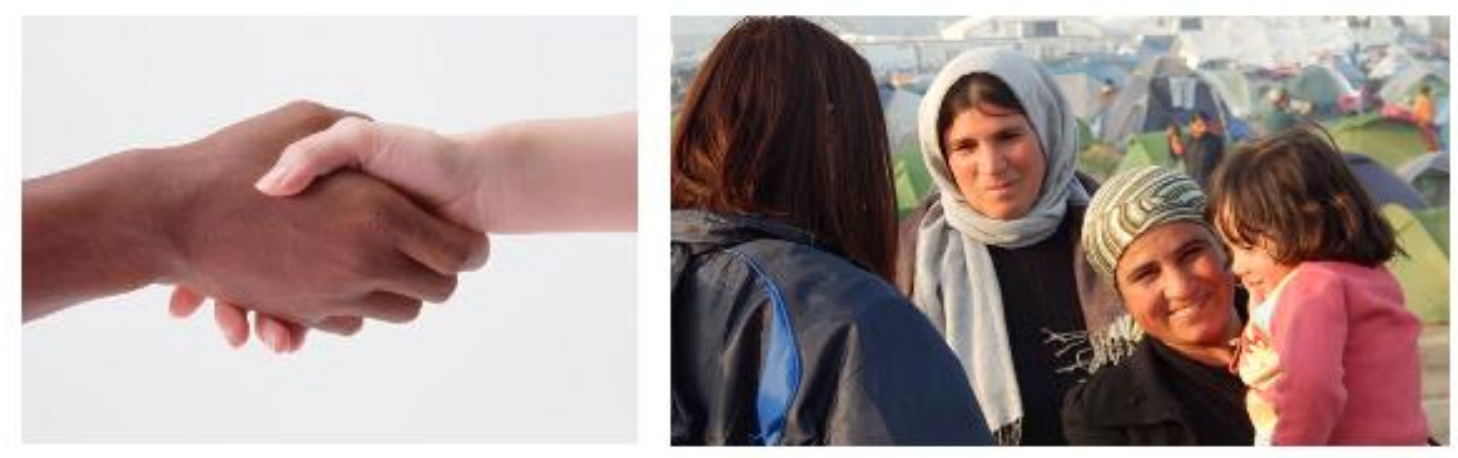

Binding Condition Images
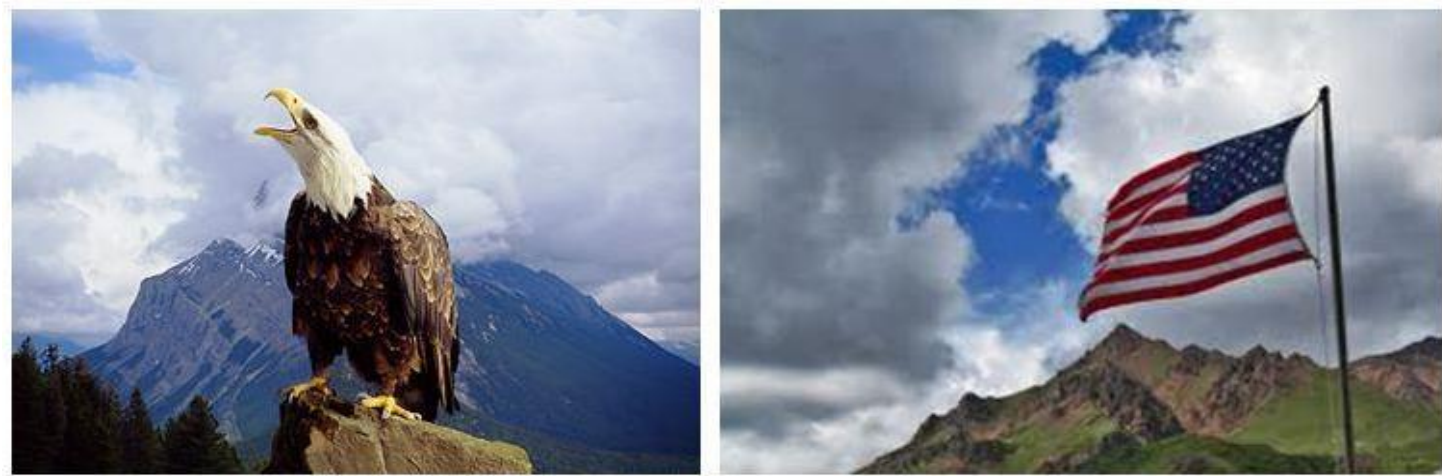

Control condition had no images. 



\title{
Nation-State Contexts and Authoritarian Value Changes of Ethnic Chinese
}

\author{
By Baodong Liu ${ }^{*}$ Porter Morgan ${ }^{ \pm} \&$ Dimitri Kokoromytis $^{+}$
}

\begin{abstract}
The recent global populist wave has reignited interest in how authoritarianism gains momentum in different nation-state contexts. A central question remains: under which conditions do individuals abandon or embrace authoritarian values? In the context of ethnic Chinese, this paper argues that Confucianism still plays a pivotal role in shaping attitudes and values. Specifically, it asserts that the Confucian value of meritocracy maintains importance in the ethnic Chinese value system. The study utilized the Chinese social media platform WeChat to deploy a four-question, snowball sample survey of 1,763 ethnic Chinese in seven regions from around the globe to evaluate their levels of authoritarianism. It tested six hypotheses derived from previous theories concerning assimilation, individual/ family resources, group competition, communist influence, and generational gap. The empirical results, however, provide the strongest support for the theory of meritocratic and conditional authoritarianism, which suggests that ethnic Chinese around the world will become more authoritarian when they perceive a threat to their status quo and will become less authoritarian when they perceive threats to their upward mobility.
\end{abstract}

Keywords: ethnic Chinese, authoritarianism, political culture, immigration, meritocracy

\section{Introduction}

The recent success of populist movements in Western countries has led to a new wave of scholarly interest in the effect of authoritarianism on the performance of electoral systems and the fate of democracy itself (Levitsky and Ziblatt 2018, Liu et al. 2020, Müller 2016, Pettigrew 2016). Though many scholars concur that the authoritarian value system consists of some key ingredients, such as the insistence on value conformity and reliance on "right" authority (Adorno et al. 1950, Altemeyer 1996, Stenner 2005), one major disagreement among scholars is whether authoritarianism is a predisposition determined by personality, or it is, in fact, a product of societal conditions. In other words, are certain people born with authoritarian traits? Or are all people more or less authoritarian dependent upon the circumstances? Scholars who study authoritarianism as a predisposition tended to treat authoritarianism as an independent variable and focus on who in democracies and which authoritarian regimes are likely to help put authoritarian political figures, such as Donald Trump, in power. For these scholars, people with

\footnotetext{
*Professor, University of Utah, USA.

${ }^{ \pm} \mathrm{PhD}$ Candidate, University of Utah, USA

${ }^{+} \mathrm{PhD}$ Candidate, University of Utah, USA.
} 
an authoritarian disposition may live in any culture or political system. People of an authoritarian disposition are different from the rest of the population because they react to threats differently from others, and they may even have some cognitive differences (Stenner 2005).

More recently, the literature on authoritarianism has moved away from the predispositional approach. For example, using the survey data from the American National Election Studies, Hetherington and Weiler (2009) stated that "When those scoring lower in authoritarianism do perceive a significant threat, we suggest that they are not heroic, small ' $d$ ', democrats. In fact, under such conditions, their preferences on issues become indistinguishable from those who score high in authoritarianism" (Hetherington and Weiler 2009, p. 7). The reason why threats may "reduce the difference in preferences between the more and less authoritarian" is because threats force the less authoritarian to use "instinct" rather than "cognition". In doing so, they became authoritarians who always seek order, security, and safety through authority (Hetherington and Weiler 2009, p. 110).

According to Hetherington and Weiler (2009), a community may become more authoritarian as more members of the community perceive specific threats. The same community may become less authoritarian as the perception of the threats fades from the memories of its members. Nevertheless, one question remains: what types of threats tend to make a community more authoritarian? To put it differently, is it possible that some threats may make authoritarianism less attractive, or even offensive, to members of a community, thus reducing the level of authoritarianism in the community? Arguably, people do not always appeal to authority when they perceive threats. But under what conditions are they likely to rely on non-authoritarian values to cope with threats? This question is difficult to answer. Two factors have limited the scope of the past research on authoritarianism, including Hetherington and Weiler (2009).

First, most members of a community who share the same value system only live in one nation-state context. For example, Americans may already have a particular value system, e.g., egalitarianism, which limits the chance of Americans to become authoritarian (King and Smith 2005). However, one cannot generalize the findings from the American nation-state context to other contexts where the political culture may be drastically different from the American one rooted in its White-Anglo-Saxon-Protestant (WASP) culutre. Second, to study the possibility of the different threat-based-effects on authoritarianism, dependent upon the types of threats, one cannot just simply engage in a comparative study of different nations (e.g., Stenner 2005). A multi-national study may obtain empirical results that are only concomitant to different cultures instead of different types of threats. Even for those nations who share deep cultural roots, e.g., those western, traditionally Protestant, European countries, or those Eastern Asian, traditionally Confucian, countries with arguably varied national characters may be significantly different, which will contribute to any observed differences between each country.

One way to address the aforementioned limitations is to study migrants who left their home country and live in a different nation-state. The advantage is that these migrants have subjected themselves to at least two cultural influences (i.e., home country and a host country). However, if a study only focuses on migrants, a 
problem may still exist because the comparison with the home country may not persist over time in the host country. In this case, it is impossible to evaluate whether a more or less authoritarian position is due to assimilation into a new culture. Furthermore, it is also significant to compare the migrants from the same home country to different nation-states to study whether the new nation-state contexts matter to them in terms of increasing or decreasing authoritarian values.

This study is designed to remedy the limitations of the past research on authoritarianism by empirically investigating the ethnic Chinese in not only Mainland China but also other six regions of the globe (i.e., overseas Chinese). This study is interested in the comparison of ethnic Chinese in different nationstate contexts. Overseas Chinese, broadly speaking, may include descendants of earlier migration waves in Southeast Asia, the United States, and Australia, or it may include Chinese citizens who have migrated abroad, maintaining their Chinese citizenship. According to this definition of ethnic Chinese, the largest Chinese populations overseas are in Indonesia ( 8 million), Thailand (7.5 million), Malaysia (6.5 million), Singapore (5.2 million), the Philippines (1.2 million), and Myanmar (1 million) in 2011. According to the 2017 data from the U.N. (the Migration Policy Institute), the top destinations for Chinese migrants that host more than 100,000 Chinese are the following countries: United States (2.42 million), Hong Kong (2.34 million), Japan (0.74 million), Canada (0.71 million), South Korea (0.61 million), Australia (0.47 million), Singapore (0.46 million), United Kingdom (0.21 million), Italy (0.2 million), Bangladesh (0.17 million), Spain (0.16 million), France (0.11 million), and Germany (0.1 million). Surprisingly, Southeast Asian countries (except for Singapore) are absent from the countries that host more than 100,000 Chinese, according to the 2017 estimates. The recent migration patterns demonstrate the Chinese's preference to migrate to developed countries in the West or East (e.g., Japan, South Korea, and Singapore). This research primarily focuses on how Chinese immigrants in the West may or may not change their value orientation to more or less authoritarian. It first reviews the literature on the Chinese political culture in Mainland China, where these Chinese immigrants originate.

\section{Confucianism and Authoritarianism}

Confucianism is a primary source of civilization for ethnic Chinese. In his landmark study of major competing civilizations in the modern world, Samuel Huntington classified the East Asian countries as those practicing Confucianism originated in China (Huntington 1996). The authoritarian tendency of Confucianism manifests itself through its emphasis on a hierarchical society; important examples are: Junwang (junwang 君王 rulers as hold authority over to their ranked officials chen 臣), Fuqin ( $f u$ 父 fathers hold authority to their sons $z i$ 子), and Zhangfu (zhangfu 丈夫 husbands hold authority over their wives qizi 妻子). Also, Confucianism in practice has adopted a clearly defined system of social customs centered on good manners and community rituals of Han China. Despite the pressure of westernization and democratization since the last period of the Qing 
Dynasty, the political system in China has gone through "many forms of authoritarianism" (Huntington 1996, p. 66), and the most recent version is the "one-party-dominant authoritarian system" (Huntington 1996, p. 219).

To equate Confucianism, or the Chinese civilization in general, with authoritarianism completely fails to capture the rich contents of Chinese political culture and the nuanced effects of Confucianism, which has been revised many times throughout Chinese history. Scholars such as Fukuyama (1995) argued that Confucianism, as one form of traditional values, may embrace liberal democracy during the process of modernization. Bell (2015) recently proposed that a unique effect (even a defining feature) of Confucian thought on social, economic, and political progress is much more salutary than the prevailing opinion of western scholars. The main reason that people need to consider the Chinese political culture as a realistic and productive, and perhaps even a better alternative than the western-style "one person, one vote" democratic principle, is that the Chinese cultural tradition has always prioritized meritocracy.

This research revisits the new theoretic perspective of Bell on China's meritocratic tradition in a later section of this article. It is imperative, at this point, to examine the rapid changes both inside and outside Mainland China that may have led to more or less authoritarian attitudes among ethnic Chinese beyond the limit of Confucianism. First, the study focuses on the effect of assimilation of Chinese immigrants into other cultures.

\section{Immigration, Assimilation, and Ethnic Chinese Authoritarianism}

Park and Burgess (1921, p. 734) defined assimilation as "the process by which the culture of a community or a country is transmitted to an adopted citizen", and for immigrants' assimilation "is a process of denationalization". If Chinese immigrants are successful in this assimilation process, they become "denationalized" from their homeland culture (Confucian thoughts) to be assimilated to the dominant culture in the host society (e.g., the WASP egalitarian culture in the USA). If the assimilation thesis is correct, one would expect that the Chinese immigrants become less authoritarian than their counterparts in Mainland China who have never left the home country.

The assimilation process, as historians repeatedly remind us, is not merely a one-way train running out of its original station. The complexity of who gets assimilated and by whom often takes on the dynamics of group politics. Gordon (1964) conceived assimilation as the maintenance or loss of group identity affecting "friendship patterns, organizational affiliations, civic participation, selfidentification, value conflict, and value integration, political life, prejudice and discrimination" (Gordon 1964, p. 8). For Gordon, successful assimilation is not solely measured by its process. More importantly, it is about how the assimilation ends. He concludes that assimilation is only complete when in the interaction between the immigrant groups and the host society's prejudice and discrimination are absent (Gordon 1964, p. 63). If one adopts this view of assimilation, there is abundant evidence against the smooth transition of Confucian thought to Western- 
societies' more egalitarian values for millions of Chinese immigrants, as evidenced by Chinese immigrants have historically been discriminated against as a racial and ethnic minority in Western societies (Lien 2001, Zhou 2009).

What are the factors that may slow down the assimilation process or even reverse it into a re-discovery of the homeland values among immigrants? More relevant to this research is: who among the ethnic Chinese immigrants in Western societies may become even more authoritarian after they migrate to a host country such as the USA, Canada, Australia, or other European countries? In this vein, the literature on other ethnic immigrants may help shed some light on this question. For example, in the United States, ethnic minorities have been found to have higher levels of authoritarianism compared to the white majority (Austin et al. 1987, Varela et al. 2004). Dornbusch et al. (1987) found that Black and Latino parents applied a higher level of authoritarian parenting than do white parents. One possible explanation for such a disparity in parenting is reportedly the lower socioeconomic status and education level among the minority families (Noel and Pinkney 1964). The findings on lower-class authoritarianism within the ethnic minority communities are in line with the general findings of the masses in all Western societies, which were presented noticeably in Lipset's (1959) classic work Political Man. According to Lipset, "the lower-class individual is likely to have been exposed to punishment, lack of love, and a general atmosphere of tension and aggression since early childhood", which contributes to the authoritarian orientation (Lipset 1959, p. 114).

Based on the empirical results of the experimental design and a sample of 273 participants from various racial and ethnic groups in the United States, Henry (2011, p. 419) rejected the notion that ethnic minority endorsement of authoritarianism is "a function of lack of sophistication or cognitive simplicity". The reason why authoritarianism may be especially potent for ethnic minorities is because of its "psychological vigilance or protective quality" (Henry 2011, p. 423). In short, the authoritarian thoughts may be especially useful for minorities to manage the effects of "chronic stigmatization" and authoritarianism, in particular, serves as a "self-regulatory process" for the "stigmatized" groups (Henry 2011, p. 433).

Authoritarianism may also find echoes from the individuals who have the socalled "superiority complex", which was vividly depicted in Chua and Rubenfeld (2014). According to them, there are certain minority groups, including the Chinese, who have achieved unprecedented successes in the USA despite their historical minority status. Superiority (i.e., in their culture and their achievements) and impulse control (e.g., strict rules on conduct) are the two essential characteristics that make them successful. The Asians in general and the Chinese, in particular, are the so-called "model minority" in the post-1965 immigration era in the USA. Amy Chua documented, in detail, how she raised her two daughters in the Chinese authoritarian way (Chua 2011). Disagreeing with Western parents who "try to respect their children's individuality, encouraging them to pursue their true passions, supporting their choices, and providing positive reinforcement and a nurturing environment", the Chinese "just have a totally different idea" of how to raise their children (Chua 2011, p. 63). Two critical components of Chua's 
Chinese parenting, both of which show an authoritarian orientation, are ultimate control of playtime and the ultimate authority of parents on educational priorities.

In sum, the literature on assimilation and ethnic minorities in Western societies call for competing hypotheses concerning how an immigrant from China who was primarily influenced by Confucianism may or may not become less authoritarian than his/her counterparts who remained in China. The classic assimilation theory (Gordon 1964, Park and Burgess 1921) would expect:

Hypothesis $1(\mathrm{H} 1)$ : a Chinse immigrant who chooses a Western country as his/her host country may become less authoritarian due to the denationalization process and the completed integration into the Western egalitarian value systems.

On the other hand, a resource model (Lipset 1959) suggests that:

H2: an ethnic Chinese with fewer resources (represented by lower SES and/or limited cognitive capability) may become more authoritarian than his/her fellow co-ethnics in Western societies.

Furthermore, a more nuanced understanding of immigrant experiences suggests that whether one becomes more authoritarian is related to how he/she perceives the relative position of his/her group in a host society. We call this expectation the group competition hypothesis (Hypothesis 3), which states:

H3: the higher the perception of being "stigmatized" (Henry 2011) or "superior" compared to other groups, the higher the level of value changes to authoritarianism.

\section{Authoritarianism and the Political Changes in Mainland China}

Lung-kee Sun, a renowned historian of the $20^{\text {th }}$-century Chinse culture, has repeatedly warned the danger of over-simplification of Western scholarships on China, especially its exaggeration of the Confucian influence in China's modern history. The penchant for degeneration theories, which devalued Confucianism in the global context, for example, was a major force among the May Fourth intellectuals in the first thirty years of the $20^{\text {th }}$ century, among whom $\mathrm{Lu}$ Xun, as a national salvationist and an icon, constantly derided the "stupidity" of the traditional Chinese thoughts (Sun 2002). The numerous struggles in finding the appropriate Western ideas (or tools) to help China's modernization eventually led to the political domination of Leninist-style communism.

One line of research suggests that individuals who experienced a communist political legacy (especially the Leninist legacy) would hold more authoritarian values (Jowitt 1992). This legacy includes civic politics, Stalinist economics, egalitarian social structures, and norms (Kopstein 2003). Communism surpasses other authoritarian regime types in its project to add a supplemental layer of political socialization to its citizens as opposed to merely ruling over citizens. Communist citizens must transcend mere compliance, and they must adopt and integrate socialism into their political worldviews. Communist regimes implemented 
systematic programs to restructure societal life using socialist precepts through party-controlled education systems, party integration in the workplace, and party meetings (Pop-Eleches and Tucker 2017). The eventual goal is to create the ideologically-inculcated, class-conscious "Socialist Man" (Deutscher 1967). Arguably, the Chinese Communist Party took this socialization one step further by emphasizing absolute selflessness, nationalism, and Maoist thought, all of which contributed to the authoritarian leadership style (Chen 1969). Pye (1992) explains the Chinese acceptance of communism based on the psychological need espoused by Confucianism to mitigate emotional pressure in order to create social harmony, which in turn created an ideology that dictated proper behavior in all aspects of social life and a clear hierarchal authority with specifically Mao as a father figure. For Lieberthal (1995), authoritarian socialization is particularly strong within the Chinese Communist Party (CCP) as Mao organized the governing party with a mixture of traditional Confucian cultural norms, Stalinist organization, and his vision for China.

The communist-style leadership under Mao, however, did not always lead to the strengthening of authoritarianism at the mass level. Mao almost singlehandedly launched his radical agenda of the Cultural Revolution during the 1960s-1970s. Targeted at the long-term adverse effect of the Confucius values, particularly the "Four Olds" (old customs, old cultures, old ideas, old habits), Maoism called for egalitarian principles that favored the poor and less powerful at the expense of the authority (Perry 2012). In sum, the influence of communism and its continued success in post-Mao China seemed to lead to two opposing hypotheses-

H4A: on the one hand, an individual that resided in Mao's communist China may be expected to exhibit a high level of authoritarianism, which stresses the forms of obeying publicly and reverence to authority (Chien 2016).

H4B: on the other hand, an individual that resided in Mao's communist China may be expected to possess an egalitarian value or less authoritarian tendency, which encourages the challenge to an authority that is considered to be against the masses.

Egalitarian values may be further incorporated into the new political culture in the post-Mao era. This is primarily due to the historical success of Deng Xiaoping's opening-up and reform policies after the death of Mao in China. The rapid economic development in China has integrated China into global economic systems. Along with unprecedented economic success, China has witnessed the influx of Western popular culture, sports, and new social customs. The egalitarian and democratic values associated with the call for political reform may have shaped the new political culture in China to be much less authoritarian in the post-Mao era. The fifth hypothesis (H5) concerns the generational gap in China:

H5 expects that the younger-generation Chinese, especially those who were born in post-Mao China, are less likely than the older Chinese to be authoritarian. 


\section{Meritocracy and Conditional Authoritarianism: A New Theory of Chinese Political Culture}

After a critical review of the applications of previous theories on authoritarianism concerning ethnic Chinese, this section proposes a new theoretical model to study authoritarianism in the global ethnic Chinese communities. This new theory attempts to resolve some competing, sometimes conflicting, expectations of the previous theories, as discussed above. It aims to establish a unified model that can explain not only the variations inside China about who is authoritarian and who is not but also the differences seen in ethnic Chinese communities across the globe. In other words, the theory asks in what contexts ethnic Chinese become more or less authoritarian after they are exposed to a new culture such as WASP egalitarianism in English-speaking countries. This new theory will bring a new light on these tough questions. In doing so, it borrows insights from the previous theories reviewed above.

Moreover, the model presented in this paper was inspired by a new scholarly work on China by Bell (2016). Different from other Western scholars such as Samuel Huntington, who discussed how the Confucian thoughts in China (or in the global Chinese communities called Hanren 汉人) may negatively lead to the authoritarian and/or other values that are contrary to the democratic (and more Western) values, Bell calls attention to a unique aspect of Confucianism that may produce some salutary effects on progress. For Bell, the defining feature of the Chinese political culture and the dominant norm of its political system is a meritocracy. Bell identified three components of meritocratic principles that have been used in Chinese history to select government officials, which are superior performance in exams, proved social skills, and good virtue. According to Bell, meritocracy is the main reason why China has experienced rapid economic growth, and the stability of China's political system persists in the Post-Mao era. To change the meritocratic rule of its political system to any alternatives, including the Western democratic rule of "one person, one vote", will only lead to disasters for China as well as the rest of the globe.

Meritocracy has worked in China because it reflects its culture and tradition and is a universally recognized and accepted social norm in the Chinese communities. In other words, the Chinese are meritocrats in their "habits of the heart" by using Tocqueville's terminology on social mores. However, are the Chinese meritocrats are authoritarians who value authority and obedience over independence and equality? Bell did not provide a clear answer in his recent book. A natural corollary of reading deeply into the Confucian thoughts leads to the logical connection between meritocracy and authoritarianism. For instance, Confucius himself famously argued that "A good scholar who studies with relative ease can become an official" (xue er you zi shi 学而优则仕), and the Confucian tradition of official rank as the sole criterion as one's worth (guan benwei 官本位) makes a strong case that the Confucian belief connects merits in the academy with earning a position in government which in turn adds one's stake in government authority. Indeed, as Bell remarked that in China's meritocratic system, a natural 
question is whether it is "really possible to structure political meritocracy so that it is seen as legitimate by the people and avoids the abuses of authoritarian rule" (Bell 2016, p. 2).

The abuses of an authoritarian rule can turn a meritocrat against government authority. This is because meritocrats are especially sensitive to how they are treated by an authority. If there is clear evidence that an individual of merits is prevented from having the opportunities for upward mobility, then the whole political system, and especially the government officials in power, can be considered an injustice. It is in this sense that the Chinese meritocratic value system has had deep roots in egalitarianism instead of authoritarianism. Even under the authoritarian rule of Mao, the communist government was fully aware of the power of the masses. As Wenfang Tang (2016) observed, the adoption of the so-called "Mass Line" policy allowed "political activism" and even "mass protests" against the "corrupted" authority, especially at the local government level (also see Distelhorst and $\mathrm{Fu} 2019$ ). Indeed, the part of the stability of political regime since Mao is rooted in the meritocratic tradition in China.

Now, this study is ready to derive two hypotheses based on "the theory of conditional authoritarianism for ethnic Chinese people", which evaluates the perception of threats to meritocrats in this way:

H6A: An individual meritocrat will become more egalitarian (i.e., less authoritarian) when he/she perceives a threat to his/her opportunity for upward mobility.

The next question is, of course, under what conditions an individual meritocrat may become more authoritarian (i.e., less egalitarian). Clearly, in a meritocratic system, those people in power (or enjoy a more advantageous position) are more likely to perceive a threat to the status quo. It is natural for them to feel that they are in power because they deserve to be there based on their merits. Thus, the next hypothesis of conditional authoritarianism is the following:

H6B: An individual meritocrat will become more authoritarian (i.e., less egalitarian) when he/she perceives a threat to the status quo.

Turning to the empirical tests of the six sets of hypotheses, derived from different theoretical approaches to the formation and changes of political cultures concerning Chinese authoritarianism and meritocracy, follows the description of the data collection process for this study.

\section{Data and Method}

To examine the extent to which the ethnic Chinese communities throughout the globe exhibit the traits of authoritarianism, this paper uses the data collected between the December of 2017 and February of 2018 through WeChat, the most popular Chinese social media network not only in Mainland China but also globally. WeChat is a mobile messaging app developed by the Chinese company Tencent in 2011, and during the first quarter of 2018, the number of WeChat users 
had already reached 1.04 billion. ${ }^{1}$ A total of 1,763 respondents responded to the survey on WeChat. This research utilized targeted snowball sampling as the data collection method. First, it is necessary to explain why this method was adopted for this research.

The targeted population of this study is the ethnic Chinese who reside not only in Mainland China but also in almost every major region of the world. It is not feasible, even if financially manageable, to collect samples based on the traditional probability sampling methods from the massive geographic areas simultaneously. To deal with the difficulty concerning a "hard to reach population", researchers have increasingly used snowball sampling as the means for data collection, in which the "sampling is undertaken when a qualified participant shares an invitation with other subjects similar to them who fulfill the qualifications defined for the targeted population" (also see Berg 2006, Dusek et al. 2015).

The snowball sampling method has been used in qualitative research on hardto-reach and/or hidden populations (Atkinson and Flint 2001, Coleman 1958, Faugier and Sargeant 1997). Through the networks of these populations, which are not generally open to researchers, snowballing sampling is especially effective in enlarging the sample size and obtaining high-quality data in quantitative research. This method also helps deal with the high rejection rate problem in random sampling surveys because the data collectors have more trust from members of their networks who answer the survey questions more truthfully and fully. As Dusek et al. (2015) indicated, traditional surveys "received from unknown researchers on sensitive topics" are usually not welcomed by the respondents "if no relationship, particularly a trusting one, exists" (Dusek et al. 2015, p. 281).

The data-collection method based on snowball sampling has also been used by scholars of ethnic Chinese who took advantage of modern social media, especially WeChat (e.g., Zhang 2018). One clear weakness of snowball sampling is that due to the non-probability nature of this method, the generalization of its research findings to the whole population can be called into question. Certain measures need to be made to enhance the external validity of snowball sampling research. To make the sample more closely representative of the population, the key to snowball sampling research is to avoid homogeneous respondents who do not reveal the necessary variations in variables used for hypothesis testing. The sample size may also become a problem when it is too small to capture the dispersions in variables. Drawing enough subsamples from different demographic segments of the population is a common way to increase the external validity of the study. In short, "Nearly all studies of hidden populations are carried out in circumstances that do not permit true random sampling. Under these conditions, and if properly conducted and tied to what is known or can be learned about population parameters, targeted sampling provides a more powerful sampling mechanism than convenience sampling and a more feasible approach than random sampling" (Watters and Biernacki 2014, p. 427).

To sufficiently address the potential limitation on the validity of snowball sampling, this study collected data from three main ethnic Chinese communities located in Mainland China, the USA, and Canada in addition to those ethnic

${ }^{1}$ https://www.statista.com/statistics/255778/number-of-active-wechat-messenger-accounts/. 
Chinese in Taiwan and Hong Kong, Australia, Europe, and the Middle East. The subsample sizes from these various Chinese communities are 1343, 242, 95, 27, 23, 12, and 7, respectively. As reported above, the Chinese communities number at least 2.42 million in the USA, 0.71 million in Canada, and 0.47 million in Australia in 2017. Immigration to Europe is a more recent phenomenon. According to the United Nations (2017), since 1990, more than two million Chinese have migrated abroad. Of those, 0.7 million have migrated to the more developed regions, and 130 thousand Chinese have migrated to Europe. The relatively small number of Chinese immigrants in Europe makes data collection difficult, despite snowball sampling's strengths of including hard to reach populations in research. While attempts were made to collect data from all seven regions, caution needs to be exercised that the responses do not yet support a large enough sample size from the Taiwan/Hong Kong, Australia, Europe, or Middle East regions. Ultimately, the lack of responses in some areas reveals another limitation of snowball sampling because the recruitment method is respondent-driven instead of researcher-driven, resulting in some respondents choosing not to forward the survey to new respondents, thus resulting in some regions underreporting responses.

The survey was first sent through WeChat to the representatives from these seven different regions. After sending back their responses, these representatives were asked to forward the original survey to their WeChat friends without informing their friends of their own answers to the survey questions. Once the responses from their WeChat friends were received and recorded, the representatives were also asked to provide detailed information regarding the respondents' age, gender, profession, education, and religious affiliation (if known). Three waves of data collection took place between December of 2017 and February of 2018 to enhance the dispersions of descriptive statistics for the subsamples.

The survey was conducted in Chinese (simplified Mandarin) and composed of four questions concerning authoritarianism (See the Appendix for the original survey). Similar to MacWilliams (2016) and Hetherington and Weiler (2009), the measure authoritarianism is based on a battery of four child-rearing questions asked in American National Election Studies (ANES). MacWilliams (2016) provided a detailed description of the history of these questions adopted by scholars in the last three decades: "These questions first appeared on the 1992 ANES survey and have since been used by some authoritarian scholars to estimate authoritarianism (Feldman and Stenner 1997, Hetherington and Suhay 2011, Hetherington and Weiler 2009, Stenner 2005). These questions tap into deep-seated preconceptions about children and child-rearing: whether it is more important for a child to be respectful or independent, obedient or self-reliant, well-behaved or considerate, and well-mannered or curious. Survey respondents who pick the first option in each of these pairs are strong authoritarians" (MacWilliams 2016, p. 718). As in Hetherington and Weiler (2009, p. 48) and Stenner (2005), the score of 0.5 is used to represent those who answered "both" on the four authoritarian questions ( 0 for anti-authoritarian answers and 1 for authoritarian answers).

\section{Results}


Figure 1 shows the distribution of the authoritarian tendency for all respondents (the authoritarianism index is standardized to be a value between 0 and 1). Overall, the ethnic Chinese throughout the globe exhibited a normal distribution with the mode located at the center of the authoritarian index value. However, the distribution also shows a slightly positive skew with more respondents located toward the left of the mode, which suggests an overall greater tendency toward the non-authoritarian direction (median $=0.375$, mean $=0.387$, $\mathrm{sd}=0.204$, skewness $=$ 0.177). This finding naturally raises the question of what are the factors contributing to the lesser authoritarian features among all Chinese and who are more likely to be authoritarian. This study turns to hypotheses testing in order to answer this question.

Figure 1. Authoritarian Distribution based on the 2017-2018 WeChat Chinese Survey

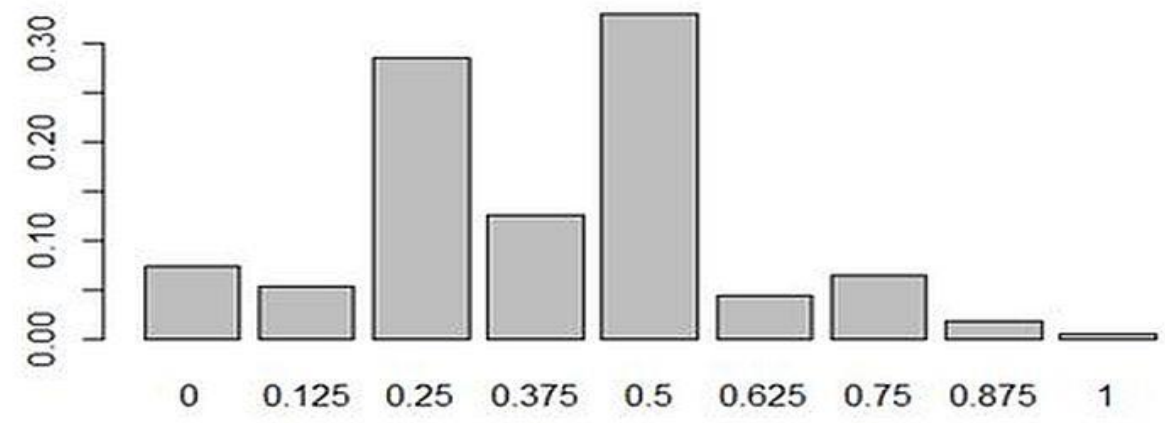

Table 1. OLS Regression for the Ethnic Chinese Authoritarianism

\begin{tabular}{|l|c|c|c|}
\hline & $\begin{array}{c}\text { Equation 1 } \\
\text { coefficient (standard } \\
\text { error) }\end{array}$ & $\begin{array}{c}\text { Equation 2 } \\
\text { coefficient (standard } \\
\text { error) }\end{array}$ & $\begin{array}{c}\text { Equation 3 } \\
\text { regression } \\
\text { coefficient (standard } \\
\text { error) }\end{array}$ \\
\hline Reside in Australia & $-0.04(0.22)$ & --- & $-0.10(0.24)$ \\
\hline Canada & $0.31(0.18) \#$ & --- & $0.28(0.19)$ \\
\hline Mainland China & $0.04(0.16)$ & --- & $-0.08(0.17)$ \\
\hline Europe & $-0.18(0.28)$ & --- & $-0.18(0.30)$ \\
\hline Middle East & $-0.54(0.35)$ & --- & $-0.59(0.36)$ \\
\hline USA & $-0.26(0.17)$ & --- & $-0.23(0.17)$ \\
\hline Teen & $-0.30(0.11)^{*}$ & $-0.50(0.15)^{* *}$ & --- \\
\hline Young & $-0.22(0.04)^{* * *}$ & $-0.24(0.05)^{* * *}$ & --- \\
\hline Senior & $0.03(0.08)$ & $0.09(0.10)$ & --- \\
\hline Generation & --- & --- & $0.09(0.04)^{*}$ \\
\hline Male & $-0.13(0.04)^{* *}$ & $-0.10(0.07)$ & $-0.10(0.05) \#$ \\
\hline Born in USA & $0.12(0.09)$ & $-0.06(0.08)$ & $-0.06(0.12)$ \\
\hline Christian & $0.01(0.08)$ & $-1.00(0.30)^{* *}$ & $0.01(0.09)$ \\
\hline Male x Middle-aged & --- & $-0.06(0.09)$ & --- \\
\hline Male x Senior & --- & $-0.19(0.18)$ & --- \\
\hline Male x Teen & --- & $0.15(0.23)$ & --- \\
\hline Profession in Science & --- & --- & $0.06(0.16)$ \\
\hline
\end{tabular}




\begin{tabular}{|l|c|c|c|}
\hline Technology & --- & --- & $-0.14(0.11)$ \\
\hline Medicine & --- & --- & $0.07(0.10)$ \\
\hline Law & --- & --- & $0.05(0.17)$ \\
\hline Business & --- & --- & $0.06(0.07)$ \\
\hline Arts & --- & --- & $0.16(0.22)$ \\
\hline Military/Police & --- & --- & $0.37(0.27)$ \\
\hline Sports & --- & --- & $-0.63(0.49)$ \\
\hline Multiple Professions & --- & --- & $0.16(0.32)$ \\
Cheap Labor & --- & --- & $0.22(0.12) \#$ \\
Unemployed/Retired & --- & --- & $0.16(0.10)$ \\
Government & --- & --- & $0.29(0.11)^{* *}$ \\
\hline R Squared & 0.05 & 0.03 & 0.06 \\
Adjusted R Squared & 0.04 & 0.03 & 0.04 \\
\hline N & 1737 & 1737 & 1087 \\
\hline
\end{tabular}

Note: Two-tailed test.

$\# \mathrm{p}<0.1,{ }^{*} \mathrm{p}<0.05, * * \mathrm{p}<0.01, * * * \mathrm{p}<0.001$

Table 1 provides three OLS models on the determinants of authoritarian characteristics. Equation 1 focuses on three groups of explanatory variables, which are: the locations in which the survey respondents resided, the generational gaps, the gender effect, as well as, the control variables concerning the birthplace and religious influence. With respect to the location as a contextual effect, Equation 1 lists six dummy variables that are all used to compare the base group: those ethnic Chinese reside in Taiwan and Hong Kong. In other words, the signs of the variables in the first group in Equation 1 indicates whether the Chinese residing in a certain location are more or less likely to be authoritarian than those from Taiwan and Hong Kong. But the statistical test shows that only the Chinese residing in Canada are more authoritarian than the base group from Taiwan and Hong Kong at the $\mathrm{p}<0.10$ level, a finding certainly inconsistent with the assimilation thesis (H1), which suggests migration to a Western country may lead to less authoritarian orientation. The next section examines which one of the hypotheses discussed above actually provides the best explanation for this "disturbing" finding.

Equation 1 of Table 1 also revealed a clear generational effect on Chinese authoritarianism, which supports H5 capturing the effect of possible value changes among the younger generations in the Post-Mao era. This can be seen from the second group of independent variables, which compare a particular generation to the base group, the middle-aged Chinese who are older than 35 and younger than 59 years of age. Equation 1 shows that the teenage and young-age group Chinese are less likely to be authoritarian than the middle-age group, though the senior group (older than 60) is not statistically different from the middle-age group. Finally, Equation 1 also shows a clear gender effect: male Chinese are less likely to be authoritarian than female Chinese (statistically significant at the 0.01 level). This finding seems to confirm $\mathrm{H} 2$ derived from the resource model. Female Chinese traditionally possess fewer resources and social prestige, and thus according to the resource model (Lipset 1959), they may become more authoritarian than their male counterparts.

To further investigate the gender gap, Equation 2 adds three interactive terms between gender and generational variables. Interestingly, none of the interactive terms turned out to be statistically significant, though religious effect (being 
Christian) became notable as it passed the statistical test at the $\mathrm{p}<0.1$ level. The Chinese Christians overall tended to be less authoritarian than non-Christians. The generational gap revealed by Equation 2 remains the same as that in Equation 1, which once again shows that teenage and young Chinese are less likely to be authoritarian than middle-aged and senior Chinese.

Equation 3 adds the final group of twelve dummy variables that compare the respondents' professions to the base group (i.e., those who work in education, humanities, and journalism-related professions). The OLS model shows that two categories of professions are statistically more likely associated with authoritarian characteristics than are those who work as educators, humanitarians, and journalists in the base group. The more authoritarian professions among ethnic Chinese are those who work as cheap labor-a finding once again confirms H2, i.e., the resource model of authoritarianism. At the same time, the empirical finding also suggests that government officials are more likely to be authoritarian. This important finding provides the first piece of evidence that the conditional authoritarian thesis, stated in H6B, which suggests that the meritocratic tradition in China lead to a greater authoritarian tendency among those who are in power and are concerned with the threat to the status quo.

It also should be noted that gender once again is a statistically significant factor (at the $\mathrm{p}<0.1$ level), with females more authoritarian than males. Furthermore, the generation effect (now measured as an ordinal variable instead of dummy variables in Equations 1 and 2) continues to present itself as a contributing factor to authoritarianism (at the $\mathrm{p}<0.05$ level). The older the generation, the more authoritarian it becomes for ethnic Chinese, even after controlling for variables such as gender, profession, and the host country.

The fact that ethnic Chinese in Mainland China are not statistically different from those from Taiwan and Hong Kong in terms of authoritarian orientation (or lack of) also suggests that the expectations (H4A and H4B) based on the possible effects of communist influence in Mainland China are not supported. Moreover, the importance of location needs to be further scrutinized, as the assimilation hypothesis (H1) leads to the potential contextual effect of living as an immigrant in a host country. In this vein, the subsamples from Mainland China, the USA, and Canada are large enough to make some statistical analyses. Running ANOVA allows seeing whether the mean of the authoritarian values from these three contexts are statistically different from each other. The F-test concludes that statistically significant different means of authoritarian values exist among Chinese from Mainland China and the Chinese who immigrated to the USA and Canada $(\mathrm{F}=21.34, \mathrm{p}<0.001)$. Which of these three groups of ethnic Chinese had the highest mean of the authoritarian values? Table 2 shows the result of the Tukey multiple comparisons of a means test. 
Table 2. Tukey Multiple Comparison of Means Test for Three Groups of Ethnic Chinese

\begin{tabular}{|l|c|c|c|c|}
\hline & Difference & Lower bound & Upper bound & p-value adj. \\
\hline China-Canada & -0.335 & -0.537 & -0.134 & 0.00 \\
\hline USA-Canada & -0.607 & -0.836 & -0.377 & 0.00 \\
\hline USA-China & -0.272 & -0.404 & -0.139 & 0.00 \\
\hline
\end{tabular}

As shown in Table 2, the mean authoritarian value (MAV) of the Mainland Chinese group is between the MAV of the Chinese immigrants in the USA and the MAV of the Chinese immigrants in Canada, as the three differences are all negative in Table 2. The lower and upper boundaries of these differences and the corresponding adjusted $\mathrm{p}$ values all indicate that statistically speaking, the Mainland Chinese are more authoritarian than the Chinese immigrants in the USA and less authoritarian than the Chinese immigrants in Canada. This finding is puzzling in that it seems to support the hypothesis derived from the assimilation theory (H1) if one uses the mean comparison between Mainland China and the USA, but it is contrary to the expectation of the mean comparison made between Mainland China and Canada.

Table 3 lists the results from the OLS models in the three contexts. The different findings from these three contexts reveal more clues about the puzzle from Table 2. In Mainland China, the continuing generational gap (again, supporting H5) is evident, that is, the older the generation, the higher the tendency to hold authoritarian principles in child-rearing practices. This generational gap, however, does not exist for those Chinese who migrated to North America. Furthermore, the OLS result for the USA context shows that those US-born Chinese-Americans are not significantly different from their parent generation in terms of child-rearing beliefs. These findings strongly suggest that contexts mattered in the formation and durability of the authoritarian value system. The immigrant experience in a different host country can have a profound impact on how they abandon or embrace the authoritarian belief system for ethnic Chinese, and the changes can have a lasting effect on their children as well.

Table 3. OLS Regressions for the Ethnic Chinese Authoritarianism in Three Contexts

\begin{tabular}{|c|c|c|c|}
\hline & Mainland China & USA & Canada \\
\hline & $\begin{array}{c}\text { regression } \\
\text { coefficient (standard } \\
\text { error) }\end{array}$ & $\begin{array}{c}\text { regression } \\
\text { coefficient (standard } \\
\text { error) }\end{array}$ & $\begin{array}{c}\text { regression } \\
\text { coefficient (standard } \\
\text { error) }\end{array}$ \\
\hline Generation & $0.10(0.05) \#$ & $-0.08(0.10)$ & $0.23(0.17)$ \\
\hline Male & $-0.09(0.07)$ & $-0.23(0.13) \#$ & $0.15(0.18)$ \\
\hline Born in USA & --- & $-0.13(0.15)$ & --- \\
\hline Christian & $-0.04(0.15)$ & $0.17(0.14)$ & --- \\
\hline $\begin{array}{l}\text { Educated in } \\
\text { Mainland }\end{array}$ & $0.48(0.24)^{*}$ & $-0.13(0.17)$ & --- \\
\hline HK/Taiwan Educated & --- & $0.40(0.40)$ & $0.04(0.17)$ \\
\hline Educated in Europe & $0.10(0.66)$ & $-0.64(0.60)$ & --- \\
\hline $\begin{array}{l}\text { Profession in Science } \\
\text { Technology }\end{array}$ & $\begin{array}{l}-0.32(0.62) \\
-0.06(0.18)\end{array}$ & $\begin{array}{c}0.35(0.21) \\
0.11\end{array}$ & $\begin{array}{l}-1.18(0.44)^{* *} \\
-0.78(0.30)^{*}\end{array}$ \\
\hline Medicine & $0.11(0.14)$ & $0.24(0.21)$ & $-0.81(0.31)^{* *}$ \\
\hline
\end{tabular}




\begin{tabular}{|l|c|c|c|}
\hline Law & $0.10(0.21)$ & $0.87(0.86)$ & $-1.18(0.58)^{*}$ \\
\hline Business & $0.02(0.09)$ & $0.09(0.23)$ & $0.18(0.26)$ \\
\hline Arts & $0.04(0.27)$ & $0.90(0.43)^{*}$ & --- \\
\hline Military/Police & $0.35(0.27)$ & --- & --- \\
\hline Sports & $-0.26(0.61)$ & --- & $-1.79(0.76)^{*}$ \\
\hline Multiple Professions & $0.57(0.44)$ & $-0.30(0.51)$ & --- \\
Cheap Labor & $0.17(0.14)$ & $1.03(0.45)^{*}$ & $-0.40(0.30)$ \\
Unemployed/Retired & $0.14(0.12)$ & $0.58(0.28)^{*}$ & $-0.66(0.32)^{*}$ \\
Government & $0.28(0.12)^{*}$ & $0.37(0.60)$ & --- \\
\hline R Squared & 0.04 & 0.13 & 0.24 \\
Adjusted R Squared & 0.01 & 0.04 & 0.14 \\
\hline $\mathrm{N}$ & 731 & 191 & 95 \\
\hline
\end{tabular}

Note: Two-tailed test.

$\# \mathrm{p}<0.1, * \mathrm{p}<0.05, * * \mathrm{p}<0.01, * * * \mathrm{p}<0.001$

One may reject the conclusion on the contextual effect of an immigrant host country on authoritarianism by suggesting that the results of the ANOVA perhaps only captured a self-selection process, which is based on the notion that those immigrants who now reside in North American were non-authoritarian, to begin with, and their decision to move to the West suggested that they are more independently minded people in relation to other Chinese who never migrated out of the country. The findings from Table 3 offer contrary evidence for this selfselection thesis. As shown in Table 2, the host countries in the West do not necessarily suggest that the Chinese immigrants are less authoritarian than those who stay in China. Furthermore, to test whether the migration history is a function of self-selection for those Chinese who are less authoritarian in the first place, the Chinese immigrants who once were educated in the USA but chose to go back to China are compared to those Chinese who were educated in China and never had an immigration history. Note the third group of independent variables about educational differences in Table 3 is all dummy variables compared to the base group representing those who were educated in the U.S. and went back to China after their American education.

The first equation of Table 3 shows that those Chinese who were educated only in China are more authoritarian than those so-called Haigui 海归 (those who were educated in the U.S. and/or Europe and went back to China after their western education). In short, it is not whether or not one is authoritarian that drives the decision to migrate out or back in China, and a Western-educated ethnic Chinese who are non-authoritarians may simply choose to live in China just like those Chinese authoritarians who had never migrated to the West.

The second and third equations of Table 3 further show that, contrary to the assimilation thesis stated in H1, the immigrant Chinese in the USA and Canada do not change their authoritarian values simply because they are educated in the host country. In other words, it is the various content of western education that has a potential impact on an immigrant's child-rearing values concerning authoritarianism. It is the immigration experience itself that had a major effect on the value system. Equation 2 of Table 3 presents the findings from the ethnic Chinese in the USA.

The statistical significance of gender is at the $p<0.1$ level, indicating males, compared to females, are less likely to be authoritarian in the USA. One possible 
explanation, based on the resource model stated in $\mathrm{H} 2$, females with fewer resources, lower SES status encounter more difficult times to be assimilated to the egalitarian American values than do their male counterparts. The same explanation can be offered for the findings that those Chinese immigrants working as cheap labor or being unemployed/retired are more likely to be authoritarian than other professionals due to their limited resources. The immigrants who work in the Arts industry may also encounter greater hardship than other immigrants in science, technology, and so on, which can be transformed into a more authoritarian orientation. It is also important to note that the above findings concerning immigrants with limited resources may be validly explained by $\mathrm{H} 3$, which suggests that the group competition between the ethnic Chinese and other racial and ethnic groups may especially produce a feeling of "stigmatization", as these lower SES immigrants are more likely to compete with other working-class Americans. The stress of group competition may cause these immigrants to trigger authoritarianism as a protective mental mechanism against marginalization, as suggested by Henry (2011).

The largest challenge is, however, as mentioned above, the puzzling difference in immigration experiences between the ethnic Chinese in the USA and those in Canada. None of the previous theories presented as Hypotheses 1 through 5 fully explain why the immigrants to the USA are less likely to be authoritarian, and their counterparts in Canada are more likely to be authoritarian than those Chinese who never left Mainland China. An explanation from the meritocracy and conditional authoritarianism theoretical perspective is provided in the next section.

\section{Ethnic Chinese in the USA and in Canada: The Meritocrats in Two Different Contexts}

While Table 2 shows that ethnic Chinese become much more authoritarian after migrating to Canada, a quick examination of Equation 3 of Table 3 suggests that the immigration experiences in Canada are drastically different from those in the USA. Beyond already possessing a higher level of authoritarianism among the ethnic Chinese in Canada as a whole, two professional groups are even more authoritarian (arguably the most authoritarian subgroups among all ethnic Chinese anywhere). These are the base-group professions (i.e., those who work in education, social sciences/humanities, and journalism) and the business group. These two groups, in comparison with other professions examined in Equation 3 of Table 3, are those with greater resources, information, and critical thinking on political and social issues. One would expect, based on Hypotheses 1 through 5, these two groups to be less authoritarian than other groups in Canada. But the findings showed exactly the opposite.

To find a plausible explanation for this puzzling result, the theory of meritocracy and conditional authoritarianism is revisited. To recap, this theory suggests that the best explanation of candidates from the ethnic Chinese communities for becoming more authoritarian are those meritocrats who are in power and/or in advantageous positions. This is because these meritocrats are 
more likely to perceive threats to the status quo and their advantaged positions, and authoritarianism becomes a protective mental check on those who represent threats and dangers. Empirical evidence from Mainland China for this conditional authoritarian model shows that those elites working inside governments are more likely to be authoritarian than the rest of the population. What happened in the context of Canada?

Canada, as in the USA, has attracted millions of high-skilled immigrants from China and other countries. But as explained by migration scholars such as $\mathrm{Li}$ and Lo (2012), the experiences after the arrivals have been very different in these two North-America countries. "Compared to the Canadian-born and white immigrant groups from Europe, a larger percentage of [Chinese immigrants] were unemployed or underemployed" (Li and Lo 2012, p. 10). The lack of economic opportunities in addition to "discrimination" and "foreign credential devaluation" all contributed to the harsher experiences of the Chinese communities in Canada. In contrast, the United States has used an immigration admission quota system that focused on family reunion. Furthermore, as "a response to the global race for talent, the 1990 Immigration Act triples the worldwide annual quota for employmentbased immigrants", and the H-1B visa category has attracted numerous Chinese students to stay and gain a green card for themselves and their family members ( $\mathrm{Li}$ and Lo 2012, p. 10). Li and Lo also noted that multiculturalism had been adopted by the Canadian federal policy to let Chinese immigrant develop Canada into a pluralist society, whereas "the dominant paradigm of immigration adaptation in the U.S. academia, media, government policy, and public's mindset remains assimilation" (Li and Lo 2012, p. 11).

The relatively harsher economic condition and intense perception of threats from other newer immigrants that may take their jobs away may have contributed to the enhanced authoritarianism in ethnic Chinese in Canada, as empirically demonstrated in Tables 1 and 2. Furthermore, it is the business groups, who enjoyed more economic success in the past, and the informed professionals in social sciences, education, and journalism who are more likely to perceive a threat to their status and advantages. In other words, these meritocrats are the most likely candidates to become authoritarians, according to the conditional authoritarianism theory (H6B).

In the United States, the greater economic security and more successful assimilation, as suggested by $\mathrm{Li}$ and $\mathrm{Lo}$, have contributed to the lesser authoritarian orientation among the ethnic Chinese (H6A). In other words, the meritocrats who share the same cultural backgrounds back in China develop different patterns of cultural changes due to the different types of threats perceived in different nationstate contexts. In Canada, the primary fear among the ethnic Chinese is toward other newer immigrants who may change the status quo enjoyed by the Chinese immigrants who migrated earlier. The mode of reaction to this threat is to embrace more authoritarian values, and of recent note is the push to help elect more rightwing political candidates who promised to cut skilled-worker immigration and refugees, especially from Muslim countries.

In the United States, the perception of threat among the ethnic Chinese, after their relatively more successful assimilation, is the loss of opportunity for upward 
mobility. This is especially reflected by the fight against affirmative action policy led by the Chinese community activists (Kim 2018). The mode of coping with the potential threats from other minority groups such as African Americans and Latinos in the college admission process includes protests, demonstrations, and lawsuits, which are all forms of egalitarian political participation, rather than authoritarian responses. In sum, better than all previous approaches introduced in this paper, the theory of Chinese meritocracy and conditional authoritarianism provides the most plausible explanation for the conflicting findings from the ethnic Chinese communities in Canada and the USA.

\section{Conclusion}

The existing migration studies suggested that the political integration of immigrants includes the "support for the core political values" of their host country (Bilodeau 2016), and yet assimilation may follow a number of different pathways (Samson 2014). It is still uncertain, however, which nation-state contexts may provide a value system that allows effective political integration of immigrants. This paper examines whether or not the philosophical bedrock of Chinese civilization (Confucianism) is likely to translate to authoritarian orientation and the extent to which the Chinese diaspora modify their traditional value system in different nation-state contexts.

Based on the survey data collected through WeChat, the most popular Chinese social media, this study analyzes the authoritarian tendencies of ethnic Chinese in Mainland China and abroad. The findings, on the one hand, reveal the minimal impact of communist influence on authoritarianism. On the other hand, the paper shows that the Chinese immigrants in the U.S. are indeed more likely to share the Western egalitarian values than the ethnic Chinese in Mainland China and other regions of the world. However, it is also discovered that the ethnic Chinese in Canada become much more authoritarian, which ran afoul with the expectation from the classic assimilation theory. In addition, this study shows the effects of gender, education, and generational cohorts on ethnic Chinese's authoritarian traits.

To solve the puzzle concerning the differing effects of Western nation-states on the Chinese immigrants, this research proposes a meritocracy and conditional authoritarian model to explain the conditions on which a meritocrat may become authoritarian. Empirical findings confirm that the perception of threat to the status quo leads to a greater tendency to authoritarianism while the perception of threat to opportunities for upward mobility may, in fact, reduce that tendency and cause more egalitarian political participation. In sum, this study demonstrates that Confucianism still plays a pivotal role in shaping attitudes and values among ethnic Chinese. Specifically, the Confucian value of meritocracy maintains importance in the ethnic Chinese communities in Mainland China and abroad. This continuing importance of meritocracy may or may not lead to more authoritarian value changes, dependent on the nature of threats that Chinese meritocrats perceive in the nation-state contexts in which they live. In order to better represent Chinese in 
the West, future research can improve an understanding of the Chinese experience by increasing sample sizes in European countries and Australia. Studying the Chinese in the different Western European societies will help understand whether ethnic Chinese are influenced by the host society culture.

\section{References}

Adorno TW, Frenkel-Brunswik E, Levinson DJ, Sanford RN (1950) The authoritarian personality. $1^{\text {st }}$ Edition. New York, NY: Harper.

Altemeyer B (1996) The authoritarian specter. Cambridge, MA: Harvard University Press.

Atkinson R, Flint J (2001) Accessing Hidden and Hard-to-Reach Populations: Snowball Research Strategies. Social Research Update (33): 1-4.

Austin TL, Hale DC Ramsey LJ (1987) The effect of layoff on police authoritarianism. Criminal Justice and Behavior 14(2), 194-210.

Bell DA (2015) The China model: political meritocracy and the limits of democracy. Princeton, NJ: Princeton University Press.

Bell DA (2016) The China model: political meritocracy and the limits of democracy. Pbk. Edition. Princeton, NJ: Princeton University Press.

Berg S (2006) Snowball sampling. I. In S Kotz, CB Read, N Balakrishnan, B Vidakovic \& NL Johnson (eds.), Encyclopedia of Statistical Sciences Volume 12, 1-5. New York, NY: John Wiley and Sons.

Bilodeau A (2016) Introduction: just ordinary citizens? Towards a comparative portrait of the political immigrant. In A Bilodeau (ed.), Just Ordinary Citizens? Towards a Comparative Portrait of the Political Immigrant, 3-26. Toronto, ON: University of Toronto Press.

Chen TH-e (1969) The new socialist man. Comparative Education Review 13(1): 88-95.

Chien C-L (2016) Beyond authoritarian personality: the culture-inclusive theory of chinese authoritarian orientation. Frontiers in Psychology 7(Jun): 924.

Chua A (2011) Battle hymn of the tiger mother. New York, NY: Penguin.

Chua A, Rubenfeld J (2014) The triple package: how three unlikely traits explain the rise and fall of cultural groups in America. New York, NY: Penguin Press.

Coleman J (1958) Relational analysis: the study of social organizations with survey methods. Human Organization 17(4): 28-36.

Deutscher I (1967) On socialist man. New York, NY: Merit Publishers.

Distelhorst G, Fu D (2019) Performing authoritarian citizenship: public transcripts in China. Perspectives on Politics 17(1): 106-121.

Dornbusch SM, Ritter PL, Leiderman PH, Roberts DF, Fraleigh MJ (1987) The relation of parenting style to adolescent school performance. Child Development 58(5): 1244 1257.

Dusek G, Yurova Y, Ruppel CP (2015) Using social media and targeted snowball sampling to survey a hard-to-reach population: a case study. International Journal of Doctoral Studies 10(1): 279-299.

Faugier J, Sargeant M (1997) Sampling hard to reach populations. Journal of Advanced Nursing 26(4): 790-797.

Feldman S, Stenner K (1997) Perceived threat and authoritarianism. Political Psychology 18(4): 741-770.

Fukuyama F (1995) Confucianism and democracy. Journal of Democracy 6(2): 20-33. 
Gordon MM (1964) Assimilation in American life: the role of race, religion and national origins. New York, NY: Oxford University Press.

Henry PJ (2011) The role of stigma in understanding ethnicity differences in authoritarianism. Political Psychology 32(3): 419-438.

Hetherington MJ, Suhay E (2011) Authoritarianism, threat, and Americans' support for the war on terror. American Journal of Political Science 55(3): 546-560.

Hetherington MJ, Weiler JD (2009) Authoritarianism and polarization in American politics. New York, NY: Cambridge University Press.

Huntington SP (1996) The clash of civilizations and the remaking of world order. New York, NY: Simon and Schuster.

Jowitt K (1992) New world disorder: the Leninist extinction. Berkeley, CA: University of California Press.

Kim C (2018) Involvement in ethnic organizations and community activism among Asian immigrants in the United States. Journal of International Migration and Integration 19(2): 315-338.

King DS, Smith RM (2005) Racial orders in American political development. American Political Science Review 99(1): 75-92.

Kopstein J (2003) Postcommunist democracy: legacies and outcomes. Comparative Politics 35(2): 231-50.

Levitsky S, Ziblatt D (2018) How democracies die. New York, NY: Crown.

Li W, Lo L (2012) New geographies of migration? A Canada-U.S. comparison of highly skilled Chinese and Indian migration. Journal of Asian American Studies 15(1): 134.

Lieberthal K (1995) Governing China: from revolution through reform. $1^{\text {st }}$ Edition. New York, NY: W.W. Norton.

Lien P-t (2001) The making of Asian America through political participation. Philadelphia, PA: Temple University Press.

Lipset SM (1959) Political man: the social bases of politics. New York, NY: Doubleday.

Liu B, Stickney ZJ, Batt NL (2020) Authoritarianism for and against Trump. Journal of Behavioral and Social Sciences 7(3): 218-238.

MacWilliams M (2016) Who decides when the party doesn't? Authoritarian voters and the rise of Donald Trump. PS: Political Science \& Politics 49(4): 716-721.

Müller J-W (2016) Protecting popular self-government from the people? New normative perspectives on militant democracy. Annual Review of Political Science 19(1): 249265.

Noel DL, Pinkney A (1964) Correlates of prejudice: some racial differences and similarities. American Journal of Sociology 69(6): 609-622.

Park RE, Burgess EW (1921) Introduction to the science of sociology. Chicago, IL: University of Chicago Press.

Perry EJ (2012) Anyuan: mining China's revolutionary tradition. Berkeley, CA: University of California Press.

Pettigrew TF (2016) In Pursuit of Three Theories: Authoritarianism, relative deprivation, and intergroup contact. Annual Review of Psychology 67(1): 1-21.

Pop-Eleches G, Tucker JA (2017) Communism's shadow: historical legacies and contemporary political attitudes. Princeton, NJ: Princeton University Press.

Pye LW (1992) The spirit of Chinese politics. New Edition. Cambridge, MA: Harvard University Press.

Samson F (2014) Segmented political assimilation: perceptions of racialized opportunities and Latino immigrants' partisan identification. Ethnic and Racial Studies 37(3): 467495.

Stenner K (2005) The authoritarian dynamic. Cambridge: Cambridge University Press. 
Sun L-K (2002) The Chinese national character: from nationhood to individuality. Armonk, NY: M.E. Sharpe.

Tang W (2016) Populist authoritarianism: Chinese political culture and regime sustainability. New York, NY: Oxford University Press.

United Nations (2017) Trends in international migrant stock: the 2017 revision. Department of Economic and Social Affairs, Population Division, United Nations Database.

Varela RE, Vernberg EM, Sanchez-Sosa JJ, Riveros A, Mitchell M, Mashunkashey J (2004) Parenting style of Mexican, Mexican American, and Caucasian-Non-Hispanic families: social context and cultural influences. Journal of Family Psychology 18(4): 651-657.

Watters JK, Biernacki P (2014) Targeted sampling: options for the study of hidden populations. Social Problems 36(4): 416-430.

Zhang C (2018) WeChatting American politics: misinformation, polarization, and immigrant Chinese media. Tow Center for Digital Journalism. Retrieved from: https://bit.ly/3cjljtn. [Accessed 19 April 2018]

Zhou M (2009) Contemporary Chinese America: immigration, ethnicity, and community transformation. Philadelphia, PA: Temple University Press. 


\section{Appendix}

The 2017-2018 Global Ethnic Chinese WeChat Survey Questionnaire

我最近有一个研究课题, 需要大家帮忙, 回答四个简单问题。

不同的人会在教育上有不同的价值体系和侧重点。根据你的个 人意见，你认为以下四组价值中，是 $a$ 还是 $b ，$ 对教育孩子相对 来说更重要?

1) (a) 拥有主见, 还是 (b) 尊重传统

2) (a) 充满好奇, 还是 (b) 好的教养

3) (a) 服从领导, 还是 (b) 独立自主

4) (a) 体贴他人, 还是 (b) 行为检点

对于第一个问题, 如果你觉得“拥有主见"比"尊重长辈"对教育 孩子更重要, 就请回 $a$; 否则回 $b$; 如果你觉得两个原则一样重 要 (无先后次序), 就请回c

请依次回答全部四个问题。（比如，如果你认为 $b$ 是所有四个 问题的答案, 就回 $b b b b)$ 。

为了不影响他人, 请私下用微信将你的回答传给我。

谢谢你的参与! 



\title{
Greek Gastarbeiter in Germany and European Expatriates from Greece: Diaspora Interactions between Immigrants and Neo-Immigrants
}

\begin{abstract}
By Eleni D. Tseligka
Between 1953 and 1973, emigration depleted the Modern Greek state by roughly one fifth of its total population. A significant number of those migrants relocated to Germany, which since 1960, has been home to a sizeable community of former Gastarbeiter (guest-workers) and their descendants. Following three decades of European Integration and relative prosperity, the 2009 Greek sovereign debt crisis initiated a new wave of Greek emigration, analogous, yet different to that of the postwar era. Germany remains an attractive destination for Greek expatriates, but in contrast to guest-workers from the 1960s, "neo-migrants" are typically skilled or highlyskilled persons who relocate individually. This paper examines the qualitative attributes of Greek expatriates and "neo-migrants" in Germany and compares them to those of former guest-workers; furthermore, this paper compares the narratives of Gastarbeiter to those of European expatriates. Finally, the perceptions of Greek expatriates for the established Greek community in Germany are looked into, as well as the individual and collective efforts of the Greek community and institutions to help and ease their socioeconomic integration.
\end{abstract}

Keywords: Gastarbeiter, neo-migrants, expatriates, Germany, Greece

\section{Introduction}

Germany is home to a sizable Greek community, which consists of former guest-workers from the 1960s and their descendants, but also of European expatriates who emigrated to Germany after Greece's induction to the European Communities and subsequently to the European Union. Guest-worker immigration to Germany was the result of bilateral agreements between the state of origin and the host state, which constituted a strict and inflexible migratory regime. On the other hand, European expatriation is a liberal migratory condition based on the freedom of movement, one of Europe's founding principles. Neo-migrants is a term used colloquially by the Greek press to describe post 2010 crisis-driven emigrants to Germany and other destinations, regardless of the fact that they are not excluded from the privilege of European expatriation. However, in this paper the term is used to distinguish crisis-driven emigrants ${ }^{1}$ from the established Greek Diaspora as well as the Greek European expatriates in a temporal manner but also in terms of motives, relocation patterns and integration opportunities. This paper highlights the differences between the qualitative attributes of Greek expatriates

\footnotetext{
*Professional Development Advisor for Reseach, Aston University, U.K.

${ }^{1}$ The Greek sovereign debt crisis of 2009, which followed the international financial crisis of 2007 and 2008 with the collapse of the Lehman Brothers (Tseligka 2016), resulted in severe austerity measures that brought a dramatic increase of unemployment (Sotiropoulos and Bourikos 2014), as well as the resurgence of Greek emigration.
} 
and neo-migrants compared to those of guest-workers, and also looks at the interaction between the established Diaspora and the newcomers, as it is reflected in the narratives of each group, shaped by the historical context and the individual experience.

\section{Data and Methods}

The narratives analysed in this article come from thirty-one semi-structured interviews, with outstanding individuals such as academics and diplomats and leading figures of the Greek communities in Germany, individuals in pastoral and parental roles, such as elected representatives of migrant associations, clerics and educators. All interviewees were selected due to their significant experience on issues of the Greek Diaspora in Germany. In all cases, it was made certain that each of the interviewees combine as many of the attributes of a good informant as possible. For example, one of the clerics interviewed is a first-generation guestworker and founder of an immigrant association, who later in life obtained education, was ordained a priest and became a writer on subjects of the Diaspora, while another is an academic who originally expatriated in Germany as a student.

All interviews were conducted between December 2012 and May 2013 and an indicative sample of fifteen of those interviews is partly featured in this article. Approximately half of the interviewees of this sample are first or secondgeneration migrants, while the other half are European expatriates. The selection of this sample was carefully chosen to equally represent the narratives of both the established Diaspora and the European expatriates, but also highlight the position of Greek institutions in Germany, such as the diplomatic corps and the Church. Particular details regarding each interviewee might constitute a breach of anonymity and cannot be disclosed.

The sum of interviews were conducted as part of a larger qualitative research project that examines the sociopolitical integration of Greeks in Germany before and after the Maastricht Treaty, based on participant observation and semistructured interviews. The research, titled "From Gastarbeiter to European Expatriates" was conducted under the aegis of Staffordshire University and the bulk of its findings were released as a monograph in 2019, under the same title. It remains the only in-depth study of Greek emigration in Germany and offers insights on the process of European Integration from the sociopolitical perspective of intra-European migration before and after the Maastricht Treaty, highlighting the transformation that migratory and diasporic typologies have undergone between 1960 and 2016 (Tseligka 2019).

The total of interviewees was carefully selected from fourteen locations in Germany, in particular Berlin, Bielefeld, Bonn, Cologne, Darmstadt, Dortmund, Düsseldorf, Erfurt, Jena, Munich, Rüsselsheim, Siegen, Stuttgart and Weimar. The selection of places was not random, as locations were chosen for the size of their communities and their importance in the history of Greek migration and establishment in Germany. 


\section{Gastarbeiter (Guest-Workers)}

The end of the Second World War found Greece in ruins, with most of its infrastructure destroyed and more than half a million dead. The four years of Nazi occupation left one quarter of all villages laid to waste and a great proportion of the rural population internally displaced, seeking refuge in the cities, yet failing to integrate, thus remaining unemployed, horribly poor and with little hope of future improvements (Shrader 1999). The general malnutrition of the population, paired with a shortage of medical supplies and inadequate sanitation conditions, resulted in the resurgence of tuberculosis and malaria. Aid provided by the Allies, the United Nations Relief, the Rehabilitation Administration (UNRRA) and overseas Greeks in 1945 was just enough to prevent famine. The needs of the population for food were so dire that despite the 100 million US dollars in food donated during that year, the optimal daily ration of two thousand calories per person was not possible (Shrader 1999). The end of the Second World War however, did not signify the end of bloodshed for Greece, but the beginning of a four-year civil war, which claimed the lives of an additional 158,000 people and caused further destruction of public and private property; the outcome of that war solidified Greece's position in the Western Bloc during the Cold War era (Koliopoulos and Veremis 2009). Between 1947 and 1952 the Bank of Greece came under American supervision, which maintained the stability of the drachma ${ }^{2}$, but led to gold coin hoarding since people did not trust banks with their savings. Despite its downsides, being a member of the Western Bloc and NATO as of 1951, secured much needed funds for Greece that was included in the Truman Doctrine, which established an era of US involvement in European politics (Koliopoulos and Veremis 2009).

Germany's state after the end of the Second World War can only be described as a big pile of rubble. Most major cities, but also many towns and villages, had been heavily bombed during the final stages of the war and most of the country's infrastructure was reduced to ash and debris. Significant cultural monuments, some dating back to the Roman Empire, were pulverised and had to be bulldozed away with the rest of the rubble. The general situation was so bad that the American Headquarters had to be placed in the spa town of Wiesbaden, which had been spared from bombing due to bad weather. The civilian death toll was dreadful, and fear of the Red Army pushed the survivors of the eastern provinces to the west, in the hope that the Western Allies would be more merciful than the Soviets (MacDonogh 2009). The first government of West Germany was formed in 1949 by Konrad Adenauer and introduced the country's economy to the free price mechanism, leading to price reductions and increase of productivity (Van Hook 2004). During the 1950s, while Greece's economy was almost entirely dependent on loans and foreign aid, the economic growth rates of Germany became so impressive that it was considered an economic miracle, or as the Germans called it, Wirtschaftswunder (Braun 1990).

By the 1960s Germany was already regarded as one of the world's rich counties, yet growth slowed down mainly because of a drop in the flexibility of the

\footnotetext{
${ }^{2}$ The modern drachma was first released in circulation in 1832 (Koliopoulos and Veremis 2009) and remained Greece's national currency until it was replaced by the Euro in 2002.
} 
labour supply. Since 1949 Germany stood divided in two separate states. The regime in East Germany had made emigration to the West a very dangerous affair, so the flow of workers from East Germany to West Germany had dramatically decreased, and in August 1961, with the building of the Berlin Wall, it stopped altogether. In order to solve the problem of a growing labour deficiency the West German government signed bilateral agreements which allowed foreign individuals to enter the labour force of Germany. A new term was created in the German language to describe the newly arrived workers from the South, Gastarbeiter, guest-workers (Braun 1990). The term described the legal status of immigrants, with few rights and a temporary position in the German society (Tseligka 2019).

Greece was among the first counties to sign such an agreement, on the $30^{\text {th }}$ of March 1960, following Italy and Spain (Meyers 2004). During the 1960s technological breakthroughs in ballistic missiles had significantly lessened the geostrategic importance of Greece. The improved military defence of the state also hindered the possibility of an invasion from its communist Balkan neighbours. That new order of things decreased Greece's importance to the USA and with it the financial aid the country was receiving from its North Atlantic partners (Koliopoulos and Veremis 2009). It was during that time when Greece became interested in the prospect of European integration, which led to its accession to the Council of Europe.

The 1960 bilateral agreement with Germany was advertised as a solution to individual poverty, encouraging people to migrate. The sudden industrialisation of the economy, followed by the urbanisation of the population, both of which began right after the War, resulted in unprecedented unemployment. It is however difficult to put the problem in numbers, as statistics from that era are generally considered unreliable (Charalambis et al. 2004), due to methodological fallacies and the systematic efforts of the Greek government to conceal the poor state of the Greek economy. After the agreement was signed, Germany created a very efficient system to link employers to foreign employees. First, the employers had to apply to their local employment office, declaring how many workers were needed and the skills those individuals should have. Then the employment office would search for workers that were already registered with them in the country, and if they could not find any, they would contact German officials in one of the countries which had agreed to dispatch workers. Until 1973 the recruitment of foreign workers bore no restrictions, except for the 1967-1968 period, marked by a recession during which the German government refused to extend work permits (Meyers 2004).

The German Committee in Greece maintained two recruitment offices, the first in Athens, at Viktoros Ougko Street, near Omonoia Square, and the second in Thessaloniki at Dodekanisou Street (Rimpa 2010). The guest-workers played an important role in the development of the German economy from the 1960s onwards. Their presence created an economic order and policy which was growth oriented and some of them introduced new, improved skills and work ethics into the job market. Of course, the immigrants were not the only factor which took the "German miracle" to the next level (Braun 1990). Technological advances and scientific innovations like nuclear power, or the transistor and later on the 
microchip, which brought forth a new generation of computers, along with the participation of the German state in the Organization for European Economic Cooperation and the European Payments Union, allowed the country to create a highly competitive economy, rebuild itself and leave its Second World War past behind (Braun 1990). The Europeanisation of Germany was seen as a crucial element in the reconstruction of the German state after the disaster of the Second World War. Thomas Mann's dictum of a preferred European Germany instead of a German Europe was taken literally by Chancellor Konrad Adenauer, who since the 1950s initiated the multilateralization of German politics as the best means to overcome Germany's past and solidify its position in the West (Marcussen et al. 2001).

Despite their initial expectations, Greek guest-workers and their families encountered very harsh socioeconomic conditions. The themes of extreme poverty and social exclusion were frequent in the interviews conducted with members of the established Diaspora and often manifested as poor housing conditions for the workers and their families, as attested in the interview segment below, by a second-generation Greek from Cologne.

"I was born in 1966 [...] in the beginning my family's living conditions were difficult. Imagine that during the first year of my life we lived in a modified garage [...] we were raised under difficult circumstances" (T.V. Journalist 2012).

In the 1970s German society was already concerned about the social consequences of foreign labour recruitment, as it became apparent that those who they regarded as guest-workers were in fact immigrants, and in their majority they were not interested in repatriation (Chin et al. 2009). Foreign labour recruitment was banned in November 1973, but most of the immigrants did not go back to their country of origin, mostly out of fear that they would not be able to return to Germany if the situation in the home country was not what they expected (Meyers 2004).

A family reunification law and new policies that would assist integration and eliminate social discrimination were introduced in the 1970s by the German government. A new curriculum was introduced to schools, along with ethnically mixed classrooms, to encourage integration and help create a new paradigm regarding the place of guest-workers in the German society, by exposing Germans to a heterogeneous social model on the one hand, and on the other hand teach foreigners German (Chin et al. 2009).

\section{European Expatriates}

The living conditions of those Greeks who decided to stay in Germany would soon begin to improve, as on the $1^{\text {st }}$ of January 1981, Greece became a full member of the European Communities, including the European Economic Community, the predecessor of the 1993 configuration of the European Union. The changes brought forth by that agreement would progressively bring into legislation the free movement of goods and the free movement of persons, services and capital, but also the common customs tariffs between Member States. Further on, that 
agreement introduced Greece to free movement of workers by the 1st of January 1988, the liberalisation of direct investments from $31^{\text {st }}$ of December 1985, and from the 1st of January 1981 the unblocking of funds and the increase of tourist allowance to no less than 400 European Units (European Union Publications Office 1979). Most importantly, it solidified Greece's position in the European family, shedding new, positive light onto the community. Entrepreneurship was greatly helped by the liberalisation of investments in 1985, but even before that the 1981 unblocking of funds, gave the opportunity to Greek nationals to transfer money they previously kept in Greek banks and invest them into the German economy. Quite often those funds were remittances previously sent home, due to feelings of uncertainty brought forth by German immigration laws (Tseligka 2019). I.P. in Düsseldorf, a senior cleric of the Greek Orthodox Church, mentioned that "those who wanted to break free from work in the factories were helped (by the EC legislations), as they made use of the new conditions in creating their own businesses" (I.P. Cleric 2013). The above development also promoted social mobility, as people gave up their old jobs in factories to start their own businesses. As explained by Dr T.F., a second-generation Greek academic from Berlin, that increased social mobility, cleared the air from the negative stereotypes of the past, such as that of the poor Greek Gastarbeiter who is a manual labourer, allowing the Greek community to be seen under new light by the German public, even enhancing the concept of European Identity (Dr T.F. Academic 2013).

Greece's accession to the European Communities and later to the European Union, helped the integration and establishment of the Greek Diaspora in Germany. A first-generation migrant and trade unionist from Munich told us in an interview:

"The European Union gave us a voice, it helped us gain political rights since we could vote in the local elections. That was as important as the free movement of people and it helped tremendously in the establishment of Greeks in Germany" (M. F1. Unionist 2013).

Often quoted as an "invisible minority" (in contrast to the concept of a "visible minority", associated with racial minorities) by German authorities, Greeks had reached the highest level of integration in German society, to the point that their presence was considered an essential element of contemporary Germany (Tseligka 2019). At the same time, the ease of relocation within the European Union became one of the pull factors for a new wave of Greek emigration.

"The European Union was tremendous help! The common European passport, or that fact that you don't even need a passport anymore, or a visa, and you can move freely and just like that! Makes you feel so at ease... I was never stopped by the authorities; I was never asked any questions at customs. In all my encounters with the German state I was treated the same way as German citizens and that sense of equality is very important to me. [...] I compare my experience to that of third country nationals and I can clearly see the benefits of the EU. How can one seek his fortune in Germany when $\mathrm{s} / \mathrm{he}$ is prohibited to cross its borders? I have met several third country nationals and I can see for myself their hardships [...]" (G.F15. Teacher 2013). 
The ease of resettlement and the equal treatment changed the qualitative aspects of Greek migration to Germany. The Gastarbeiter of the 1960s and 1970s were by default unskilled or low skilled workers in dire need for work; they fled extreme poverty and, in some cases, political persecution. The European expatriates however left for Germany from a significantly wealthier Greece, to some extent due to the political and financial benefits of Greece being a Member State.

"It is not extreme poverty any longer that brings people here; Greeks do not migrate anymore for the same reasons they emigrated in the 1900s or in the 1960s. The living standards in Greece have since then improved dramatically. The European Union reduced the distance between the two states; bureaucracy it was decreased, and moving from Greece to Germany was never easier. Human mobility has been facilitated by the Union, but the target group of such policies is not the poor, but rather the educated" (Dr T.K. Teacher 2013).

A generation of European citizens has been raised to take mobility for granted, often experienced life abroad at a young age by joining a European program, such as Erasmus, designed especially to promote intra-European mobility of students and scientists. It is quite common for Greek European expatriates to have had their first migratory experience as students.

"I first came to Germany for six months after joining the Erasmus program and I liked it so much that I decided to study the German language, as a foreign language. After I graduated in 1994 I moved to Germany for postgraduate studies. I met my (German) wife and I stayed here. But I think that I truly wanted to stay here (in Germany), at some point I realised that I never really intended to go back to Greece" (N.TH1. Teacher 2013).

Unlike guest-workers, who in most cases did not speak German, successful neo-migrants possess high language proficiency.

"I was a student the first time I came to Germany and was for a month at the University of Frankfurt, to enhance my knowledge of the German language. Then in 2006, after I graduated from the university in Greece, I enrolled in a postgraduate course at the University of Bielefeld. I was really interested in the experience of living abroad and I thought it would really improve my German language skills [...]. I currently work at the school, but I have not decided yet if I will settle here (in Germany) permanently" (A.E. Teacher 2013).

In addition to language proficiency, many of the neo-migrants are highly educated, often through the receiving state's educational system.

"What originally brought me to Germany was the opportunity to study for a funded doctoral title $(\mathrm{PhD})$ [...] I applied to several universities across Europe, but what attracted me to the one I eventually enrolled in, was that they offered me a serious scholarship in order to conduct my research with them [...]. I really had no reason to decline that offer, it was an honour to be selected, it would enhance my CV and it gave me the opportunity for publications" (Dr D.F. Academic 2013). 
That new educated, middle-class face of Greek emigration to Germany disconnected further the image of Greeks from unskilled guest-workers and additionally contributed to their acceptance and integration in Germany (Tseligka 2019). However, the social status of middle-class neo-migrants contrasts with the working-class background of former guest-workers and their descendants, perceiving them as too traditional and insular.

"They keep themselves to themselves; they are a small, micro-archaic, society [...] Their celebrations are so traditional, wherever they gather it looks like a village square $[\ldots]$ and they all smoke indoors[...]" (G.F1. Teacher 2013).

"They are a closed society, their Greekness comes from the 60s and the 70s, I presume it has to do with their rural background [...] The huge social changes that took place in Greece in the 1980s and onwards have not affected them [...] you can see that even from the way they dress [...] their parties resemble those that can be found in villages..." (N.TH1 Teacher 2013).

\section{Neo-Migrants}

The living conditions in Greece have worsened since the beginning of the economic crisis, particularly due to the rise of unemployment, which reached 27 percent by the end of 2013, as well as the loss of income to salary cuts and the high cost of living (Sotiropoulos and Bourikos 2014). Those circumstances diversified the demographics of neo-migrants in Germany. A.G. is a member of the established Diaspora, born and raised in Germany by Gastarbeiter parents, and actively participates in the charities that provide for neo-migrants.

"Some Greeks think that Germany is the land of opportunity and I think this is wrong. A lot of them (the neo-migrants) go back because they could not find a job. Somebody told them that they can come to Germany to serve at a restaurant or wash dishes and that is mostly the kind of neo-migrants we meet in Dortmund. [...] The majority of neo-migrants who bring their children to our school are without work. Last year several people came, spent the whole year here and in the end they returned to Greece; they did not succeed (to get a job). In Diakonie we organise fundraisings for such cases; us Greeks have now gone to the opposite end (of where they used to be)" (A.G. Teacher 2013).

The lack of secular and organised support system for neo-migrants was highlighted in many of the interviews. "Newcomers first turn to the Church and then perhaps to the Greek community" (Dr T.K. Teacher 2013). Some parishes have set up an informal support system, which introduces neo-migrants to the institutions of the receiving state.

"Yes, they keep coming. We have put together a team, which helps neo-migrants to integrate. We escort them to the German authorities, help them register. We also help them to rent accommodation, and we cooperate with Greek businesses to help them find their first job, if they speak German, or to send them to language school to learn 
German. I prefer to advise them to learn German, so they can integrate better and stand on their own feet instead of depending on the good will of their fellow Greeks" (Dr P.M. Cleric 2013).

However other parishes are overwhelmed by the influx of neo-migrants and acknowledge that they are no longer in a position to help. I.P. is among the few remaining elderly clerics who witnessed Gastarbeiter migration in Germany.

"Unfortunately this period the neo-migrants are one of our biggest problems. First of all, too many are coming; secondly, they do not possess a craft or speak German; and thirdly they are victims of fraudsters from Greece. There are so called agencies that charge between 400 and 800 Euros to find employment for people in Germany [...]. When they arrived at the airport someone from a restaurant was there to pick them up and put them somewhere to sleep [...] a week later they were told that the restaurant does not have a lot of work and it will probably go out of business, therefore they must leave $[\ldots]$ which resulted in those people being made homeless overnight [...]" (I.P. Cleric 2013).

Under the circumstances neo-migrants who had not previously secured work become vulnerable to exploitation and extreme poverty.

"It is not just in Düsseldorf that you see homeless Greeks. A friend of mine was telling me about the same problem in Offenbach-am-Main. They drove to Germany with their cars, Greek licence plates and everything, and now they sleep under the bridges of Main" (G.F12 Teacher).

"Some people believe that they will come to Germany and they will find a job right away; however, that is not the case [...]. Others found themselves victims of exploitation by their fellow Greeks, by those established here. I am not referring to scientists, but those destitute people who are being exploited by their fellow-Greek employers [...]" (Dr T.K. Teacher 2013).

Greece's diplomatic corps in Germany is also overwhelmed by the influx of neo-migrants and turns to the German authorities and the Greek communities for help.

"Back then (in the 1960s) there was a state-orchestrated migratory movement, while present migration is not structured and many of those who attempt to migrate nowadays might not speak the language or have anywhere in particular to go, and often come to the Greek diplomatic authorities in search for shelter. [...] the German institutes as well as the Greek communities provide information through brochures regarding work and accommodation in Germany. The German embassy in Athens offers useful information online as well as hosts relevant events, but also in Germany a system for the reception of Greek migrants has been developed" (A.K. Diplomat 2012).

The system in place, mentioned in the interview segment above refers to the cooperation between the Greek communities and the German institutes, with little if any support from the Greek authorities. 
It is not easy to have a full picture of the new Greek migration to Germany. Greece does not keep records of expatriates, except from those who have transferred their tax base abroad, who are a small minority. Therefore, it relies exclusively on statistical records of the German state and Eurostat. However, European expats need a fixed address in order to register with the German authorities, and that means that homeless Greeks or those residing in temporary accommodation are not being recorded.

"For the past two and a half years, from the beginning of the fiscal crisis in Greece, the migratory flow from our country to Germany has been increased. Particularly, and according to the official statistics being handed to us on a yearly basis from the Federal Statistical Office of Germany (Statistisches Bundesamt, shortly called Destatis), we observe an increase of 78 percent during the first half of 2012 in comparison with the first half of 2011. Equally when comparing the first half of 2011 to that of 2010 we also see an increase of approximately 80 percent. Therefore it is beyond obvious that a very large group of our fellow countrymen from Greece have willingly chosen Germany as their destination towards a better future" (A.K. Diplomat 2012).

"Based on the records given to us by the German authorities, we estimate that since the beginning of the crisis and until now (February 2013) there have been 30,000 new Greek migrants in Germany [...]. We have seen families enrolling their children in Greek schools and after a few months they leave. We are not sure however if they relocate internally in Germany, go back to Greece or go elsewhere in Europe. We also do not know if the parents remain and just send their children back to Greece, to their grandparents, as was done in the 1960s" (Anonymous Diplomat 2013).

In addition to the lack of data from Greek authorities, the free movement of people within the EU allows irregular patterns of return migration, which often complicates data gathering. Short term holidays and family visits for particular reasons, such as a marriage or an emergency, should be considered as an occasional return. A periodic return presents a typology of regular movements, such as visiting for the same holidays each year and staying approximately for the same fixed period of time during every visit. Seasonal returns are usually common for migrants who work for seasonal industries, such as tourism or agriculture, but also teachers and academics. A temporary return entails the will for re-emigration and is motivated by change of circumstances, such as the end of a work contract (King 1978).

The case of Greek migrant workers in Germany offers examples of all the above types of returnees. It is, for example, quite common for people working in education to spend their winter, spring and summer breaks in Greece, demonstrating a typology of periodic return.

"I go to Greece every summer; I spend all of my summers in Greece, Easter too. I don't always visit during Christmas though, I went last year but I don't plan to spend Christmas in Greece this year" (G.F15. Teacher 2013). 
"It has become so easy; it's not expensive any more. Did you know that you can fly with less than twenty Euros if you book early with Ryanair? [...] I visit whenever I'm off work" (N.TH1 Teacher 2013).

"It's my first year in Germany, I've been here since September [...]. I went (to Greece) for Christmas and I've already booked (tickets) for Easter [...]. I'm looking forward to it" (M.F1. Teacher 2013).

Equally, it is common for retired industrial workers to spend six months of the year in Germany, usually during autumn and winter, and return for the remaining six months in Greece.

"My father first came with a five-year contract. He did not speak the language at all, so he was among those who were stuck in the factories [...]. (After his retirement) he returned to Greece, but he could not stay there permanently [...]. He continues to be a permanent resident of Germany [...], he spends six months of the year in Greece and then he comes back (to Germany)" (A.G. Teacher 2013).

"The first-generation ones, you won't find them here (in Germany) at this time of the year (spring); those who are still holding up, have left for Greece already [...]. I call them the "six-month-ers" because they spend six months in each of the two countries" (I.P. Cleric 2013).

\section{Conclusions}

Greece has a long history of dependence on foreign aid and loans, even for financing its most rudimentary requirements for food and medicine. Acting like a protectorate state, it had to surrender part of its sovereignty to whichever state or bloc of states would fund its needs and safeguard its existence. The economic disparity between Greece and Germany in the 1960s led to a bilateral agreement that allowed Greek workers to find employment in Germany, which resulted to the establishment of a Greek Diaspora in the country. Greece's accession to the European Communities and later in the European Union provided the necessary resources for Greece's development and at the same time guaranteed the free movement of people. European expatriation emerged as a new paradigm of migration and changed the qualitative attributes of Greek migrants in Germany. In contrast to guest-workers from the 1960s, European expatriates were mostly middle class and educated individuals.

Roughly fifty years since the bilateral agreement for Gastarbeiter employment was signed, Greece and Germany are once again at the opposite sides of the economic spectrum. Soaring unemployment, a result of Greece's sovereign debt crisis, has made emigration once again attractive to the general population, including low skilled workers without language proficiency. The migratory regime of European expatriation has made relocation between European Member States easy for individuals, but the changed socioeconomic environment has become inhospitable and perilous for low skilled workers. In the absence of state institutions to support the neo-migrants, the established Diaspora is gathering its 
Vol. 9, No. $1 \quad$ Tseligka: Greek Gastarbeiter in Germany and European Expatriates...

own resources to facilitate the integration of newcomers. The Greek-Orthodox Metropolis, along with Greek migrant associations and Christian charities of the Evangelical Church, provide a safety net from impoverishment and homelessness.

\section{References}

Braun H-J (1990) German economy in the twentieth century. London: Routledge.

Charalambis D, Maratou-Alipranti L, Hadjiyanni A (2004) Recent social trends in Greece, 1960-2000. Montreal: McGill-Queen's University Press.

Chin R, Fehrenbach H, Eley G (2009) After the Nazi racial state: difference and democracy in Germany and Europe. Ann Arbor: University of Michigan Press.

European Union Publications Office (1979) Documents concerning the accession of the Hellenic Republic to the European communities. Official Journal of the European Communities 22(11): L 291.

King R (1978) Return migration: a neglected aspect of population geography. The Royal Geographical Society 10(3): 175-182.

Koliopoulos JS, Veremis TM (2009) Modern Greece: a history since 1821. Hoboken: Wiley-Blackwell.

MacDonogh G (2009) After the Reich: the brutal history of the allied occupation. New York: Basic Books.

Marcussen M, Risse T, Engelmann-Martin D, Knopf HJ, Roscher K (2001) Constructing Europe? The evolution of nation-state identities. In T Christiansen, J Knud, E Wiener Antje (eds.), Social Construction of Europe, 101-120. London: SAGE Publications Ltd.

Meyers E (2004) International immigration policy: theoretical and comparative analysis. Gordonsville: Palgrave Macmillan.

Rimpa D (2010) Gastarbeiter or else guest-worker, a part. Elliniki Diaspora 121(Jul-Aug): 3-5.

Shrader CR (1999) Withered vine: logistics \& the communist insurgency in Greece, 19451949. Westport: Greenwood Press.

Sotiropoulos DA, Bourikos D (2014) Economic crisis, social solidarity and the voluntary sector in Greece. Journal of Power, Politics \& Governance 2(2): 33-53.

Tseligka E (2016) Becoming the other - stereotyping of Greeks by the German press. Continuum 30(6): 627-635.

Tseligka E (2019) From "Gastarbeiter" to European expatriates. Bern, CH: Peter Lang.

Van Hook JC (2004) Rebuilding Germany: the creation of the social market economy, 1945-1957. West Nyack: Cambridge University Press.

\section{Interviews Conducted by the Author}

A.E. Teacher (2013) Interview with L.L. Teacher on $24^{\text {th }}$ April 2013. Bielefeld. [Recording in possession of author]

A.G. Teacher (2013) Interview with A.G. on $22^{\text {nd }}$ April 2013. Dortmund. [Recording in possession of author]

A.K. Diplomat (2012) Interview with A.K. on $20^{\text {th }}$ December 2012. Berlin. [Recording in possession of author]

Anonymous Diplomat (2013) Interview with Anonymous Diplomat on $21^{\text {st }}$ February 2013. Stuttgart. [Notes in possession of author] 
Dr D.F. Academic (2013) Interview with Dr D.F. Academic on $1^{\text {st }}$ May 2013. Erfurt. [Recording in possession of author]

Dr P.M. Cleric (2013) Interview with Archimandrite Dr P.M. Cleric on 22 ${ }^{\text {nd }}$ April 2013. Dortmund. [Recording in possession of author]

Dr T.F. Academic (2013) Interview with Dr T.F. Academic on $28^{\text {th }}$ January 2013. Berlin. [Recording in possession of author]

Dr T.K. Teacher 2013 Interview with Dr T.K. Teacher on 29 ${ }^{\text {th }}$ April 2013. Munich. [Recording in possession of author]

G. F1. Teacher (2013) Interview with G.F1. Teacher on 24 ${ }^{\text {th }}$ April 2013. Bielefeld. [Recording in possession of author]

G.F12. Teacher (2013) Interview with G.F12. Teacher on $22^{\text {nd }}$ April 2013. Dortmund. [Recording in possession of author]

G.F15. Teacher (2013) Interview with G.F15. Teacher on 22 ${ }^{\text {nd }}$ April 2013. Dortmund. [Recording in possession of author]

I.P. Cleric (2013) Interview with Father I.P. Cleric on $16^{\text {th }}$ April 2013. Düsseldorf. [Recording in possession of author]

M.F1. Teacher (2013) Interview with M.F1. Teacher on 29 th April 2013. Munich. [Recording in possession of author]

N. TH1. Teacher (2013) Interview with N.TH1. Teacher on 24 $4^{\text {th }}$ April 2013. Bielefeld. [Recording in possession of author]

T.V. Journalist (2012) Interview with T.V. Journalist on $15^{\text {th }}$ December 2012. Cologne. [Recording in possession of author] 



\title{
Rethinking the Origins and Purpose of Religion: Jesus, Constantine, and the Containment of Global Revolution
}

\author{
By Mike Sosteric
}

\begin{abstract}
For sociologists, Jesus Christ and the associated Catholic Church are generally seen are regressive, conservative, and authoritarian. For this reason, Sociologists avoid reading the Bible as a textual research source. Overcoming sociological resistance, however and examining the Christian New Testament reveals a story much different than expected. While the Church may certainly be conservative, regressive, authoritarian, even predatorial, Jesus Christ and his apostles were not. Exegesis of Christian gospels reveals not a gentle shepherd of sheeple, but a revolutionary Christ that is neither conservative, gentle, nor passive - an impassioned and committed revolutionary set on progressive social change and fundamental revision of elite power structures.
\end{abstract}

Keywords: Religion, Christianity, Jesus Christ, Critical theory, Narrative analysis.

"It is time to put an end to the distorted picture of the Bible as a pious church-andfamily book that teaches submissive obedience, other-worldliness, mortification of the flesh, and indifference to social betterment. To wrest the most powerful tool of progress from the forces of reaction is simply a matter of decency and honesty. This most revolutionary of all documents must no longer be used for the purposes of social oppression. It is time to take the document which set the pattern for all later revolutions back."

Eric Gutkind - The Biblical Call to Revolt

\section{Rethinking the Origins and Purpose of Religion}

I was born a Catholic, dutifully went to Church every Sunday, and even spent time as an altar boy. However, I rejected the faith at an early age, twice in fact. I rejected it once when I was eight or ten, and once again when I entered university. The first time I rejected it was because I couldn't abide the mean-spirited hypocrisy of the people (parents, my teachers in Catholic school, neighbours) who professed a Christian faith but then were violent and mean to others. I didn't reject all human spirituality at that point, however. Driven by a powerful need to know (Sosteric and Ratkovic 2018), and presuming that ultimately there must be something to see, I spent my adolescent years fishing about in the New Age bookstore that had popped up in my hometown in the early 1980s, but without much spiritual satisfaction. None of it made any sense to me. I kept hope alive, but years later, while doing a Sociology degree, I read the famous words of Karl Marx who said: "religion is the opiate of the masses" (Marx 1978). I scanned back at my childhood experience of religion, my meandering dissatisfaction with New Age teachings, all the things I had learned in sociology, and a couple of those Python movies, and I

*Associate Professor, Athabasca University, Canada. 
had to agree. Religion was a collective human delusion. It was elite machination designed to control the population of the planet period (Berger 1969) Further examination would be a waste of my time, I felt, and so I rejected it again, this time permanently.

Since that time, as a sociologist, I have not felt comfortable talking about spirituality, especially when in the company of other sociologists, because sociologists generally dismiss religion and human spirituality as a topic "dripping with reactionary supernaturalism" and "beyond the pale at self-respecting faculty parties" (Berger 1999: 4). Individual paths of rejection may be different than mine, but most (if not all), eventually reject it. Some sociologists do look at human spirituality, but it is always with an institutional focus. Those that look, look at religious institutions, but leave out any consideration of spiritual experience (Sosteric 2017). They talk about churches, sects, and sometimes cults (Wallis 1976), and are generally very critical about them. They (we) see the manipulative aspects of organized religion (Berger 1969). We see it is an opiated delusion (Marx 1978), and an ideological tool of the elites (Weber 1904). The kinder amongst us give religion some credit for providing social solidarity and community (Durkheim 1965). However, beyond this institutional focus, we do not go. We don't take human spirituality, and in particular spiritual experience, seriously. In fact, we pretty much ignore. If we are being honest, we expect all aspects of "reactionary supernaturalism" spirituality to eventually die in a modernizing, secularist, rush (Bruce 2002, Chaves 1994).

Given this rejection of religion and spiritual experience, it should come as no surprise that sociologists don't spend much time reading the Bible, even though they do examine the Church, and even though it is the textual source of one of the world's biggest religions. Why should they? If religion is "reactionary supernaturalism," then the Bible is the source of all that, at least for Christianity. The assumption of most sociologists, I think it is fair to say, is that the Bible is chock full of elite lies and collective self-deception. Within the sociological community, the Bible has the status of a vomitous soaked rag. We keep it as far away from us as possible.

This rejection seems to be written into the DNA of the discipline. Auguste Comte (1798 - 1857), one of the heavyweight fathers of sociology, said societies passed through three stages, a theological stage where humans rely on supernatural explanations, a metaphysical stage where humans replace superstitions with abstract forces governing human behaviour, and a final positive stage where humans replaced their superstitions with logical, positive thought. For Comte, and for many sociologists, these stages represent an evolution from a dark and primitive past to a future of bright scientific light-filled rationality. The message is clear: as we evolve, religion dies away. Sociologists even formalized their expectations into secularization theory (Berger 1968, Dobbelaere 2002, Bruce 2002, Chaves 1994). Secularization theory states clearly the sociological prediction that religion and human spirituality will eventually be replaced by secular, rational, "positive" thought.

For a long time, I bought the party line. I didn't have any interest in religion at all, I didn't consider "spiritual experience" to be anything more than individual or 
collective self-delusion, and like Saul on the road to Damascus, I wasn't shy about my disgust and disdain for it. Of course, I wouldn't touch the Bible with a ten-foot disinfectant pole. I hadn't read the bible when I was a child because the priests always fed it to me in little spoonfuls, and I certainly wasn't going to read it after Marx. Then one day after having experienced "mystical" experiences (I call these connection experiences) (Sosteric 2018a) powerful enough to cause me to call into question my Marxist atheism, I reversed my antagonistic position and became quite interested in human spirituality and spiritual experience (Sosteric 2014, 2018b, 2019b, 2018c, 2018d), not as some stupid human delusion likely to die away, but as a core and important aspect of human experience. In all that effort and research, however, I stilled stayed far away from the Christian Bible, believing that even though there might be something in human spirituality, there was certainly nothing in the Bible itself.

I changed my tune on the Bible, quite dramatically, however, after discovering a fellow by the name of Bartolome de las Casas. Las Casas was a brutal Spanish colonizer who literally burned slaves alive to promote the colonial agenda. However, after reading a passage from the Christian Bible during a Sunday service, like a logic switch, he flipped. One day he was burning and mutilating the natives of Hispaniola and the next he had taken a sudden "turn to the left" and was campaigning to end exploitation (Sosteric 2018c). It was a remarkable transformation, yet it took a while for me to process the full significance of Las Casas's "conversion" (i.e. turn to the left), and the fact that it happened after he read the Bible. As I did process the significance of that, a question formed. What was it about the Bible that had caused his dramatic shift? After an unproductive search for previous research that might provide for me a focused view (notice I was still avoiding the Bible), I eventually decided to pick it up and actually read it for myself. I skipped the Old Testament and started with the four gospels, Mathew, Mark, Luke, and John. These gospels, written sometime in the first century after Christ's death, ostensibly contain the last few years of this famous messiah's life.

So, what did I find when I picked up the bible? ${ }^{1}$ I can tell you, it was exactly the opposite of what I had expected. As a recovering Catholic who had rejected Christianity as hypocrisy and self-delusion, as a sociologist who had absorbed the revelatory reasoning of Karl Marx, even as someone who had had a few connection experiences, I expected to find nothing but drivel. As a child raised in a Catholic family and indoctrinated by our Church's priestly pulpit pundits, I expected to find a gentle Shepard tending to a passive flock. As a Sociologist who'd read Marx, Weber, and Berger, I expected to find elite ideology and mind control. As a budding mystic, i.e. as someone who induces Connection with the

\footnotetext{
${ }^{1}$ There are many versions of the Christian Bible in existence. The Bible Gateway website (https://www.biblegateway.com) lists 60 English versions. Not all of these represent significant textual forks, but some do. Given the soteriological cornucopia a question must arise, which bible did I choose for this exegesis? I chose the New International Version by the International Bible Society, a "completely original translation of the Bible developed by more than one hundred scholars working from the best available Hebrew, Aramaic, and Greek texts" ("New International Version (NIV) - Version Information - BibleGateway.Com" 2019). The methodology used to translate the original texts was impressive. For more see the Biblica website at https://www.biblica. com/niv-bible/.
} 
express purpose of exploring, understanding, and writing about spiritual things, I wasn't expecting anything but empty words. What I found was much different than that.

Upon exegesis, I learned that Jesus was a grassroots kind of guy. He was modest and egalitarian (John 15: 12-15). He hung out with the lowest of the low, i.e. adulterers, prostitutes, sinners (Mark 2: 15), and tax collectors (Mathew: 9: 1012). He showed respect to society's detritus by humbly washing their feet (John 13: 4-8), said we should love each other (Mathew 22: 34-40), and otherwise treated most of the men and women around him as equals and with respect. Interestingly, he had much more respect for women than the typical citizen of his day. He treated them as his equals (John 4: 27) and even suggested that women should not be treated as property. In one bible scene, Sadducees (local priestly elites) asked Jesus which of seven brothers a woman, who had been married to them all, ${ }^{2}$ would "belong" to "in heaven" after they were all dead. In a remarkably progressive pronouncement, Jesus intimates marriage was a property thing and suggests that in fact, you shouldn't treat anybody like property. "You are in error because... at the resurrection people will neither marry nor be given in marriage" (Mathew 22: 2330)

When I read the above bible story, I was quite surprised. As a child, the priest drilled into me the sacrosanct and sacred nature of marriage and the patriarchal nature of power. The man was the king of his home throne, they would say. Because of the things they'd taught me about God, the Church, Adam, and after Sociology opened my eyes to the true nature of religion, I had always assumed that patriarchy was a bible thing; but then I read the Bible and found Jesus saying we shouldn't treat each other, and in particular women, as property. I wasn't expecting that at all, and I didn't expect what came next. To make a longer story short, the New Testament, and in particular the Gospels and the Acts, painted a picture of Jesus, and the Christian $\mathrm{Way}^{3}$ as an anti-elite, anti-authoritarian, progressive political revolutionary who was impatient with people's ignorance and who got himself in serious trouble with the ruling class of his day because he a) had no respect for their authority, b) was undermining their power and privilege, and c) was threatening a socialist revolution.

Consider, he ignored the rules and authority of the ruling class by repeatedly working (Mathew 12: 1-2) and healing (Mathew 12: 9-12) on the Sabbath, even after being repeatedly instructed not to do so (John 5: 16-17).

He aggressively and violently kicked people out of the sacred spaces (i.e. temples) for what he considered blasphemous commercial activity (John 2:13-17).

When the elites and higher-level authority figures questioned him about his activities, he told them they had no authority over him (John 5: 16-27).

He made fun of the rich and powerful, calling into question their inability to connect, and comparing them, derisively, to fat camels trying to get through tiny needles (Mark 10: 25).

\footnotetext{
${ }^{2}$ Take a moment to wrap your head around that for a moment. Married to all seven brothers?! This woman was family property, not an independent human being.

${ }^{3}$ Jesus's teachings are referred, subsequent to his assassination, as "The Way" several times in the Bible. See Acts 9: 1-3; Acts 19:9, Acts 24: 14.
} 
He called the "priests and lawmakers" hypocrites to their faces (Mathew 23: 1-7), made them look like idiot fools (John 8:1-11), said "tax collectors and... prostitutes" were better (Mathew 21: 28-31), accused them of being blind and filled with sin (John 9: 38-41), ${ }^{4}$ and generally (and very publicly) brought out their guilt and their shame. In one particularly interesting scene, the "Pharisees and teachers of the law" ask Jesus why he and his disciples were "breaking the tradition of the elders" by not washing their hands before they eat (Mathew 15: 1-2). ${ }^{5}$ Annoyed by this question, perhaps because he was tired of hearing from them and just wanted to sit peacefully and eat, Jesus looks up and snaps back.

"Why do you break the command of God for the sake of your tradition," he says.

"You hypocrites!' he exclaims.

"Isaiah was right," Jesus says with disgust.

"These people," he says, sneering at and referring to the priests, "honour me with their lips, but their hearts are far from me."

"They worship in vain; their teachings are merely human rules" (Mathew 15: 8-9).

"Listen and understand," Jesus says, "What goes into someone's mouth does not defile them, but what comes out of their mouth, that is what defiles them" (Mathew 15: 10-13).

These people, he says, these Pharisees and lawmakers, these pretenders to spiritual connection, are hypocrites.

"Be careful" (Mathew 16: 6) of them, he says elsewhere. "Be on Guard against ... [their]... teaching[s]" (Mathew 16: 6)." "They are liars and fools who don't deserve entrance into the Kingdom (Mathew 22: 1-10).

As a sociologist, recovering Catholic, and mystic, reading the above story was definitely a WTF moment for me. When I picked up the Bible, I had expected to find a passive shepherd of sheeple. As it turns out, however, Jesus was no patient sheepherder. He was nice to the common people, especially the downtrodden, but not fond of the elites at all. He could even, much to my surprise, be impatient with his friends and followers. When Peter, his disciple, asks him to explain something he did not understand, he snaps back at him and wonders out loud, "Are you still so dull?" (Mathew 15: 16-20). Jesus displayed similar impatience with ignorance when he tried to teach Nicodemus, who was a member of the Israeli elite, a Pharisee, and "teacher of the people." At one point, Nicodemus expresses confusion about what Jesus was saying, to which Jesus expresses surprise that this man, who claims to be a teacher of the people, could not understand even some basic spiritual truths. "You," scoffs Jesus, "are Israel's teacher... and [yet you do not] understand these things?" (John 3: 8-10). If you can believe the accounts in the Bible, Jesus even killed a tree just because it didn't have any fruit for him when he walked by it one early morning (Matthew 21:18-20)

And it wasn't just that Jesus was an impatient anti-authoritarian who did not think twice about thumbing his nose at the local authorities. If this was all, we

\footnotetext{
${ }^{4}$ Mathew 21 through 22, is one parable after another (the Parable of the Two Sons, the Parable of the Tenants, and the Parable of the Wedding Banquet) slamming and shaming the elite.

${ }^{5} \mathrm{We}$ will ignore, because it is irrelevant, what this says about the hygiene of Jesus and his apostles and instead focus on their anti-authoritarian response.
} 
could call Jesus a punk and leave it at that. However, Jesus was, in fact, an actual dyed in the wool revolutionary. In his own words, or as close to his own words as we have left, he had come to set the prisoners and the oppressed free, and had come to bring "good news" to poor. The "good news" was presumably the end of their poverty and oppression, for what could be better news than that to a poor person? In John 4, Jesus quotes from Isaiah when he says...

The Spirit of the Lord is on me, because he has anointed me to proclaim good news to the poor. He has sent me to proclaim freedom for the prisoners and recovery of sight for the blind[folded], to set the oppressed free.... Luke 4: 18.

In the above passage, Jesus clearly presents himself as a revolutionary leader working for the spiritual, political, and economic emancipation of the people. These were no idle claims. Despite his annoyed dismissals of the danger, Jesus knew exactly what he was doing and that his revolutionary activity put him in danger. From early on, he kept boundaries and didn't entrust his safety to those he did not trust (John 2: 23-25). He revealed himself only to his closest and most trusted friends, and told them explicitly "not to tell anyone who he was" (Mathew 16: 20). He was wary about the amount of attention he was drawing, and when he started to draw too much, he left an area (John 4: 1-3) so things could quiet down. It was even necessary for him to go into hiding at certain points (John 11: 54). Even his apostles knew there was a danger, warning Jesus that it was dangerous to offend the elites (Mathew 15: 12).

And there was danger. According to the Bible, Jesus was a populist revolutionary who was so charismatic and effective that despite his initial attempts to fly under the radar, he become popular nevertheless. Jesus was making believers fast, even outside his own Jewish grouping (John 4: 39-41). "News about him spread quickly over the whole region of Galilee (Mark 1: 28). The people travelled for miles to see him (Mark 1: 45). He was followed everywhere he went (Mark 3: 7-8). "They gathered in such large numbers that there was no room left, not even outside the door, and he preached the word to them" (Mark 2: 1-2). They were "amazed" (Mathew 22: 22) and "astonished" (Mathew 22: 33). Curiously, he was even converting Roman centurions (Mathew 8: 5-13) and members of the ruling elite, though they were often too attached to their power and privilege to publicly show their support (John 12: 42-43). He became so popular that, at a certain point, he "could no longer enter a town openly but stayed outside in lonely places." (Mark 1: 45).

Near his end, the people, and the elites, recognized him as a revolutionary leader. At a certain point he returns to Jerusalem and when he does, the people throw down the ancient Mediterranean version of a red carpet, branches and leaves cut from trees, (Mathew 21: 8) and declare him their king and saviour (John 12: 12-15; Mathew 21: 1-11) while their children sing "Hosanna" (Mathew 21: 15). Jesus, in a symbolic act that undermines hierarchy, power, and privilege, and befitting the populist proletarian revolutionary that he was, takes it all in while riding a donkey (John, 12: 14). And lest there be any doubt that Jesus is a revolutionary, consider that when he enters the town he goes straight to the temple and, enraged by the sacrilegious commercial activity, overturns "the tables of the 
money changers and the benches of those selling doves," calls everybody within a thief (Mathew 21: 12-13), and drives out the buyers and the sellers! Then, once he has control of the temple, he infuriates the local elites by healing and teaching freely with neither authority nor accreditation (Mathew 21: 14-17).

Not surprisingly, all this revolutionary activity pisses off the Powers that Be and the next day "the chief priests and the elders of the people" (Mathew 21:23) storm into the temple and demand Jesus explain himself (Mathew 21: 23). Jesus asks them a simple question (Mathew 21: 24-27) and then dismisses them as ignorant when they cannot come up with an answer (Mathew 21:27).

And it doesn't stop at the temple. In the days that follow he calls the elites blind liars, deceivers, and vipers (Mathew 23: 33-34). He says they are shallow hypocrites, pretty on the outside but diseased and rotten within (Mathew 23: 2326). He accuses them of pompous and self-aggrandizing displays (Mathew 23: 57), says they do not practice what they preach (Mathew 23: 2), says that they prevent people from connecting (Mathew 23: 13), and accuses them of never being connected for themselves (Mathew 23: 13). He even calls them anti-Christ (consciousness) by saying they undermine people's spirituality, and twist and corrupt what they touch (Mathew 23: 15).

Astonishing.

Here is Jesus, a mere carpenter from working-class Nazareth (Mark 1: 9), totally ignoring rules, laws, and convention, spitting in the face of elite authority, and being recognized by the common folk as Messiah and king. As you can imagine, this did not sit with well the ruling class of his day. Jesus was poking the belly of the Beast, so to speak, undermining them in front of the masses, and they did not like that one bit. Jesus was, in fact, a clear threat to their power and the status quo (John 12: 19), and they did not take the threat lying down. They wanted to have him arrested, but couldn't because they were "afraid of the crowd" (Mathew 21: 45-46) whom they knew would defend him. Even when the elites got over their fear and tried to have him arrested, they had trouble. Not only did they risk a riot if they tried to take him (Mathew 26: 3-5), but they lost their guards to the movement. When the "chief priests and the Pharisees sent temple guards to arrest him," (John 7: 32), the guards came back converted, or at least sympathetic (John 7: 45-46), and they refused to bring him in. Flabbergasted at the fact that their own police would not follow orders, they cry out, "You mean he has deceived you also?" (John 7: 47).

Of course, just because they couldn't have him arrested did not mean they stopped trying to deal with him. They tried to undermine him at every turn. They tried to entrap him, for example, by getting him to admit to tax evasion (Mathew 22: 15-22), or to illegally healing on the Sabbath (Mathew 12: 9-10)). They painted him as a sinner and a demon and called him Beelzebub behind his back (Mathew 12: 24). They accused him of "being his own witness" (i.e. bragging about his qualification) (John 8: 12-14), questioned his youth and inexperience (John 8: 57), shamed him for coming from the 'hood that was Galilee (John 7: 52), tried to get people to rat him out, excommunicated those who acknowledged him as Messiah (John 9: 22), and generally got themselves so riled up that they were at times ready to stone him on the spot (John 8: 59). 
In one particularly electrifying incident, the elites tried to entrap him by bringing an adulterous woman to Jesus whom, according to the laws of the land, should be brutally stoned to death. Testing Jesus to see if he'd follow the law they said, "Teacher, this woman was caught in the act of adultery. In the Law Moses commanded us to stone such women. Now what do you say?" Brilliantly, disrespectfully, and with insolent disregard, Jesus put his head down, drew circles in the dirt, and actively ignored them. Refusing to be put off, the elites keep badgering him. Finally, perhaps knowing they wouldn't leave him alone until he said something, Jesus looks up and, with the perfunctory grace that only a master can affect, fires off an earth-shattering meme that rattles the collective consciousness of this planet even down to this day. Looking up from his doodles, Christ simply says, "Let any one of you who is without sin be the first to throw a stone," after which he looked back down and ignored them once again (John 8: 19). What could the elites say? In a single perfunctory retort, Jesus masterfully exposed them as hypocrites and skilfully stripped them of their power. Left with nothing but their own guilt and shame, they turned and walked away.

Notably, Jesus's disrespect for authority is contagious, making even the blind steadfast and defiant. In one event, we find the Pharisees trying to dig up dirt on Jesus by questioning a formerly blind man whom Jesus had allegedly healed. They badger the man and his parents trying to get them to say something that would incriminate Jesus, but the man simply says that Jesus "is a prophet" (John 9: 17). Not accepting this, the Pharisees interrogate him, suggesting that maybe he wasn't blind after all, but his parents confirm that he was (John 9: 20-21). Getting no traction, the elites admonish the man to "tell the truth" because everybody knows that Jesus "is a sinner" (John 9: 24), but the blind man doesn't fall for it (John 9: 25) and in fact ends up getting insulted (John 9: 26-28) and kicked (John 9: 34) because he owns their attempted interrogation (John 9: 13-33)

For the elites, it was a bad scene, indeed. Not only was Jesus undermining their authority, but his attitude and disrespect were contagious. They couldn't let it go and they knew it. At a high council meeting of the Sanhedrin, ${ }^{6}$ the ruling elites of the city of Judea worried that they were rapidly losing control of the situation. For them, it was a political issue, not a spiritual one. They saw their political and economic power under threat. Note, however, their particular worry was not so much Jesus himself as their overlords in Rome. The elites worried that if Jesus got too popular, if he became too much of a threat to their local colonial power, if the people did try to install him as an authority in the region, the colonizing over-lords would send Roman soldiers to take back control and throw them out of power. This concern is stated quite plainly: "Here is a man performing many signs," noted the elite priests of the day. "If we let him go on like this, everyone will believe in him, and then the Romans will come and take away both our temple and our nations" (John 11: 45-48).

They had to contain the threat. They struggled, as already noted, to arrest and entrap him. Finally, one particular member of the elite, a high priest by the name

\footnotetext{
${ }^{6}$ Sanhedrin is the Hebrew word for city council. The Sanhedrin were a patriarchal group of twenty-one men with "full authority" over the people of the city. They made all the rules which the people, according to ancient scripture, were commanded by God to obey.
} 
of Caiaphas, came up with a brilliant solution. He does not mince words, or hide his intent. He wants Jesus dead. "It is better," he says, "for [this]... one man [to] die..." than that "the whole nation perish" (John 11: 50). ${ }^{7}$ Caiaphas knows if they do not act it is only a matter of time before the Romans military steps in. Convinced by Caiaphas of the imminent threat, the elites immediately began plotting to have Jesus assassinated (John 11: 53). Caiaphas takes the lead on this. Knowing full well that simply arresting and murdering Christ would be too difficult/explosive, he initiates an unusual and darkly brilliant propaganda campaign designed to open a psychological space that will allow them to arrest and assassinate the people's leader. Instead of condemning Jesus like his colleagues were doing, Caiaphas came out on his side, or so it seemed. Caiaphas admits that Christ is special and a prophet, but in an evil twist says God had sent Jesus to die.

"... as high priest that year he prophesied that Jesus would die for the Jewish nation, and not only for that nation but also for the scattered children of God, to bring them together and make them one" (John 11: 51-52).

The message sent by Caiaphas was clear. Jesus was going to die, but that was a thing that should be welcomed because it would bring unity to the scattered children and save the Jewish nation. It wasn't a lie. If the Jewish elites could get rid of Christ, their authority over Jerusalem would continue. Jesus would die for the Jewish nation, just not in the way you assumed when you glossed over the story. It was dark and devious take-down. Knowing full well that the people would simply ignore him if he called Jesus down, or revolt if he had Jesus arrested and executed, he acknowledges what the people already believe, which is that Jesus is the Messiah. After he's convinced the people he's a trustworthy source that sees "the truth," he manipulates their thinking and sets in them the expectation that God has sent Jesus to die for their sins. In this way, Caiaphas opens a space in their minds that allows him and "the family," as I like to say (Sosteric 2016), to get away with murder. Under the influence of this remarkable propaganda campaign, when Jesus is finally arrested, tried, and executed, the people, instead of rising up to defend their Savior as you would expect given his popularity amongst them, simply stand by and watch him die. Why should they interfere? Why should they revolt? The people, the masses, believe what we might want to call the Caiaphas Lie, ${ }^{8}$ later formalized in Catholic "Jesus died for your sins" dogma, that God had produced a "passion play," with Jesus as a willing sacrificial victim who died specifically to save your foul soul.

\footnotetext{
${ }^{7}$ In some circles, Jews are blamed for the assassination of Jesus. This reading of the Bible, however, is only possible if one has not read the Bible, or if one takes quotes like John 11: 50 out of context. When one reads the entire gospel, it is very clear that Jesus does not threaten the Jewish people. If anything, he's converting gentiles to the cause. Jesus was in fact an admitted threat to the economic and political elites of the time, and not only the Jewish elites, as we'll see.

${ }^{8}$ https://spiritwiki.lightningpath.org/Caiaphas_Lie.
} 


\section{Mock Trials}

Not surprising, perhaps, the elites were successful in their bid. With propaganda seeded in mind, the elites easily have Jesus arrested (John 18), after which they put him through some mock trials. First, they bring him before Annas, the father-in-law of Caiaphas. Annas questions Jesus (John 18:19) and ends up slapping him in the face because he can't brook Jesus' insolence (John 18: 20-23) and defiance (John 18: 23). Frustrated, Annas sends him "bound to Caiaphas" (John 18: 24) who then takes Jesus directly to the Roman overlord Pilate (John 18: 29). Pilate asks the leaders what the charges are, but they cannot provide any, saying only that "If he were not a criminal...we would not have handed him over to you" (John 18: 30). Seeing that the local elites have nothing on Jesus, Pilate, dismisses the nonsense, saying, "Take him yourselves and judge him by your own law" (John 18: 31). But the local elites don't want that. They want Jesus to die (John 18: 31), but they know if they do it, it will burst the ideological bubble that surrounds the Caiaphas Lie. To preserve the "dying for your sins delusion," they need Pilate, a Roman, to kill Jesus; so, they keep pushing and pushing. Finally, Pilate gives in to their pressure and takes Christ inside for more questioning. ${ }^{9}$ Scrambling for something concrete upon which to justify charges, he asks Jesus directly, "Are you the king of the Jews" (John 18: 33)?

"Is that your own idea, or did others talk to you about me?" Jesus asks (John 18: 34).

Pilate admits, he does not know anything about this situation (John 18:35), so Jesus says no I'm not a King because if he were, my "servants would fight to prevent my arrest by the Jewish leaders" (John 18:36: emphasis added). I'm just here to "testify to the truth," Jesus says. "Everyone on the side of truth listens to me" (John 18: 37), to which Pilate, perhaps thinking that Jesus is no threat at all, scoffs and says "What is truth?" (John 18: 38).

Finding no basis for charge, Pilate once again confronts the local elites saying, "I find no basis for a charge" (John 18: 38)." He goes further and gives the local leaders and out. He says, "it is your custom to release a prisoner at the time of Passover;" so, do you "want me to release" him? (John 18: 39). But, the elites, who are so threatened by Jesus that they must see him dead, say they would rather have another Jew, Barabbas, an actual revolutionary who participated in an uprising, released (John 18: 40).

\footnotetext{
${ }^{9}$ The next few sentences recount a "scene" where the only two people in the room were Pilate and Jesus. We really don't know what happened in that room, and we never will. We don't know whether the gospel is offering a total fabrication, an account based on some form of research, or just a best guess as to what really happened in the room. Personally, I think it may be an account based on some form of research. I can see details of the conversation getting out. Pilate seems to see the whole affair like as a triviality and nothing more. He almost certainly would have talked about what happened to his closest associates, they would have almost certainly talked about it to others, and so on. This information could have eventually got out into the streets where somebody interested in the whole thing could have written it all down. Of course, even if this is true, how accurate the recounting would be after passing through so many mouths, and whether or not the scribe (in this case "John") added his or her own particular spin, would be an open question. The veracity of the scene here is open to question. But the point is, even though it was a private audience, it is possible we could have learned the details.
} 
At this point, Pilate, who doesn't believe Jesus is guilty of anything, sends Jesus to the back to be flogged and publicly shamed (John 19: 1-2). After his flogging, Pilate brings him back out and once again tries to release him: “...I find no basis for a charge against him" (John 19: 4). But the elites want him dead. Over the broken and beaten body of Jesus they yell, "Crucify! Crucify!" (John 19: 6), yet in the face of this, Pilate still refuses (John 19: 6) and repeatedly tries to release Jesus (John 19: 12). But pushing, pushing, pushing, the leaders will have none of that. Finally, the local elites find his Achilles heel, his fear of Caesar. They threaten Pilate, saying that letting Jesus go would reveal Pilate as a traitor to Caesar (John 19: 12). His hand forced, Pilate capitulates. He brings the tortured body of Jesus out one last time and then hands him over for execution (John 19: 13-16).

\section{Fomenting Revolution}

At this point, we need to take a step back. Is this interpretation I am offering correct? Was Jesus truly a revolutionary, populist leader challenging the elite status quo? It does appear to be that way. Consider his celebrity status, people's readiness to anoint him King, his explicitly stated goal of emancipating the oppressed, the elite's recognition of the threat, Caiaphas's sophisticated propaganda campaign, and their insistence that he be executed. What is more, Jesus himself was aware of his mission and the threat it posed to the system. He knew his teachings put him in danger, and he took precautions from the start. At a certain point, he even knew he was going to be assassinated. He didn't like that idea, but he knew there was nothing he could do to stop it. He also knew, with full consciousness, that his murder would make him a revolutionary martyr. He says as much in John 12 when, comparing himself to a stalk of wheat, he says that "unless a kernel of wheat falls to the ground and dies, it remains only a single seed. But if it dies, it produces many seeds" (John 12: 19-24). In this passage, Christ is saying that when he dies, the kernel of his teachings will create many seeds which will then spread throughout the world.

He was right. This is exactly what happened. He died as a martyr, and the seed of his teachings immediately started to spread. It spread because the apostles and other believers "never stopped teaching and proclaiming the good news" (Acts 5: 43). Despite the word of mouth nature of the times, it spread fast, with an increase of disciples (Acts 6:7), sometimes as many as three thousand (Acts 2: 41) or even five thousand (Acts 4:4) at a time, and not only amongst the target audience Jews, but amongst the Gentiles as well (Acts 10: 44-45). We see the conversion of Roman centurions (Acts 10: 23-26), traditional priests (Acts 6:7), foreign state officials (Acts 8: 32-36), and even top-level elites (Saul's Conversion Acts 9). There is conversion "through the whole region" (Acts 13: 49). In Iconium, Lystra, Derbe, Syria, (Acts 14), Philippi (Acts 16), Thessalonica, Berea, Athens (Acts 17), Corinth, (Acts 18), and Ephesus (Acts 19), Christ's martyrdom created a revolutionary steamroller plowing through the region. 
As you might expect, confronted with the failure of their assassination, and facing a growing revolutionary threat, the elites pushed back. It was an apostolic gong show worthy of Monty Python treatment. The elites arrest the apostles but release them for lack of evidence (Acts 4: 13-17). They order them to cease and desist, but the apostles refuse to stop teaching (Acts 4: 18-20). They are arrested again, "carefully," (Acts 5: 17-18) because the "captain of the guards" was afraid of being stoned by their supporters (Acts 5: 25-36), but they escape, only to be arrested again (Acts 5: 25-29). The Sanhedrin ask the apostles why they ignored their orders to stop teaching (Acts 5: 28), and the apostles tell them they've no respect for their authority, but "must obey God rather than human beings!" (Acts 5: 29-32). Enraged, the Sanhedrin considered murder (Acts 5: 33), but eventually settle on flogging (Acts 5: 40). The apostles consider the flogging a badge of spiritual honour and joyfully go back to their teaching (Acts 5: 41-42). ${ }^{10}$

Of course, it doesn't always end so happily for the apostles, or their followers. Sometimes, when they showed too much disrespect (Acts 7), they were brutally murdered (Acts 7: 54-60). Acts 7 tells the story of the apostle Stephen who, when brought before the Sanhedrin on trumped-up blasphemy charges (Acts 6: 8-12), enrages the Sanhedrin priests to the point where they have him violently stoned to death. They lay out the charges but instead of responding to them, he goes into a long retelling of the story of Moses (Acts 7: 2-50) which ends with him namecalling the Sanhedrin (Acts 7: 51-53). Furious to the point of bruxism (Acts 7:54), he insults them even further by pointing out the strength of his own connection while passively aggressively attacking their lack (Acts, 7: 54-56). "Oh look," he says pointing to the sky, "I see Jesus and God." The Sanhedrin snap! Covering "their ears" they scream "at the top of their voices," rush him, drag him out into the streets, and stone him till he's dead (Acts 7: 54-60).

As we can see, the struggle was real, revolutionary, and vicious. It led to military pogroms (Acts 8: 1-4), mass deportation, and the scattering of "the faithful" far and wide (Acts 11: 18). It was pervasive persecution (Acts 20: 22-24) aimed at stamping out the threat.

\section{Detailed Nature of the Threat}

At this point, it seems reasonable to conclude there was something revolutionary going on at the time. Something had got the people so worked up that they were converting in droves. Something had got the elites so uptight that they had Jesus assassinated, were murdering his apostles, and were engaged in mass deportation and persecution. The question at this point is, what was the nature of the threat? I believe the threat was three-pronged. There was a political threat, an economic threat, and a theological threat.

\footnotetext{
${ }^{10}$ This is the story that Mel Gibson should have told.
} 


\section{Political Threat}

For sure we know there was a political threat. Everything excised from the Gospels and Acts in this paper so far points to the reality of this threat. Jesus neither liked nor respected elites. He repeatedly insulted them, called them out, and dismissed their authority, all the while calling for freedom and revolution. His followers were ready to oust the local elites and proclaim him king and they had to assassinate him to terminate that threat. Assassination did not end the threat, however. It only made him a martyr and probably encouraged a faster spread through the activity of committed apostles who become involved in revolutionary activity as well. We also know that the apostles were not passive lambs either. At one point we find Paul telling the Corinthians to quit acting like fools, quit putting up with exploitation, resist (2 Corinthians 11: 19-20), and rise up and proclaim the revolutionary good news despite oppression and suppression, as he had done (2 Corinthians: 23-29). And the Corinthians were not the only ones he was encouraging towards progressive political positions. Elsewhere, Paul reminds the Galatians of the importance of freedom from the "yoke of slavery," and advises they not allow themselves to be enslaved once again (Galatians 5: 1). Paul's was a revolutionary call made more focused and dangerous because he was erasing hierarchy and division, and, in a perverse fulfillment of Caiaphas's twisted prophecy, uniting the people as one. "There is neither Jew nor Gentile, neither slave nor free, nor is there male and female, for you are all one in Christ Jesus" (Galatians 3: 28). Calls for unity like this are always fundamentally revolutionary because they always move past the elites "divide and rule strategies, which make exploitation and oppression possible.

\section{Economic Threat}

The threats Jesus and his apostles represented were not just political. At root, politics is always about economics, and there is evidence to suggest that there were socialist/communist undertones to the Christian revolution underway in the region. We already know Jesus didn't think much of the rich or their abilities, suggesting it was simply impossible for them to connect (Mathew 19:24). ${ }^{11}$ Beyond that, he made clear statements against the accumulation of wealth. ${ }^{12}$ In Mathew 19, when a rich man asks Jesus, "What good thing must I do to get eternal life?" (Mathew 19: 16), Jesus says point-blank, "If you want to be perfect, go, sell your possessions and give to the poor....Then come, follow me." (Mathew 19: 21).

This communistic rejection of personal possessions was not confined to Jesus himself. His apostles picked up on it as well. Consider the following as a clear indication of the communal/communist nature of the early Christian community.

\footnotetext{
${ }^{11}$ It is, of course, impossible to get a camel through the eye of a needle.

${ }^{12}$ For my take on "accumulation" see my Rocket Scientists' Guide to Money and the Economy Sosteric (2016)
} 
All the believers were one in heart and mind. No one claimed that any of their possessions was their own, but they shared everything they had... And God's grace was so powerfully at work in them all that there were no needy persons among them. For from time to time those who owned land or houses sold them, brought the money from the sales and put it at the apostles' feet, and it was distributed to anyone who had need (Acts 4: 32-37).

Selling your home and giving the proceeds away for redistribution? It doesn't get any more communistic than that. The early Christians took the communism quite seriously. Consider the story of Ananias, a Christian convert who sold his property but kept some money back for himself.

Now a man named Ananias, together with his wife Sapphira, also sold a piece of property. With his wife's full knowledge he kept back part of the money for himself, but brought the rest and put it at the apostles' feet. Then Peter said, "Ananias, how is it that Satan has so filled your heart that you have lied to the Holy Spirit and have kept for yourself some of the money you received for the land? Didn't it belong to you before it was sold? And after it was sold, wasn't the money at your disposal? What made you think of doing such a thing? You have not lied just to human beings but to God." When Ananias heard this, he fell down and died. And great fear seized all who heard what had happened. Then some young men came forward, wrapped up his body, and carried him out and buried him." About three hours later his wife came in, not knowing what had happened. Peter asked her, "Tell me, is this the price you and Ananias got for the land?" "Yes," she said, "that is the price." Peter said to her, "How could you conspire to test the Spirit of the Lord? Listen! The feet of the men who buried your husband are at the door, and they will carry you out also." At that moment she fell down at his feet and died. Then the young men came in and, finding her dead, carried her out and buried her beside her husband. Great fear seized the whole church and all who heard about these events (Acts 5:1-11).

Ananias kept the money for himself. When the community found out, he was challenged by the apostle Paul. When the seriously misaligned nature of his selfish actions was discovered and brought to his attention, first he, and then his complicit wife, dropped dead. Those are pretty serious consequences for stealing a little cash from the community; I think you'll agree. Perhaps it is just a moral tale, and Ananias and his poor wife didn't really drop dead, but even so, the story clearly shows how serious the early Christians took their redistributive socialism.

Speaking of redistribution, there is obvious talk about income redistribution in the Bible. In 2 Corinthians 8, Paul writes a letter to the Corinthians and in that letter appeals to them to be as generous as the Macedonians when they give over their excess production for redistribution. Paul's stated goal is general equality. $\mathrm{He}$ says, and I paraphrase, "You folks got lots, they got a little, and so now it is your time to help them. Then, one day, they will have a lot and you will have a little, and in their turn they will help you."

The point, as Paul repeatedly says, is simple equality. 
Our desire is not that others might be relieved while you are hard pressed, but that there might be equality. At the present time your plenty will supply what they need, so that in turn their plenty will supply what you need. ${ }^{13}$ The goal is equality, as it is written: "The one who gathered much did not have too much, and the one who gathered little did not have too little" (2 Corinthians 8: 13-15).

We redistribute, Paul says, so we can achieve general equality.

The socialist goal of Paul is obvious, as is his usage of ancient Jewish scripture to justify it. And note, this is not about giving a few pennies on Sunday; this is about serious redistribution. This is about looking out for all people. It is not about being lazy and parasitical, says Paul, it is about working hard, helping the poor and the weak, and making sure everybody has enough. They rejected, I have to say, consumerism and indulgence and embraced compassion and service to others (Galatians 5: 13; Philippians 2: 3-4).

I have not coveted anyone's silver or gold or clothing. You yourselves know that these hands of mine have supplied my own needs and the needs of my companions. In everything I did, I showed you that by this kind of hard work we must help the weak, remembering the words the Lord Jesus himself said: 'It is more blessed to give than to receive' (Acts 20: 32-35).

\section{Theological Threat}

When you combine the clear socialism with the anti-authoritarian politics, you begin to get a different picture of Jesus, the apostles, and the Bible story. I think there is enough evidence left in the Christian bible to suggest that the early movement represented a communist/socialist threat. But it was more than that. Early Christianity also represented a theological threat to Jewish monotheism, to the notion that there was some authoritative "God" up in the sky. Jesus and his apostles presented a different, perhaps more nuanced, view of God. Jesus and his apostles taught a very "revolutionary" truth, which is not really revolutionary at all, given it is a common theme in this world's spiritual traditions (Bhattacharyya 2006, Jantzen 1995, Ichazo 1976, Underhill 2002), which was that we were all sparks of divine Consciousness, that inside us we are all equally God incarnated in a physical body.

Jesus himself is quite clear about this. At a certain point, Jesus is about to be stoned for blasphemy, because as the elite priests are saying, he is, "a mere man," claiming "to be God" (John 10:33). Even though he's about to be stoned to death, Jesus does not deny that he says this. Instead, he points to Jewish scripture, specifically Psalm 82, and says we are all god.

"You are gods; and all of you are children of the Most High." (Psalm 82:6)

\footnotetext{
${ }^{13}$ This sound frighteningly close to what communist Karl Marx said about equality and redistribution, "From each according to his ability, to each according to his need."
} 
This isn't the only place where Jesus erases the distinction between God and humans. In Mathew 18:17-18 Jesus again suggests we are all equally divine. Later, in the "letters" section of the Bible, this theology is repeated by Paul in 1 Corinthians 6:19 where he says "Know ye not that ye are the temple of God, and that the Spirit of God dwelleth in you?" He says it again in Colossians 3: 11: "Christ is all, and is in all." Notably, this isn't something that has been lost to subsequent generations of Christians. Meister Eckhart carries the idea forward into the European Middle Ages when he says.

The seed of God is in us. Given an intelligent and hardworking farmer, it will thrive and grow up to be God, whose seed it is; and accordingly, its fruits will be God-nature. Pear seeds grow into pear trees, nut seeds into nut trees, and God's seed into God. God expects but one thing of you, and that is that you should come out of yourself, in so far as you are a created being and let God be God in you. Meister Eckhart.

\section{Discussion}

Don't listen to authority. Ignore meaningless tradition. Don't follow their rules. Give your possessions away. Redistribute wealth. Embrace your divinity! You are God. We are god's. God is in us. God becomes us. Gender, ethnicity, nationality don't matter. We are all one. We all deserve equality. We should help the weak, not prey on them. Is this remarkably progressive message really contained in the Bible? And if so, what are we to make of this?

As to the question whether the message is contained in the bible; arguably, it is. It is right there in black and white for all the world to see. As for what to make of this, as a recovering Catholic, I'm wondering, why I was never told this as a child, and I'm a bit confused by the teachings of the Church. Even though I spent the first decade of my life immersed in the Church and its teachings, dutifully attending Sunday Mass every week of every year, I had no idea about this. The priests never said any of this about Jesus or his apostles. They never told me he was a revolutionary, that he taught collective divinity, or that his politics were far left. I realize now they didn't tell me the truth; they told me the Caiaphas Lie. They told me he was a passive Sheppard who died on the cross for my sins. Why would the Catholic Church tell the Caiaphas Lie? Why were they covering up the sins of the High Priests who had Jesus executed?

As a former Catholic, I have a hard time understanding the Church and its perspectives, but as a sociologist, I have a clear view of what's going on. As a sociologist, it all makes perfect sense. It makes sense why Jesus was so popular. It makes sense why the people proclaimed him king. It makes sense why Caiaphas told that lie. It makes sense why he was assassinated, and why this martyred him. It makes sense why his message spread. It makes sense why the Roman's persecuted and deported early Christians. It also makes sense why the Church, throughout the middle ages, repeatedly worked to circumvent the progressivism and social "activation" that emerged from an authentic practice of Christ's authentic spiritual teaching by forcing mystics, especially women mystics, into monasteries, editing 
their teachings, threatening them with the violence of the inquisition, and otherwise containing the progressive impulse (Bruneau 1998). It makes sense why the Church "fathers," the elites who started the Church, handpicked only a sample of the writings available at the time for their official Bible, and destroyed everything else (Starr 2013: 179). It makes sense why they wouldn't let the common folk read the bible for themselves for over a thousand years (Starr 2013: 162), and why they still organize their Sunday sermon around out of context selections that allow priests to whitewash the revolutionary message. It makes sense why there is so much predatory behaviour and mental illness amongst the patriarchs of the Church (Sosteric 2019a). The Church isn't about freeing the soul. Nor is it only about opiating the people (Marx 1978) or ideological manipulation of masses (Weber 1904) though all this is certainly a part. It is equally about containing a problematic, progressive, spirituality that breeds political activation (Sosteric 2019b) which, if left unchecked, might otherwise transform the world (Sosteric 2018c). As a sociologist, I can clearly see the Church, headed by elites like Emperor Constantine, was not created to spread the word, but to contain the socialist/theological threat.

As a sociologist, the case seems clear enough, and the need for research on the question obvious. But as a sociologist, another bothersome issue arises. The bible has been easily available for decades. In the last ten years, especially so in the last decade where multiple versions are easily accessible online. Progressive sociologists have been interested in social change and social evolution since the beginning. Clearly, Christ was a progressive. So why have sociologists never spoken about this charismatic, progressive, and highly successful figure in terms that reflect the story in the Bible? Why such derision? That doesn't seem right. The answer, I think, is simply that despite pretensions to actually know something about Christian religion, most sociologists who claim to know about Christian spirituality haven't actually read the bible. Consequently, their understanding of Christianity is based on what the Church says, and what the Church says is not the full story. Take Marx as an example. Marx said that religion was "the sigh of the oppressed creature, the heart of a heartless world, and the soul of soulless condition. The opium of the people" (Marx 1970). Anybody who actually reads the gospels would have a hard time making that statement. Engels is a bit more accurate when he says the following:

The history of early Christianity has notable points of resemblance with the modern working-class movement. Like the latter, Christianity was originally a movement of oppressed people: it first appeared as the religion of slaves and emancipated slaves, of poor people deprived of all rights, of peoples subjugated or dispersed by Rome. Both Christianity and the workers' socialism preach forthcoming salvation from bondage and misery; Christianity places this salvation in a life beyond, after death, in heaven; socialism places it in this world, in a transformation of society. And in spite of all persecution, nay, even spurred on by it, they forge victoriously, irresistibly ahead. Three hundred years after its appearance Christianity was the recognized state religion in the Roman World Empire. (Engels 1894)

But even he shows signs of not having read the Bible carefully. To be sure, early Christianity was socialist, but it did not place "salvation in a life beyond, after 
death, in heaven." There was a practical, real-time concern to improve material conditions by eschewing accumulation and redistributing income. It was only later, when the elites took control, that this revolutionary message was occluded. Religion is not the "opium of the people," a "tool of the ruling class," a "general theory of this alienated world," (Molyneux 2008), even a "response to human alienation" (Molyneux 2008). Religion, at least the Christian variety, is an institution developed to sanitize and suppress the progressive human spirituality of Jesus Christ, and others (Harvey 2001). This, in my view, more accurate statement of the role of religion moves us past the flawed Marxian view, not to mention the banal inanity of folks like Richard Dawkins (2006) and presents a more nuanced view of human spirituality. As a few sociologists are aware, religion is not an opiate; it is a containment strategy. It is the spearhead of an ancient and sophisticated control process (Sosteric 2017) that sanitizes (Jantzen 1995), manipulates (Sosteric 2018b) co-opts, and defuses (Bruneau 1998), an otherwise revolutionary human spirituality. Given this, it is time we, as sociologists, get past the neglectful, "parochial - concentration on ecclesiastic institutions," and take a closer, more scientific and less prejudiced look at human spirituality and its transformative (Bien 2004, Miller 2004, Hastings 2010, White 2004) and revolutionary (Sosteric 2018c) potential.

\section{References}

Berger P (1968) A Bleak Outlook Is Seen for Religion. vol. April 25. The New York Times. Berger P 1(969) The Sacred Canopy: Elements of a Sociological Theory of Religion. New York: Anchor Books.

Berger P (1999) The Descularization of the World: Resurgent Religion and World Politics. Grand Rapids MI: Eerdmans.

Bhattacharyya AK (2006) Hindu Dharma: Introduction to Scriptures and Theology. Lincoln, NE: iUnvierse.

Bien TH (2004) Quantum Change and Psychotherapy. Journal of Clinical Psychology 5: 493.

Bruce S (2002) God Is Dead: Secularization in the West. Oxford: Blackwell.

Bruneau MF (1998) Women Mystics Confront the Modern World. Albany: State University of New York Press. https://amzn.to/2L1L0m2.

Chaves M (1994) Secularization as Declining Religious Authority. Social Forces 72(3): 749-74.

Dawkins R (2006) The God Delusion. Feb. 12. New York: Mariner Books.

Dobbelaere K (2002) Secularization: An Analysis at Three Levels. Frankfurt: Peter Lang.

Durkheim E (1965) The Elementary Forms of Religious Life. New York: Free Press.

Engels F (1894) On the History of Early Christianity. Marxists Internet Archive. https:// bit.ly/34wY2OK.

Harvey A (2001) Teachings of the Hindu Mystics. Kindle. Boston: Shambhala Publications. https://amzn.to/2WQoduv.

Hastings A (2010) William James, Conversion and Rapid, Radical Transformation. Journal of Consciousness Studies 17(11-12): 116-20.

Ichazo O (1976) The Human Process of Enlightenment and Freedom. New York: Arica Institute. 
Jantzen GM (1995) Power, Gender, and Christian Mysticism. New York: Cambridge University Press. https://amzn.to/2U490E9.

Marx K (1970) A Contribution to the Critique of Hegel's Philosophy of Right. Cambridge: Cambridge University Press.

Marx K (1978) The German Ideology. In The Marx-Engels Reader, edited by R. Tucker. New York: Norton.

Miller WR (2004) The Phenomenon of Quantum Change. Journal of Clinical Psychology 60(5): 453-60. https://doi.org/10.1002/jclp.20000.

Molyneux J (2008) More than Opium: Marxism and Religion - International Socialism. International Socialism, 2008. http://isj.org.uk/more-than-opium-marxism-and-religi on/.

"New International Version (NIV) - Version Information - BibleGateway.Com" (2019) 2019. https://www.biblegateway.com/versions/New-International-Version-NIV-Bib le/.

Sosteric M (2014) A Sociology of Tarot. Canadian Journal of Sociology 39(3).

Sosteric M (2016) Rocket Scientists' Guide to Money and the Economy: Accumulation and Debt. St Albert, Alberta: Lightning Path Press.

Sosteric M (2017) The Sociology of Mysticism. ISA ESymposium for Sociology July.

Sosteric M (2018a) "Everybody Has a Connection Experience: Prevalence, Confusions, Interference, and Redefinition." Spirituality Studies 4 (2). https://bit.ly/2GubUBA.

Sosteric M (2018b) From Zoroaster to Star Wars, Jesus to Marx: The Science and Technology of Mass Human Behaviour. https://www.academia.edu/34504691.

Sosteric M (2018c) "Mystical Experience and Global Revolution." Athens Journal of Social Sciences 5(3): 235-55.

Sosteric M (2018d) Star Wars Is a Religion That Primes Us for War and Violence. The Conversation. https://bit.ly/33z19Xc.

Sosteric M (2019a) A River of Power Runs Through Us. Culturally Modified. https://cul turallymodified.org/.

Sosteric M (2019b) Rocket Scientists' Guide to Authentic Spirituality. St. Albert, Alberta: Lightning Path Press. https://bit.ly/33xBe28.

Sosteric M, Ratkovic G (2018) What Does It Mean to Be Human: Abraham Maslow and His Hierarchies of Need. https://www.academia.edu/35635479.

Starr B (2013) Jesus Uncensored: Restoring the Authentic Jew. OmniHouse Publishing.

Underhill E (2002) Mysticism: A Study in the Nature and Development of Spiritual Consciousness. Kindle. New York: Dover Publications. https://amzn.to/2C91xNY.

Wallis R (1976) The Road to Total Freedom: A Sociological Analyysis of Scientology. London: Heinemann.

Weber M (1904) The Protestant Ethic and the Spirit of Capitalism. New York: Roxbury Press.

White WL (2004) Transformational Change: A Historical Review. Journal of Clinical Psychology 60(5): 461-70. 
